\title{
Participation, Power and Practice in Development: A Case Study of Theoretical Doctrines and International Agency Practice in Tuvalu
}

by

Nicki Wrighton

A thesis submitted as partial fulfillment of a Master of Development Studies

(MDS), School of Geography, Environment and Earth Sciences,

Victoria University of Wellington

2010 


\section{Acknowledgements}

I warmly acknowledge my friends and colleagues in Tuvalu whose situation inspired this research and whose support and commitment enabled it to take place.

I would like to sincerely acknowledge my family and friends without whose support and encouragement this thesis would not have been possible.

I also extend a special thanks to my supervisor Professor John Overton whose guidance was invaluable throughout.

Finally, this thesis is dedicated to the memory of Sala Abbott who shared her Tuvalu with me and died a week before this thesis was submitted. 


\section{List of Acronyms}

$\begin{array}{ll}\text { ADB } & \text { Asian Development Bank } \\ \text { AusAID } & \text { Australian Agency for International Development } \\ \text { BBC } & \text { British Broadcasting Corporation } \\ \text { CPI } & \text { Consumer Price Index } \\ \text { CROP } & \text { Council of Regional Organisations of the Pacific } \\ \text { DAC } & \text { Development Assistance Committee } \\ \text { DRTM } & \text { Donor Round Table Meeting } \\ \text { EU } & \text { European Union } \\ \text { FAO } & \text { Food and Agriculture Organisation } \\ \text { GDP } & \text { Gross Domestic Product } \\ \text { GOT } & \text { Government of Tuvalu } \\ \text { JICA } & \text { Japan International Cooperation Agency } \\ \text { LDC } & \text { Least Developed Country } \\ \text { MDGs } & \text { Millennium Development Goals } \\ \text { MIRAB } & \text { Migration Remittances Aid and Bureaucracy } \\ \text { NBSAP } & \text { National Biodiversity Strategies and Action Plans } \\ \text { NGO } & \text { Non Government Organisation } \\ \text { NZAID } & \text { New Zealand Agency for International Development } \\ \text { ODA } & \text { Official Development Assistance } \\ \text { OECD } & \text { Organisation of Economic Cooperation and Development } \\ \text { PACTAM } & \text { Pacific Technical Assistance Mechanism } \\ \text { PICS } & \text { Pacific Island Countries } \\ \text { PIFS } & \text { Pacific Islands Forum Secretariat } \\ \text { PNG } & \text { Papua New Guinea } \\ \text { PRIF } & \text { Pacific Regional Infrastructure Facility } \\ \text { PSIP } & \text { Public Sector Investment Programme } \\ \text { RAMSI } & \text { Regional Assistance Mission to the Solomon Islands } \\ \text { RNZ } & \text { Radio New Zealand } \\ \text { ROC } & \text { Republic of China Taiwan } \\ \text { SID } & \text { Small Island Developing State } \\ \text { SPC } & \text { Secretariat of the Pacific Community } \\ \text { SPREP } & \text { South Pacific Regional Environment Programme } \\ \text { TA } & \text { Technical Assistance } \\ \text { TOR } & \text { Terms of Reference } \\ \text { TTF } & \text { Tuvalu Trust Fund } \\ \text { TTFAC } & \text { Tuvalu Trust Fund Advisory Committee } \\ \text { UN } & \text { United Nations } \\ \text { UNCTAD } & \text { United Nations Conference on Trade and Development } \\ \text { UNDP } & \text { United Nations Development Programme } \\ \text { UNESCO } & \text { United Nations Education Social and Cultural Organisation } \\ \text { UNICEF } & \text { United Nations Children's Fund } \\ & \end{array}$


UNIFEM United Nations Development Fund for Women

UNV United Nations Volunteers

WHO World Health Organisation 


\section{Contents}

Chapter One - Introduction

1.0 The Genesis of this Research 1

$\begin{array}{lll}1.1 & \text { Thesis Overview } & 7\end{array}$

Chapter Two - The Contradictions of Participation 11

2.0 Overview 11

2.1 Origins of the "Paradigm of the People' 11

2.2 The Emergence of a Participation Paradigm 15

$\begin{array}{ll}2.3 & \text { Institutionalising Participation } \\ 2.4 & 19\end{array}$

2.4 The Tyranny of Participation in the Development Arena 23

2.5 The Aid Effectiveness Agenda and the Policy Realm 27

2.6 Size Really Does Matter 33

2.7 Conclusion 35

Chapter Three - Tuvalu: Small Islands, Big Issues 37

3.0 Setting the Scene 37

3.1 The Pacific's Intersection with the Global Aid Agenda 38

3.2 Pacific Principles of Aid Effectiveness 41

3.3 Introducing Tuvalu 44

3.3.1 Tuvalu's Population 47

3.3.2 Tuvalu's Government Setting 48

3.3.3 Tuvalu's Economy $\quad 51$

3.3.4 Tuvalu Trust Fund 53

3.4 Tuvalu as an Aid Recipient 55

3.5 Tuvalu's Development Planning 62

Chapter Four - Tuvalu's Reality and the Temporary Insider 65

4.0 Introduction 65

4.1 Positionality of the Researcher 65

4.2 Development Reality in Tuvalu $\quad 67$

4.3 Tuvalu as a Case Study 68

4.4 Research, the Researcher and the Researched 70

4.5 Taking a Qualitative Approach 71

4.6 Talanoa Research $\quad 73$

4.7 Researching in the Developing World 75

4.8 Research Design 77

4.9 Interviewing Government Officials 78

4.10 Attribution $\quad 81$

4.11 Conclusion 83

Chapter Five - Partnership, Practice and Pressure 84

5.0 Introduction $\quad 84$

5.1 Rapid Appraisal Findings $\quad 84$

5.1.1 Tuvalu Visitor Statistics $\quad 87$ 
5.1.2 Development Mathematics $\quad 88$

5.2 Semi-Structured Interview Findings 91

5.2.1 Types of Consultation 91

5.2.2 Bilateral 92

5.2.3 Regional 95

5.2.4 Multilateral 96

5.3 Meetings, Meetings, Meetings 97

5.3.1 Overseas Meetings 100

5.4 Issues With Levels of Engagement 101

5.4.1 Time 101

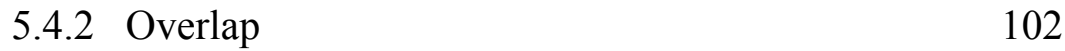

5.4.3 Reporting 103

5.4.4 Preparedness 104

5.4.5 Projects That Take Place Inside Government 105

5.5 Opportunities that Exist for Tuvalu 107

5.5.1 External Relationships 107

5.5.2 Internal Structure 107

5.5.3 Donor Changes 109

$\begin{array}{lll}5.6 & \text { Conclusion } & 110\end{array}$

Chapter Six - The Case in Context 112

6.0 Key Questions 112

6.1 Participation: a Blessing or a Burden? 112

6.2 Who Holds the Power in the Development Relationship? 121

6.3 Improving Practice 127

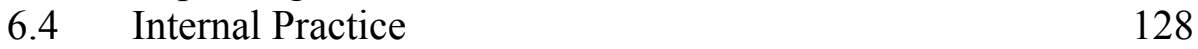

6.5 Donor Practice 131

$\begin{array}{ll}6.6 \text { Conclusion } & 134\end{array}$

Chapter Seven - Who Are You Working For? 137

Appendix One - Interview Schedule 145

Appendix Two - Information Form 146

Appendix Three - Consent Form 147

$\begin{array}{ll}\text { References } & 148\end{array}$ 


\section{Tables}

$\begin{array}{lll}\text { Table } 1 & \text { Pretty's Typology of Participation } & 18\end{array}$

$\begin{array}{lll}\text { Table } 2 & \text { Pacific Islands Forum Secretariat } & 38\end{array}$

Table $3 \quad$ Paris and Pacific Principles 42

Table $4 \quad$ Tuvalu Population from 2002 Census 47

Table $5 \quad$ ODA as \% of GDP for Pacific Least Developed Countries 58

Table $6 \quad$ Grant Aid Inflow 2002-2008 by Donor 60

Table $7 \quad$ Grant Aid 2002-2008 by Type of Aid 61

Table $8 \quad$ Number of Development Related Visitors October $2009 \quad 86$

Table $9 \quad$ Number of Development Related Visitors April $2010 \quad 90$

Table $10 \quad$ Donor Representation in Tuvalu 93

Table $11 \quad$ Strengthening Tuvalu Government Aid Management 130

\section{Figures}

Figure $1 \quad$ Map of Tuvalu 46

Figure 2 Grant Aid to Tuvalu 2002-2008 56

Figure $3 \quad$ Grant Aid as Percentage of GDP 57

Figure 42008 Visitor Arrivals by Category 87

$\begin{array}{lll}\text { Figure } 5 & \text { Participation Pressures } & 113\end{array}$ 


\section{Chapter One - Introduction}

\subsection{Genesis of the Research}

Back in 2008, I was sitting in the office of one of the permanent secretaries of a Tuvalu government department having a brief meeting. His phone rang, I was signaled to remain, so I sat there listening to one side of the conversation. It became apparent that this official was explaining to the caller why they had turned down an invitation to attend an international meeting hosted by the regional agency the caller worked for. The Government of Tuvalu official was explaining that he could not come because he would be away for too long and it was a busy time in the government's budget cycle. I then heard the official acknowledge that it may be important for Tuvalu to be seen to at the meeting, but he still could not come and no, there was no-one else available to come either. Finally the official, sounding cross, said that it didn't matter that the meeting was at no cost to Tuvalu he still could not come. Finally the Tuvalu official relented and said he would arrange for someone to attend. After the conversation ended, I asked why he had given in and my friend said

'You know Nicki, this happens all the time, they grumble about us never being here because we are always at meetings yet the same people grumble about us if we say we can't come to their meetings because we are too busy. We can't win.' (Anonymous, Personal Communication, 2008) 
It was that conversation that sparked the desire to undertake some research looking into this issue of participation. It seemed to me that the situation I had witnessed was by no means an isolated incident. When I thought more about it, it became clear that the very agenda that seeks to have everyone involved in development that concerns them and their region, is the very same agenda that makes it extremely difficult for officials in a small country like Tuvalu to manage the multiple roles they have.

This conversation stuck in my mind and merged in with the myriad of other conversations I have had with both Tuvalu officials and with development agency officials about why development assistance in Tuvalu is difficult, why agencies feel like work never gets done, why Tuvalu government officials feel swamped and unable to do their own work in the face of relentless pressure from donors. And so the genesis of this thesis was born.

Over recent decades discourses of consultation and participation have become pervasive in the mainstream development arena. Participative and consultative processes have become a prerequisite to the approaches of development agencies based on the assumption that high levels of consultation and participation are essential to delivering development outcomes that meet the needs of local communities and donor agencies alike. As Baaz argues, these discourses are characterized "by a paternalism in which the donor identifies the problem, namely 
passivity and dependency, and promulgates the right treatment - teaching the partner how to be independent and use their own resources' (Baaz, 2005:168).

Almost as soon as the participatory discourse became established so too have critiques emerged challenging consultation and participation as guiding methodologies of partnership both at the institutional and local levels. Hickey and Mohan (2004) and Cooke and Kothari (2001), for example, suggest that the dual approaches of consultation and participation, while intended in good faith, may generate the opposite effect. Such approaches may compromise the development outcomes they seek to initiate. Moreover, they argue these approaches are deeply embedded discourses, a tyranny surrounding the granting of funds and the maintenance of ongoing donor relations.

It has long been realized that there is a tension between the multiplicity of development partners delivering aid assistance in a consultative and participatory manner and the recipient country's ability to absorb the assistance offered. (Little and Clifford, 2006) Arising from an acknowledgement of this tension, and a real desire to make positive change, the global aid agenda in the last decade has focused around the need to make aid more effective. (Easterley, 2008; Feeny and Rogers, 2008; Jayaraman and Ward, 2008; OECD, 2008) Consultation and participation have remained underpinning practices in discourse relating to aid effectiveness. 
The Paris Declaration signed in March 2005 was the culmination of discussion at a global level on how to enhance aid effectiveness. The Declaration comprises five partnership commitments (ownership, alignment, harmonisation, managing for results, and mutual accountability). (ibid 2008) When signing the Paris Declaration, both donors and partner countries made commitments to ensure aid delivered on the ground is more effective and delivered at a lower cost in terms of time and compliance for the recipient. The Paris Declaration was signed by all major development partners who operate in the Pacific as well as eight Pacific Island countries.

The Pacific, as a region, has had discussions to reflect the Paris Principles against regional reality. These discussions led to the development of the Pacific Aid Effectiveness Principles, which were signed in Koror, Palau, in July 2007. While the intentions of both sets of principles are admirable, there has been no research on the implementation of these commitments by development agencies as they undertake their work in the Pacific. This research intends to plug some of that gap.

This research examines the conventions and understandings of 'good' development practice surrounding consultation, participation and their relationship to aid effectiveness and absorptive capacity in the context of a small island developing country, Tuvalu. The study will identify contemporary development intervention patterns in Tuvalu and will explore tensions emerging within the Tuvalu 
Government as it services the needs of its population as a sovereign nation while also servicing the needs of a multiplicity of development partners.

Tuvalu is a micro-state, it has a small population of 9359 (SPC, 2005a), is small (less than 26 square kilometres in 757,000 square kilometers of ocean), capacity poor and geographically isolated. In much of the literature around development and country size (Baldacchino, 2006; Bertram and Watters, 1984, 1985, 1986; Warrington, 1998, Armstrong and Read, 2002; Armstrong and Read, 2006; Read, 2008; Clarke, Fry and Mihajilo, 2008) this equates to being vulnerable. We will relook at this issue in chapter two. Aid inflow is a major component of GDP in Tuvalu. The size related factors, plus the significance of aid against GDP (over $30 \%$ in 2008) mean Tuvalu is easily impacted and influenced by the large number of development partners working across a range of sectors, managing a significant number of aid projects which all need support, reporting, acquittal, monitoring and other processes by a very small number of officials.

It is the smaller island nations, like Tuvalu, where the impact of donor activity is felt the most. Discussions with officials in Tuvalu over nearly a decade indicate that the range of development partners, the number of missions they are involved in, and the number of projects or programmes that are funded cause significant problems for their small administrations. Tuvalu officials would like the opportunity through this research to articulate the realities for them and to show 
how they would like to see the principles for aid effectiveness applied in their situation.

The results of this research will inform wider development theory as it will allow the voice of a small Pacific nation to be reflected against the practice of development agencies in Tuvalu, the Pacific and in other parts of the world. It will also aim to contribute to current understandings about aid delivery as it relates to the concepts of participation, power and practice.

According to fieldwork conducted by the researcher in October 2009 and again in April 2010 there are approximately 900 annual arrivals to Tuvalu who are selfidentified as agents of government/business. Set against the total population of Tuvalu (9359) this level of activity demands a disproportionate investment of human and institutional resources yet is seen as mandatory for the maintenance of an ongoing donor commitment. More controversially perhaps this activity goes unquestioned by international donor agencies as they regard it as being in Tuvalu's own best interest and consistent with the doctrines of 'good development practice'.

Against this context the research is guided by the following questions:

- What are the current participation pressures facing the Tuvalu Government? 
- How does Tuvalu, with a small and stretched civil service, respond to the myriad of ways it is asked to participate in the development of its own citizenry?

- How does Tuvalu, a small country with a relatively high percentage of GDP comprising aid assistance, manage the conflicting values that exist in the power relationship between its partners who disburse money and expertise and itself, as a recipient of these funds?

- What improvements can be made to both donor and recipient practice to enhance the efficiency and effectiveness of the development partnership?

\subsection{Thesis Overview}

The literature review in Chapter Two examines the emergence of the consultationparticipation paradigm from an alternative fringe activity to mainstream practice at the global level. Recent literature examining the implications of this shift will then be examined and arguments posing challenges to the discourse will be proposed. Literature around power relationships will be analysed and the discourse of smallness explored in relation to both power and to participatory methodologies. The literature review will then introduce the key aid effectiveness literature and the agreements and commitments arising from this agenda. Finally the chapter will reflect how the aid effectiveness agenda has been interpreted in the Pacific region.

Chapter Three introduces us to our case study location - Tuvalu. We explore Tuvalu as a nation and where it fits in the Pacific. We learn about its government 
and economy. We examine the role of aid in Tuvalu, its major development partners and its own development planning.

Chapter Four examines the methodological aspects of the research. It provides a chance for me, as the researcher, to state my position clearly and to outline what I believe is the 'temporary insider' status I have achieved in Tuvalu from my longstanding relationships in country. The chapter examines the rationale for the choice of Tuvalu as a single case study and discusses the postmodern theoretical perspective of the research. Semi-structured interviews with Government of Tuvalu officials form the basis for exploring the implications of the practice of development agencies who interact with Tuvalu, particularly how their desire for participation and consultation impacts on the Tuvalu government's own sovereign efforts to meet the needs of their population. Here an obvious contradiction emerges with the research in that the methodology proposed demands the participation of, and consultation with, local officials and community representatives and in doing so becomes part of the issue under question.

We examine the methodological choice I made to monitor development related visitors arriving into Tuvalu over two periods (one in October 2009 and the second in April 2010). The quantifying of development visitor traffic provides legitimacy to the claims by Tuvalu officials that they are swamped under the tide of development related visitors. The research methodology reflects stakeholders' 
views, as part of the attempt to give voice to Pacific aid recipients and to influence the policy and practice relating to development assistance.

The findings of the research are outlined in Chapter five. We explore what we learned from the two rapid appraisals of development related visitors arriving into Tuvalu over the two research periods, and discover that approximately 900 people enter annually on development business. We explore how much time Tuvalu officials take to service this number of visitors. And by examining their comments from the interviews we get to understand the implications of this workload on officials.

Chapter Six reflects the statistical information gathered and the interview material against the findings of the literature review to articulate the implications of these development approaches in the context of Tuvalu. This provides the basis for discussion on the impact of such approaches against the literature on participation, power and practice. The chapter also gives the Tuvalu government officials a chance to articulate their views on how to make changes so that development effectiveness is enhanced.

Finally the research concludes by synthesizing the main issues that run through this thesis. The final chapter then goes on to clearly outline the nature of the problem, how it affects Tuvalu and what, in the eyes of those involved, can be done to alleviate the pressure they are under. The chapter concludes with a 
discussion on the potential for learning from the Tuvalu experience and the relevance of reflecting this experience against that of other Pacific research contexts in order to build on the literature of aid effectiveness in a broader regional context.

The situation I described at the beginning of this introduction identified a problem which we have examined throughout this research, in order to understand the nature of the problem it is necessary to turn to the theoretical domain in order to place it within the context of the broader development process.

It is in the interests of both development agency officials but more importantly the officials in the Government of Tuvalu that conversations like the one that started this thesis become fewer. Prior to looking at the specific situation in Tuvalu it is necessary first to look at some of the theoretical background to the challenges raised in this introductory chapter. 


\section{Chapter Two - The Contradictions of Participation}

\subsection{Introduction}

In Chapter One we outlined the problem that this research seeks to address. It is important that before we look at the specific Tuvalu situation we embed this research project in a theoretical context. Therefore the purpose of this chapter is to provide an overview of relevant theory. Given the problem outlined in chapter one - the impact of donor consultation in Tuvalu on the officials of that country is a direct result of the prevailing paradigm of partnership and consultation, literature about the emergence of this paradigm and then the literature that critiques it will form a major part of this chapter.

This chapter starts by looking at the origins of participatory development, and then the literature that critiques it. We also look at literature relating to power relationships in aid, and the discourse on the effects of smallness on the effectiveness of aid. We reflect both of these discussions against the situation in Tuvalu. Finally this chapter will present a discussion on the aid literature around aid effectiveness. We will look at the international agreements and commitments that form the nucleus of this agenda. The chapter concludes by looking at how the Pacific as a region and in an individual case has responded to this global aid effectiveness agenda.

\subsection{Origins of the 'Paradigm of the People'}

Development thinking, over recent decades, has moved from a focus on things to a focus on people (Chambers, 1983, 1997). As the following discussion reveals the 
modernisation paradigm that characterised the genesis of the contemporary development model and its institutionalisation has been gradually but systematically reinvented through the embracing of a participatory paradigm, a 'focus on people'. As this chapter, and indeed this research, argues the challenges for development lie not so much in adapting the ideas and thinking that underpin the participatory paradigm but in shifting the inertia of its implementation, through its institutions, in order to reflect that thinking. To illustrate the nature of the issues which emerge from this problem some attention to the surrounding context and its background is necessary.

The emergence of a development school of practise and theory from its start in the post World War Two period, was influenced by modernisation theory with its underpinning view that 'underdevelopment' is a problem which needs to be tackled with assistance from well meaning patrons. It was assumed that the introduction of capital, commodities and the process of industrialisation, technology transfer and globalisation would transform a 'traditionally isolated subsistence peasantry into participants in a modern economy' (Nelson and Wright, 1995:2; Rist, 2003, Pronk, 2004).

Early development interventions provided financial aid and technical assistance and focussed on the provision of infrastructure and the support of industrialisation, with limited conditions attached, as it was based on the 'assumption of the superiority of outside knowledge' (Robb, 2004:22). Indeed, the focus on the outside expert helping to lead the way from a state of underdevelopment to a state of development implied that people were neither economically or politically active before the outside agents came 
along (Nelson and Wright, 1995). Chambers, (1995) refers to this period as the 'paradigm of things'.

Questions have been asked about the efficacy of development assistance in this mode from its earliest days. Little and Clifford (2006) in their update of their 1965 treatise, showed that even in 1965 they were highlighting that differences of opinion between donor and recipients were bound to occur and noted that if donors went to the trouble and expense of building up their knowledge of recipient's economies, this in itself would help to improve the standard of planning' (Little and Clifford, 2006:97).

The prevailing approach to development placed the expert and the beneficiary at either end of a paternalistic relationship. This separation between the two main stakeholders emphasises that aid is 'by its nature a dualistic process with much potential for conflict' (Pronk, 2004:17). Given that the discourse on aid has been as passionate as it has, from the 1950 s to the present day, it is not surprising that this situation has come to pass.

Much development literature focuses on whose interests will prevail if relationships are unequal. Griffin and Evans in 1970, for example, were arguing that aid, instead of leading to economic growth, which was the main reason for the existence of aid, may in fact retard economic growth in the long run by directing investment in recipient countries to areas donors want to support, including a bias towards capital intensive projects which lead countries to a long term need for capital (see Pronk, 2004:8). 
The oil crisis of the 1970s impacted significantly on developing countries. It led to significant balance of payments deficits and led donors to advocate a basic needs approach, an approach to aid delivery that focused on meeting the basic needs (food, shelter etc) of recipients. This sort of approach was more people-centred and came as there was an increasing realisation that economic growth alone was not enough to reduce poverty (Robb, 2004).

The 1980s were characterised by a 'significant shift in the role of the state' (Robb, 2004:27). The age of structural adjustment which followed led to trade barriers coming down, exchange rates being liberalised and the public sector in many countries being reduced in size. The effects of this were felt throughout the Pacific Region in the 1990s (Storey et al., 2005). But Tuvalu, did not find itself subject to the same pressures at this time and the public sector was (and still is) by far the most significant employer in the country.

Economic growth as a result of aid assistance across the history of development has been highly uneven and developing countries have not emerged into the modern economy in any uniform way. The real story about development and its relationship to economic growth has been the ability of some regions to achieve 'unprecedented long term increases in total production while other regions stagnated' (Sachs, 2005:31). Those from the developing regions who, by the 1980's, had not achieved the nirvana of sustained economic growth could question why 30 years of aid intervention had not made any material difference to the life of many in the developing world. 
For some, this 'failure of development' was largely attributed to the sense of 'alienation' felt by the 'beneficiaries' of the development process (Nelson and Wright, 1995:3), yet from a neo-liberal perspective the blame for the lack of growth was placed firmly at the feet of the beneficiaries themselves (Martinuson, 1997; Craig and Porter, 2006).

Whilst the debate on who is to blame for this failure of development continues to circulate in some sectors of development, the stark failures of the modernist paradigm provoked a search for alternative approaches. Foremost, and in line with a ground swell of wider social theory, came a perspective that inverted the predominant top-down model that placed institutions at the top and the people at the bottom to a bottom up model of 'people centred' development which aimed to be driven all or in part by the beneficiaries.

In time, this new model assumed the more encompassing label of 'participation' (Freire, 1970, Chambers, 1983, Chambers, 1995).

\subsection{The Emergence of a Participation Paradigm}

During the 1980s and into the 1990s the rhetoric of 'participation' became more mainstream as the demand that the beneficiaries take active part in the development decisions that effect them gathered momentum. By the early 1990s participation had become commonplace in policy discourse for most major development agencies. (see Crewe and Harrison 1998, Pronk 2004, Robb 2004). A shift towards participatory methodologies was evident in the 1990s in a plethora of guidebooks explaining the why and how of participatory methods (see for example: Slocum et al.,1995; Chambers, 
2002). By the mid 1990s Chambers' analysis of the Participatory Rural Appraisal in practice showed that PRA methodologies had been used in 40 countries (Chambers, 1994).

It was indeed logical (as well as ethical) to involve the recipients of development in decisions affecting them because:

'if development initiatives are to truly support needs of poor people, there must be more of an emphasis on continuity of process, consistency in approaches and commitment to working with people and relationship building' (Groves, 2004:76).

Scott-Villiers (2004), taking more of a rights based approach to the issue, asserted that it is not only that people have the right to participate, rather

'that people and the environment already do participate and control is not possible - only engagement. It makes sense to participate with them not to treat them as controllable units in our calculations' (Scott-Villiers, 2004:203).

It is only when 'there has been devolution of planning and monitoring to villagers, people in rural communities are no longer seen as simply informants, but as teachers, extensionists, activists and monitors of change' (Pretty and Scoones. 1995:160). 
Because participation is such a 'warmly pervasive word' (Nelson and Wright, 1995:2), there is a tendency of people who use it to 'adopt the moral high ground' (Pretty and Scoones, 1995:159) in the belief that any form of participation is better than no participation.

The belief that any participation is better than none is challenging because there are many definitions of what participation actually is. Chambers identifies three ways in which the term 'participation' is used, firstly as a cosmetic label to make things look good, secondly as a co-opting practise to mobilize local labour and reduce costs and thirdly as an empowering process which enables local people to do their own analysis, to take command and to make their own decisions (Chambers, 1995:30).

Jules Pretty (1995) in his Typology of Participation unpacks the language of participation even further. He presents seven types of participation. (Table 1 below)

These range from participation being something that happens to you, (he calls this passive participation) through to self mobilisation, where people drive the participation by take initiatives themselves, independent of outside institutions. In my career as a development professional I have been involved in 'participatory activities' along the full Pretty continuum. The ease with which an agency can say it is being participatory compared with the difficulty of unpacking what they mean by the term is the basis of much of the literature critiquing the paradigm. 
Table 1 - Pretty's Typology of Participation

\begin{tabular}{|c|c|}
\hline $\begin{array}{l}\text { Passive } \\
\text { Participation }\end{array}$ & $\begin{array}{l}\text { ople participate by being told what is going to happen or has already } \\
\text { ppened. It is a unilateral announcement by an administration or project } \\
\text { anagement without any listening to people's responses. }\end{array}$ \\
\hline $\begin{array}{l}\text { Particip } \\
\text { in infor } \\
\text { giving }\end{array}$ & $\begin{array}{l}\text { eople participate by answering questions posed by extractive researchers } \\
\text { ing questionnaire surveys or such similar approaches. People do not have the } \\
\text { sportunity to influence proceedings, as the findings of the research are neither } \\
\text { lared nor checked for accuracy. The information being shared belongs only to } \\
\text { ternal professionals. }\end{array}$ \\
\hline $\begin{array}{l}\text { Participation } \\
\text { by } \\
\text { consultation }\end{array}$ & $\begin{array}{l}\text { People participate by being consulted, and external agents listen to views. } \\
\text { These external agents define both problems and solutions, and may modify } \\
\text { these in the light of people's responses. Such a consultative process does not } \\
\text { concede any share in decision-making, and professionals are under no } \\
\text { obligation to take on board people's views. }\end{array}$ \\
\hline $\begin{array}{l}\text { ion } \\
\text { al }\end{array}$ & $\begin{array}{l}\text { People participate by providing resources such as labour, in return for food, } \\
\text { cash or other material incentives. It is very common to see this called } \\
\text { participation yet people have no stake in prolonging activities when incentives } \\
\text { end. }\end{array}$ \\
\hline & $\begin{array}{l}\text { People participate by forming groups to meet predetermined objectives related } \\
\text { to the project, which can involve the development or promotion of externally } \\
\text { initiated social organisation. Such involvement tends not to be at early stages } \\
\text { of project cycles or planning, but rather after major decisions have already } \\
\text { been made. These institutions tend to be dependent on external initiators and } \\
\text { facilitators, but may become self-dependent. }\end{array}$ \\
\hline & $\begin{array}{l}\text { People participate in joint analysis, which leads to action plans and the } \\
\text { formation of new local institutions or the strengthening of existing ones. It } \\
\text { tends to involve interdisciplinary methodologies that seek multiple objectives } \\
\text { and make use of systematic and structured learning processes. These groups } \\
\text { take control/ownership over local decisions, and so people have a stake in } \\
\text { maintaining structures or practices. }\end{array}$ \\
\hline $\mathrm{S}$ & $\begin{array}{l}\text { ticipate by taking initiatives independent of external institutions to } \\
\text { tems. Such self-initiated mobilisation and collective action may or } \\
\text { allenge existing inequitable distributions of wealth and power. }\end{array}$ \\
\hline
\end{tabular}

(Pretty, 1995:4-5)

If participation is to be more than cosmetic and to become an empowering process, in other words for move from the passive end of the Pretty's continuum to the self mobilisation end, there must be a shift in power and practice in agencies and this is difficult to achieve because 'any true partnership depends on reciprocity, preferential and or mutually supportive actions' (Kakande, 2004:92). 
It is precisely the fact that development institutions remain the prime agents in bilateral and multinational aid and development implementation that raises some significant challenges for the paradigm of participation from the perspective of donors and recipients alike.

\subsection{Institutionalising Participation}

At the core of this research is not the issue of participation itself but how agencies institutionalise participation and how that activity impacts on the recipients of this form of development assistance. The way in which an agency understands the term participation will determine which of these meanings are ascribed to it and therefore which practices take place in the field and the management and implementation processes of development assistance. An agreed definition of participation is only the start to identifying what 'meanings are attached to it in any context and how they are contested and deployed and who wins and who loses' (Nelson and Wright 1995:1).

Pronk (2004), in his discussion on catalysing development acknowledges it is difficult to attach meaning to something if you do not know why you are doing it. He identifies lack of consensus on the objectives of aid programmes but in his analysis articulates three common objectives:

1. Aid for charitable purposes - arising out of a desire to be good global citizen and help alleviate misery and hunger;

2. Aid for economic purposes arising out of a desire to develop resources and strengthen the conditions for growth 
3. Aid for political purposes arising from the need to provide support for ex-colonies or out of a desire for stability or promotion of democracy (Pronk 2004:3).

This lack of consensus as to why agencies enter aid relationships adds to the tensions they face as they embrace the concepts of participation and try to identify how they are going to institutionalise it. The appropriation of language like empowerment, partnership, ownership, transparency and accountability into the policy environments of the development agencies did not automatically lead to the ability to translate this policy to practice (Mosse 2001:18).

The focus on participation and partnership introduced another paradox for development agencies: how can one partner - the development agency - build up the 'self capacity and participation' of the other partner (Eyben and Ladbury, 1995:195)? How can donors make the mistake of 'promoting ownership' (Sobhan, 2004:178) or empowerment on the part of someone else as this is clearly a contradiction in terms?

This contradictory nature of agencies seeking to work in partnership with unequal partners from within organisational structures that are not at all responsive to participatory approaches is evident in other ways too. It is important to understand the concept of power when looking into the discourse surrounding partnership and participation. The empowerment or self mobilisation models of participation are predicated on equality of relationships. However the hierarchical structure and power relations within development organizations give rise to 'procedures designed for control 
and upward mobility rather than participation and innovation' (Chambers and Pethit, 2004:139).

Consistent with these observations, Blackburn and Holland (1998) provide a series of case studies illustrating the implications for recipients when participation in development is institutionalised. This collection shows us that agencies need to make changes in their methods and procedures, AND the culture of the institution AND the personal behaviour and attitudes of their staff if participation is to be effectively institutionalised.

Further literature critiqued both participation itself and the difficulties for agencies in practising what they preached (Cooke and Kothari, 2001; Mosse, 2001; Chambers and Pethit, 2004; Groves and Hinton, 2004 Arora-Jonsson and Cornwall, 2006).

As noted earlier, the process of implementing participation through development institutions can be driven by a range of pressures not always consistent with the philosophical objectives which sparked its emergence. Mosse (2001), for example, claims that development agencies have sought to secure the benefits (financial, political, symbolic) of participation but avoid the costs of participation. He argued that participation is a 'political value' signed up to by institutions for different reasons but in reality it remains a way of 'talking about' rather than 'doing things' (Mosse, 2001:32). This view is backed up by Marsden (2004) who refers to the realities of aid organizations - tight timeframes, scheduled deadlines, a work culture of urgency and efficiency as being contrasted against the 'realities of a pace of work that was largely determined by 
the environment, by the remoteness of the location, and sometimes the weather' (Marsden, 2004:100). For bureaucrats within development agencies there is a tension between the rules, which are there to help keep everyone on a level playing field and the complex environment in which development takes place (Jassey, 2004).

On this same issue Pasteur and Scott-Villiers (2004:182) admit that some 'incongruity between ideals and reality is inevitable and indicate that this situation can create healthy dialogue and reflection'. They go on to note that shifts to 'value based aid delivery policies' have complex implications for both individuals and organizations themselves, in terms of how they operate and who drives the decision making. This complexity can lead to a blurring of the lines between policy advice, policy influence and conditionality in aid delivery because of the "unavoidable power dynamics in the relationship make the best of intentions hard to achieve'. Agencies often believe that changing the organisational structure so that it better reflects the desired values is enough for the change to take place in practice, yet as Owusu (2004:108) explains, it is in fact the 'attitudes, values, behaviours and commitments that underlie the structure that are the most important'.

Organisations are not monolithic entities and policy documents do not reflect the differences in opinion or tell of the 'politics of arriving at the agreed position' (AroraJonsson and Cornwall, 2006:81). If bureaucrats are busy (and most are) it can be difficult to work in an environment where the values espoused by the organisation are not reflected in the technocratic procedures that make up the majority of the actual work. 
This situation is particularly significant for this study. As the above discussion reveals, there are inherent difficulties in adapting institutional practices, and their embedded power relations (Crush 1995), to reflect the participatory ethos. What should also be considered however is the extent to which these problems are symptomatic of a more overarching value position, which some in Tuvalu might argue, in which participation has itself become a new 'tyranny' of development practice.

\subsection{The Tyranny of Participation in the Development Arena}

Cooke and Kothari (2001) argue that participatory development is tyrannical in that it facilitates the 'illegitimate and/or unjust use of power'. They assert that current aid structures promote:

- tyranny of decision making and control as participatory facilitators override other legitimate decision making processes;

- tyranny of the group as group dynamics reinforce the interests of the powerful; and

- tyranny of method as participatory methods drive out others which have also have advantages (ibid 2001:7).

While institutionalising development presents inherent problems for the participatory model, Mosse (2001) accepts the tyranny of the group as a significant issue in development practise on the ground and claims that what makes the use of participatory methods so subject to the 'effects of dominance and muting is their character as public events' (ibid:19). He cites examples where the planning process, driven by a 'shared 
need to produce a concrete plan for action' suppresses difference in the interests of consensus and prioritises action over planning (ibid:21-22).

The tyranny of decision making and control extends to a discussion on accountability and responsibility for the outcomes of development interventions. Donors claim that partnership is important yet rarely share mutual responsibility for the outcomes (Shutt, 2006). The international aid agenda contains abstract and ideological goals, which take place in the long term while the objectives of aid organisations are 'short term and results orientated' (Groves, 2004:79). Donors are ultimately accountable to their taxpayers at home rather than to the poor people in the countries in which they are working. Gaining support for an ongoing aid programme often requires activities that are able to be understood and supported by the constituency at home as well activities that show tangible results in the short term. Contractors funded by a donor often find themselves 'servants to two masters' whose wishes don't always match: their paymaster and their local stakeholders. In this situation the contractor (or staff member funded by a donor) often feel more responsibility to their 'pay master' than the needs of local stakeholders (Pasteur and Scott-Villiers, 2004; Shutt, 2006).

Furthermore, Shutt $(2006: 154)$ argues that 'mutual dependence is implicit' in the aid relationship, recipients require financial assistance and donors require recipients to facilitate development interventions and spend their budgets as good global citizens. Recipients do have power and leverage (but often unrealised) as the donors need them in order to expend their budgets. Yet this mutual dependency is often ignored as donors 
have 'for too long, attempted to lead reform and define its goals' (Sobhan, 2004:78). In the context of Tuvalu this observation has particular significance for this research.

The agencies driving development are not only a reflection of the prevailing priorities of domestic politics, but they also bear the stamp of decades of institutional inertia in terms of policies, structures, processes, systems and indeed, personnel. Reinhardt's central argument is that ODA is determined not only by national level priorities but also by the way the decision making structures of the development agencies work. Individuals in these donor agencies make funding decision in the light of their own incentives. He expresses concern that recipients targeting their appeals for assistance to match what donors offer may mean they lose their implementation effectiveness, either through cooption of agenda or diversion of resources.

Such observations are by no means confined to the contemporary development context, and indeed such is the nature of institutions that they are a reflection of their past more than they are of the present, or more significantly, where they want to be in the future. Little and Clifford (2006) in the mid 1960s for example identified three types of problems in what they foresaw as a likely multi donor environment:

- Problems for the recipients in handling aid negotiations, receiving technical assistance, aid in kind from donors with different languages, standards and systems;

- Problems when administration is weak and donors take an intimate interest in a country's policies and want to supervise the use of the aid they provide: and 
- Problems for projects when policies are directed by something different from development eg tied aid, military intervention, and if projects cause competition between donors.

The first two problems have been significant in the Tuvalu setting as we shall see when we look at the findings of this research. Little and Clifford (2006:201) went on, rather prophetically, to summarise that 'better administration of aid, however desirable in itself, cannot contribute very much to development unless better coordination is also achieved'. They foresaw a situation where all donors might want their own representative in an office in-country, which they indicated would enhance the stress for recipient governments. The number of development partners in Tuvalu who now have their own presence in country has risen to five in 2009 (up from two in 2002). As we will see from the findings the stress this enhanced representation might cause the developing country government is a reality for Tuvalu officials.

Little and Clifford's proposal for a coordinated approach was the development of a single multilateral but donor controlled office in each country. This office would work to one plan and donors would delegate to this agency all technical, advisory and supervisory functions that are at present carried out by their aid missions. In later chapters we will see how the government of Tuvalu has responded to this increase in representation. Clearly the need for coordinated donor commitment is not a new concern yet few have heeded the call. 
As noted at the beginning of this chapter the challenges to development practice lie not in the realm of ideas, which are by their nature fluid and forever subject to change, but in the institutions charged with the implementation of these ideas. Little and Clifford's remarks from nearly 50 years ago have particular relevance today, a significance not lost on agencies themselves. Just as development discourse sought to change the nature of development practice to a bottom up people centred model through participatory methodologies, a similar process has emerged at 'the top' whereby agencies have sought to embrace a cooperative agenda to overcome many of the issues discussed above.

\subsection{The Aid Effectiveness Agenda and the Policy Realm}

It is widely recognised that the practices of donors add to the burden of national governments through their inability to work together effectively (Kakande, 2004). All developing countries do operate in a multi donor environment where their individual country needs are assessed against a multitude of national and international agendas and targets. The 'increasing and intensifying C's: Complexity, Change and unCertainty' (Horstman, 2005:43) continually impact on international development organizations and their partners.

Much has been written about the large numbers of donor, all with increased aid programmes, overwhelming bureaucracies in recipient countries with a proliferation of negotiating, reporting and supervisory procedures and these duplicative efforts being wasteful (Cooke and Kothari, 2001; Easterley, 2006; Freitag, 2006; Jayaraman and Ward, 
2006; Little and Clifford, 2006; Shutt, 2006; UNCTAD, 2006; Mavrotas, 2007; Easterley and Pfutze, 2008).

Sobhan (2004:173) refers to the 'deep disillusionment' felt by donors that, after 30 years of development assistance, poverty is still pervasive. Given the huge investment in aid since the 1950s of 1 trillion US dollars and the uneven nature of economic growth and development experienced by many recipient countries, it is not at all surprising that donors would once again look at how aid was being delivered.

The growing awareness among donors that their own actions and behaviour are just as important for the effectiveness of aid as are the actions and behaviour of the recipient (UNCTAD) was evident in discussion and subsequent adoption of the Declaration on Aid Harmonisation (Rome) in February 2003. The subsequent Paris Declaration on Aid Effectiveness containing the much lauded Paris Principles was signed in 2005 by all development agencies who work in the Pacific region and eight Pacific Island nations. Donors and recipient countries signed up to the five principles of:

- Ownership - Development assistance must centre around helping countries to meet their own development objectives

- Alignment - Development work must be aligned to the policies and systems of the partner country

- Harmonisation - Cooperation between donors is needed to increase the efficiency of the aid effort 
- Managing for Results - Using information about the results of development work systematically to improve decision-making and strengthen performance

- Mutual Accountability - Donors and partners should be accountable to each other (OECD, 2008).

These principles were all reaffirmed in the Accra Agenda for Action signed in Accra in 2008. It is positive to see the prominence that aid effectiveness does have on the global agenda but it is surprising how long it took aid effectiveness to re-appear centre stage given issues first being flagged over 30 years ago.

Mavrotas (2007:213) argues that the adoption of these 'altruistic initiatives' seems to indicate that donors' use of aid to influence foreign relations in order to achieve their own goals has declined. However as Armon (2007: 655) counters 'the Paris agenda is not clear or convincing', he claims that where the principles are 'applied faithfully' (ibid:653) there is increased scope for recipients to perform better in the planning, allocation and management of resources but warns that bringing politics squarely into the aid equation (which he claims the aid effectiveness agenda does) takes many development professionals outside both their 'zones of comfort' and what their agencies are mandated to do. (ibid:656). Pronk (2004:11) is less concerned about politics entering the aid agenda as in his view 'aid cannot buy policies; policies have a greater impact than aid, but together they have a greater impact than either one alone; and this combined effect is greater than the sum of the two isolated effects'. 
In all this comment though, there is one line of consistency - the signing of such declarations of intent, while important, is not as important as the application of the principles in practice. It is this that will determine whether or not aid becomes more effective.

Institutions at the recipient end of the equation have an important role to play in enhancing the effectiveness of aid - Mavrotas (2007:222) identifies how the injection of aid can either contribute to a 'virtuous circle' where desirable policy change and the building of effective institutions leads to economic growth and poverty reduction or to a 'vicious circle' where the delaying of policy reforms and undermining of local institutions leads to negative economic growth and the increase of poverty and conflict.

Institutions at the donor end of the equation have an equally important role to play in enhancing the effectiveness of aid. As Jassey (2004:131) warns

'if a state bureau is working in development it is not only 'gambling' with the taxpayers' money, but also 'meddling' with other countries' and people's development and welfare. In that sense we have to be doubly sure that our decisions are the best possible, even if it takes time and is cumbersome'.

Donors do have a range of options to enhance aid effectiveness they can: adapt rules and procedures; improve aspects of aid flow - magnitude, timing, predictability and harmonisation; make decisions to specialise their aid delivery by country or sector; give 
recipients greater 'policy space' and apply less intrusive policy conditions to their partners; and be clear on what is not negotiable in policy and practise. (Chambers and Pethit, 2004; Sachs, 2005; Easterly and Pfutze, 2008). But echoing the earlier discussion, Sachs (2005) cites the tension between what donors seek from recipients - national development plans - and the reality of what donors can and will actually fund. He argues that recipients cut the cloth to meet the donors thereby undermining their own planning processes.

One of the reasons why donor coordination and harmonisation have a higher profile in rhetoric than they do in reality is what Kakande (2004:94) refers to the "visibility syndrome' suffered by most donors in their desire to attribute achievements to their own efforts which runs counter to the ability to work together.

Although the behaviour of donors and recipients is changing we have in the late 2000's what Robb (2004:37) refers to as a

'fragmented aid system that continues to use many uncoordinated and inappropriate procedures, is still dominated by the domestic policies of Northern governments; often disempowers Southern governments; lacks accountability in both the North and the South; and continues to interact on the basis of asymmetric power'. 
This dichotomy leads to the situation where donors are 'stuck in a shadow play' where what they know privately is not the same as what they say publicly. (Easterly 2008:268). It also has led to the situation where what donors and recipients plan is not the same as, and arguably more important than, what they can do. Indeed Easterley centres the analysis in his book White Mans Burden (Easterley 2006) on the notion of planners and searchers. He argues that planners 'plan' while searchers 'do' and it is unfortunate for developing countries that the aid business is firmly in the business of planning. He gives the example of how it was possible for the latest Harry Potter novel, and all accompanying merchandise, to be delivered worldwide, embargoed, and then released on the same day all across the world, when it is impossible for malaria nets to be delivered to everyone who needs one. He argues that this is because the Harry Potter scenario was organised by searchers and the malaria net scenario is organised by planners.

Easterley goes on to highlight the centrality of the planning agenda in development practise and theory. Easterly's comparison highlights the extent of the challenges facing development institutions and their implementation of effective development. Indeed the above discussion reveals a certain circularity to issues and arguments which are consistent throughout development as a concept. The contradictions which tend to characterise practice in the recipient, donor and inter-institutional contexts appear inherent in the process itself. In order to bring the subject of this research into sharp relief there is one dimension which is so far missing in the discussion. This issue of scale needs to be addressed. While the subject of differential power relations has emerged in several contexts earlier in this chapter, the intrinsically geographical nature of 
development means that the above discussion needs to be embedded culturally and situated somewhere. That 'somewhere' needs to be scale specific.

As the following section discusses the issue of scale is of particular significance as runs parallel to the aforementioned references to power differentials. The subject of scale as regards particular places reintroduces a necessary geographical reality to the discussion. If this reality is ignored there is the tendency for development discussions to be cyclic, to feed on themselves, to the exclusion of any reference to people and place.

\subsection{Size Really Does Matter}

Any discussion on scale needs to start by answering the question what is small and what is big? These terms are difficult to define as they exist in relation to each other not as independent truths. The discussion of size tends to be predicated by a focus on landmass. Small is often linked closely with concepts of vulnerability to economic, political and environmental shocks of one sort or another (Bertram and Watters, 1985; Bertram and Watters, 1986; Warrington, 1998; Armstrong and Read, 2002; Read, 2008; Clarke, Fry and Mihajilo, 2008). This focus on vulnerability has led to what Warrington (1998:101) refers to as a 'bleak' literature on size that concentrates on a sense of weakness, and isolation on the part of these smaller nations. These disadvantages in turn, mean the weaker nations need to maintain a reliance on the welfare of richer nations in order to survive. Hau'ofa (1993:6) calls this an 'economistic and geographic determinist view of a very narrow kind' 
A new literature has emerged from small island researchers challenging this narrowness and seeking a more holistic view. An understanding that recognises small nations exist within, and in relation to, hinterlands of resources and relationships outside that of their own borders. Hau'ofa (1995:7) as part of his call for this more holistic view sees the countries in the Pacific as a 'sea of islands' a description which acknowledges interrelatedness rather than as 'islands in the middle of the sea' a description that which emphasises remoteness and geographical separation.

Thaman (1995) argues that smallness and isolation rather than being derogatory states offer great potential for promoting independence. He cites the example of Kiribati, which, he argues is self reliant at a community level precisely because it is so small and isolated.

Small island economies are, because they have to be, active and strategic in determining their own fate (Baldacchino 2006). This is because they are obliged to treat resources outside their own land as part of their hinterland, which they then colonise for their own ends. He also argues that the smaller the territory and the higher the population density the more likely it is that its 'footprint extends beyond its shores' and the more generous the 'openness and integration' such nations must exhibit in order to survive (ibid:46-47). We will apply this discussion of size to case study Tuvalu in Chapter Three of this research. 


\subsection{Conclusion}

This chapter has sought to provide the necessary theoretical backdrop to the subject of this research. In turn it has looked at the emergence of the modernist development paradigm and the institutionalisation of a global development process. Despite the revisioning of the ideas behind that process, as a result of the obvious failures, the agencies charged with implementing development practice face their own challenges not least of which are their structures, policies and practices. In light of these challenges and the apparent pressures they place on development recipients, further initiatives have been pursued at the interagency level in order to address them. Yet instead of moving development closer to its intended goals the efforts have revealed perhaps more vividly the inherent weaknesses and contradictions of development as a concept.

The fact that a discussion centering on the emergence of participation inevitably comes to focus on the challenges facing development agencies is a case in point, the significance of which should not be ignored. The discussion on issues of scale with particular reference to small states seeks to bring the discussion back to earth and thereby set the scene for this research.

And at the crux of this research? - What is the impact on recipients when agencies/institutions/individuals arrive to enable them to participate in their own development? What is the impact on recipients when the baggage these visitors bring contains the challenges, problems, issues and ideas that underpin the development discourse? How do the internal pressures of development agencies play out amongst 
those participating with them and receiving development assistance given the asymmetrical power relationship? And more to the point of this research, what can be done about it?

As outlined in chapter one this research focuses on how the above tensions affect the small island state of Tuvalu. By virtue of its size and isolation the relationships with donors can be observed more vividly, yet conversely, the dependence its geography prescribes becomes a metaphor for the inherent contradictions of the development process itself.

But before we can to look at the way that Tuvalu officials articulate the tensions they experience it is important to gain an understanding of the context that this research takes place in. The next chapter places us firmly in the Pacific, it starts by providing us a contextual understanding of the Pacific response to the aid effectiveness agenda, before moving into an analysis of Tuvalu itself, geographically, economically and politically. 


\section{Chapter Three - Tuvalu: Small Islands, Big Issues}

\subsection{Setting the Scene}

Chapter Two showed clearly that the current aid effort is hampered by the participation/consultation paradigm. Aid agencies grapple with how to be participatory within institutions that find such ways of working difficult. Recipients know that aid delivery in practice, is splintered among many donors, and each donor's effort is similarly splintered among many countries and across many different sectors. (Easterley and Pfutze, 2008; AusAID, 2009) Such a high degree of fragmentation, as well as being inconsistent with what donors have signed up to as good practice, is also counter productive in terms of efficiency and capacity. It also serves to undermine any trust relationship between development agencies and partner country governments. It is this counter productivity that is at the centre of this research. We have also seen that small size heightens the effects of ineffective application of the participation process on the part of development agencies. Such fragmentation and the related inefficiencies and tensions relating to smallness are especially evident in the Pacific and more especially in Tuvalu where this research is centred.

In order to place Tuvalu at the centre of this research this chapter looks first at the Pacific as a region against the wider context of the global aid effectiveness agenda. It then places Tuvalu within the context of the Pacific and finally provides a broad understanding of the specifics of Tuvalu itself. 


\subsection{The Pacific's Intersection with the Global Aid Agenda}

The Pacific Island Forum is the lead regional development agency for the Pacific. The Forum is an international organisation that was founded in 1971 to strengthen regional cooperation and integration. The administrative arm, the Pacific Islands Forum Secretariat (PIFS) is based in Suva, Fiji and is funded by contributions from its sixteen members. Its mission, goals and roles are included in Table 2 below.

\section{Table 2 Pacific Islands Forum Secretariat}

\begin{tabular}{|l|l|}
\hline PIFS Mission is: & $\begin{array}{l}\text { To ensure the effective implementation of the Leaders' } \\
\text { decisions for the benefit of the people of the Pacific. }\end{array}$ \\
\hline PIFS Goals are to: & $\begin{array}{l}\text { Stimulate economic growth } \\
\text { Enhance political governance and security for the region } \\
\text { Strengthen regional integration and cooperation }\end{array}$ \\
\hline PIFS Primary & $\begin{array}{l}\text { Policy advice and guidance in implementing the decisions of the } \\
\text { Leaders } \\
\text { poordes are to }\end{array}$ \\
$\begin{array}{l}\text { the Leaders } \\
\text { Support to the Leaders' meetings, ministerial meetings, and } \\
\text { associated committees and working groups }\end{array}$ \\
\hline
\end{tabular}

Source: (PIFS 2010a)

PIFS has a wide mandate covering a wide range of issues including: economic and political governance; security; strategic partnerships and coordination. They are the lead agency for Pacific Island input and response at the international level. There has been a long tradition of regionalism in the Pacific area. It has been recognised by individual Pacific nations that they can achieve far greater benefits by having their views presented and negotiated from a regional platform than as separate nation states. 
The Forum Leaders established the Council of Regional Organisations of the Pacific (CROP) in 1988 as one way to improve cooperation and coordination amongst the intergovernmental organizations working in the Pacific. There are 11 CROP agencies working across the Pacific, some of these are broad in scope eg Secretariat of the Pacific Community (SPC) which has mandates in several areas, some are specific in scope eg Forum Fisheries Agency (FFA) (SOPAC, 2010).

PIFS has a relationship with each Pacific Island member through political structures in each country. Pacific Island leaders attend the annual Leader's Forum, the Economic Ministers attend the Economic Ministers Forum, the Education Ministers attend the Education Ministers Forum and so on. Each CROP agency also has a relationship with each Pacific Island member as they deliver programmes, run training and follow policy initiatives in their particular interest area/s.

PIFS has taken the lead in discussion on the aid effectiveness agenda at a global and regional level as well. The problems and issues relating to ineffective or inefficient aid delivery have been on the PIFS agenda and appeared in the Leaders' communiqués since the inception communiqué in 1972. In the inception communiqué 1 from 1972, the issue was framed as:

'Australia and New Zealand expressed their willingness to work closely with Island members and the Bureau to ... encourage cooperation in consultancy 
services, in design and construction projects, including joint ventures with a maximum practicable use of Island resources' (PIFS 1972a:2-3).

Communiqué 2 in 1972 firmly placed aid effectiveness within the mandate of South Pacific Bureau of Economic Cooperation (the first incarnation of PIFS) when it identified one of the principal functions of the as being to 'study the development plans and policies of Forum Members in an effort to promote cooperation in the region; and to investigate the scope for regional development planning' (PIFS, 1972b:1-2).

Aid coordination first appeared under its own heading in the 1974 communiqué and has continued to appear regularly ever since. The specific challenges faced by small island nations were first raised at the Forum Leaders' meeting (hosted in Funafuti) in 1984. In the 1985 communiqué, the report on these challenges for small island nations stated:

the smallest and most vulnerable members of the family deserve special attention. The Forum therefore recognises that special emphasis on meeting the needs of smaller island countries should be given through support of their national development strategies and through preferential treatment in regional programmes' (PIFS, 1985:5).

In the communique of 1984 the first mention is made of the desire of the Forum Leaders to investigate having a single regional organisation to provide development assistance 
and technical advice for Pacific Island members, rather than the number of individual organisations that existed at that time.

These historical matters are highlighted in order to make two points: The first is that core issues in today's global aid effectiveness agenda - coordination, harmonisation, efficiency, needs of small nations, role of the bilateral, regional and multilateral agencies in development delivery, centrality of country development plans to development decision making etc - are not new. They have been part of the discussion at Leaders' level in the Pacific region for over 35 years.

Secondly, is that notwithstanding continued discussions on improving aid coordination and management within the region, the number of bilateral aid partners across the Pacific has increased, the ODA inflow to the region has increased, and the global and regional aid agenda has become laden with more agreements, declarations, and high level planning documents than ever before all of which require small developing country response.

\subsection{Pacific Principles of Aid Effectiveness}

The Paris Principles for Aid Effectiveness were signed in 2005. In response to these principles, the Pacific Island Forum leader's communiqué of 2006 agreed to make aid effectiveness 'an integral part of the Pacific Plan' (PIFS, 2006:9). In July 2007 in Koror, Palau, Pacific Leaders signed the Pacific Principles on Aid Effectiveness. These principles were an attempt by the Pacific to articulate the issues relating to aid 
effectiveness that are specifically relevant in the Pacific region. There are seven Pacific Principles, and while most of them come out of the Paris Principles, they also differ in important ways. Table 3 compares both sets of Principles.

\section{Table 3 Paris and Pacific Principles}

\begin{tabular}{|l|l|}
\hline Pacific Principles & Paris Principles \\
\hline 1. Country leadership and ownership & Ownership \\
\hline $\begin{array}{l}\text { 2. Multi year commitments by development partners and } \\
\text { countries aligned nationally identified priorities }\end{array}$ & Alignment \\
\hline 3. Greater Pacific ownership of regional development & Ownership \\
\hline $\begin{array}{l}\text { 4. Development partners and countries pursue a a } \\
\text { coordinated approach ... encouraging harmonisation }\end{array}$ & Harmonisation \\
\hline $\begin{array}{l}\text { 5. Strengthened institutional mechanisms and capacity } \\
\text { in countries in enable increased use of local systems. }\end{array}$ & Alignment \\
\hline $\begin{array}{l}\text { 6 (i). Provision of technical assistance that ensures } \\
\text { capacity is built and benefits are tangible to support } \\
\text { national ownership }\end{array}$ & Ownership \\
\hline $\begin{array}{l}\text { 6 (ii) Short term Technical assistance addresses local } \\
\text { skills gaps and are culturally sensitive }\end{array}$ & Alignment \\
\hline $\begin{array}{l}\text { 7. Use of agreed monitoring and evaluation framework } \\
\text { that will ensure joint assessments }\end{array}$ & Mutual Accountability \\
\hline
\end{tabular}

Source: (OECD 2008, PIFS 2010)

It is interesting that there is no Pacific Principle that relates to the Paris Principle of Managing for Results. It is also interesting that the Pacific felt the need to address issues relating to the provision of Technical Assistance (TA) so directly in the Pacific Principles when it is not so prominent in the Paris Principles. The significance of 
Technical Assistance as a modality of development support in Tuvalu will be dealt with later in this chapter.

The Pacific Principles are not legally binding and several key development agencies such as the EU and Japan have expressed some reservations about them. However it is a sign of the prominence of the aid effectiveness agenda in the Pacific that such principles exist at all.

Several countries in the world have taken the next step of enshrining the Paris Principles into a set of nationally relevant principles about aid effectiveness. The country that is leading the Pacific in this regard is Papua New Guinea with its Kavieng Declaration signed by donors and PNG Government officials in February 2008. The Kavieng Declaration contains a set of targets for implementation including limits on the number of missions the country will receive, targets for the percentage of aid inflow to be targeted to priority areas etc (PNG 2008).

It is promising that the Pacific is involved in such contextualisation of the international aid effectiveness agenda, both regionally and at a national level. What remains to be seen, is whether or not donors who are more powerful, are going to be able to lose some of their self interest in fashioning what Naidu (1995:52) calls Pacific Island dependency.

Now that we have an understanding of the importance of regionalism and the place of aid effectiveness in the Pacific it is time to turn our attention to Tuvalu. 


\subsection{Introducing Tuvalu}

The Pacific Ocean is as large as all the other oceans in the world put together, yet the land masses in it are tiny by comparison. There are 22 island countries and territories in the Pacific. The largest in terms of land mass and population is Papua New Guinea where nearly 6 million of the region's 8 million people live. At the other end of the scale is Tuvalu, which is the second smallest country in the Pacific region in both land size and population. Tuvalu has the third smallest population in the world and the fourth smallest landmass. (NZAID, 2010)

Tuvalu is a low lying atoll nation, comprising eight islands or groups of islands comprising a total land mass of 26 square kilometres. The island chain stretches $676 \mathrm{~km}$ from north to south and covers 757,000 square kilometres of ocean (Nations Encyclopedia, 2010).

The name Tuvalu means group of eight. The eight core islands or island groups that make up Tuvalu are: Nanumea, Nanumaga, Niutao, Nui, Vaitupu, Nukufetau, Nukulaelae and Funafuti. Funafuti is the capital as well as the centre for government administration and the only airport. The ninth island, Nuilakita has not had a permanent population and, as it belongs to Niutao, was not taken into account when naming Tuvalu at independence in 1979. 
Tuvalu, was originally the Ellice Islands in the Gilbert and Ellice Island colony. It became independent in 1978. The traditional life of Tuvaluan society existed for hundreds of years before the arrival of European traders, the blackbirders, and the European and Samoan missionaries in the 1860s. (Laracy, 1983). In 1877 Tuvalu, as the Ellice Islands, together with Kiribati (the Gilbert Islands) came under British jurisdiction. In 1892 the Ellice and the Gilbert islands became a British colony. Tuvalu was home to the American military during world War Two when the United States of America sought to hold back the Japanese advance across the Pacific. In 1975, following overwhelming support, in a referendum, for independence from Kiribati, the country became an independent constitutional monarchy. On October $1^{\text {st }} 1978$ Tuvalu became the $38^{\text {th }}$ member of the Commonwealth (Isala, 1983).

The UN (2002) describes Tuvalu's atolls as 'amongst the planet's harshest environments'. Tuvalu's soil is poor and there is not much diversity in flora and fauna. Rain water is the main source of freshwater, supplemented by a small amount of underground water and a recently introduced desalination system. The land only supports coconut palms, pandanus, pulaka (a type of taro grown in a pit) and a small amount of vegetables and fruit. 
Figure 1 Map of Tuvalu

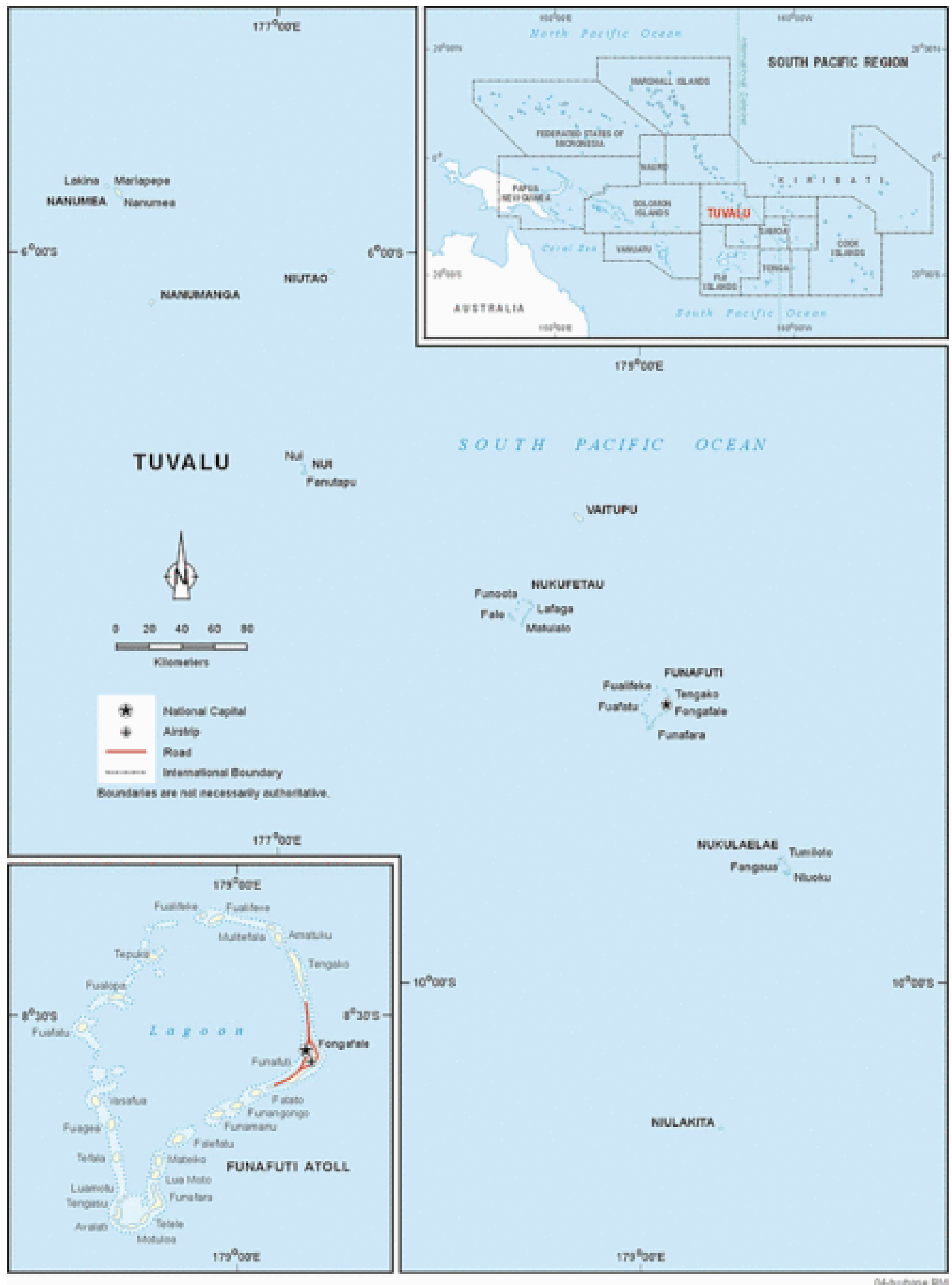

Source: (Mappery 2010) 


\subsubsection{Tuvalu's Population}

The most recent census in Tuvalu took place in 2002. The total resident population at that time was $9359 .{ }^{1}$ Forty two percent of the population resides on Funafuti, the island with the fourth smallest land mass. Funafuti's population density (1,610 persons per square $\mathrm{km}$ ) is much greater than that of the Outer Islands (222 persons per square $\mathrm{km}$ ), putting intense pressure on the land on Funafuti (SPC, 2005a:9).

Table 4 Tuvalu Population from 2002 Census

\begin{tabular}{|l|c|c|c|c|c|c|c|c|c|}
\hline & \multicolumn{3}{|c|}{$\begin{array}{c}\text { Total Enumerated } \\
\text { Population }\end{array}$} & \multicolumn{3}{c|}{ Non Residents } & \multicolumn{3}{c|}{$\begin{array}{c}\text { Total Resident } \\
\text { Population }\end{array}$} \\
\hline \multicolumn{1}{|c|}{ Island } & T & M & F & T & M & F & T & M & F \\
\hline Nanumea Island & 664 & 305 & 359 & 5 & 2 & 3 & 855 & 397 & 458 \\
\hline Nanumaga Island & 589 & 276 & 313 & 8 & 4 & 4 & 710 & 343 & 367 \\
\hline Niutao Island & 663 & 314 & 349 & 9 & 2 & 7 & 817 & 403 & 414 \\
\hline Nui Island & 548 & 263 & 285 & 25 & 13 & 12 & 610 & 285 & 325 \\
\hline Vaitupu Island & 1591 & 799 & 792 & 15 & 8 & 7 & 1310 & 657 & 653 \\
\hline Nukufetau Island & 586 & 286 & 300 & 4 & 2 & 2 & 701 & 351 & 350 \\
\hline Funafuti Island & 4492 & 2281 & 2211 & 130 & 82 & 48 & 3962 & 1994 & 1968 \\
\hline Nukulaelae Island & 393 & 186 & 207 & 6 & 2 & 4 & 392 & 182 & 210 \\
\hline Niulakita Island & 35 & 19 & 16 & 0 & 0 & 0 & 2 & 2 & 0 \\
\hline Total Tuvalu & $\mathbf{9 5 6 1}$ & $\mathbf{4 7 2 9}$ & $\mathbf{4 8 3 2}$ & $\mathbf{2 0 2}$ & $\mathbf{1 1 5}$ & $\mathbf{8 7}$ & $\mathbf{9 3 5 9}$ & $\mathbf{4 6 1 4}$ & $\mathbf{4 7 4 5}$ \\
\hline
\end{tabular}

Source: (SPC 2005c)

There was a 7\% increase in the total resident population between the 1991 census and the census of 2002. This equates to 609 people. The increase in resident population on Funafuti during the period was $10 \%$ whereas on the Outer Islands it was only $4.3 \%$.

\footnotetext{
${ }^{1}$ Total population enumerated was 9561 less 202 non residents $=9359$
} 
Tuvalu's 9359 residents fall into 1579 households, giving an average of 6 persons per household with slightly more than this in Funafuti (6.2) and slightly less on the outer islands (5.3) (SPC, 2005a).

Tuvalu is a very homogenous population: $94 \%$ of the population identify themselves as 'Tuvaluan' with a further $4.6 \%$ as 'part Tuvaluan'. (SPC 2002a:22). 91\% of the population are affiliated to the Ekalesia Kelisiano Tuvalu protestant church (ibid:23). Tuvalu is recognised as being a society with strong commitments to cultural traditions, family, community, religion and living in a manner that is closely linked to the marine environment and the ocean (Knapman, Ponton and Hunt 2002).

Similarly to other Pacific Island nations, Tuvalu has a young population. The median age of the resident population dropped from 25.1 in 1991 to 23.6 in 2002 (SPC 2005a:18). The 2002 census showed that the dependency ratio (the number of dependent people (over 60 years or under 14 years) for every 100 persons of working age) increased from 80 in 1991 to 82 persons in 2002 (ibid:19). This may seem a small increase but given the small population size is in fact significant as more people are having to be supported by each Tuvaluan of working age.

\subsubsection{Tuvalu's Government Setting}

As an independent nation Tuvalu is a constitutional monarchy with the British Sovereign as Head of State. The Governor General is a Tuvaluan citizen. The system of governance is a unicameral parliamentary system based on the Westminster model but 
without party affiliations. There are no real political parties in Tuvalu, but there are 15 members of Parliament. Each Island votes for two representatives except for Nukulaelae which has the smallest population and therefore has only one member. The Prime Minister is elected by the members of Parliament and has a Cabinet of no more than five ministers (GOT 2010).

Given $42 \%$ of the population is under voting age there is an average of 360 persons for each parliamentary member in Tuvalu. Hughes and Gosarevski (2004:17) argue Tuvalu is 'saddled with swollen political establishments' and that the cost for such establishments for such small states is 'ridiculously high,' however they then, by way of seeming contradiction, go on to say that Tuvalu deserves the title of the 'most successful government in the Pacific' (ibid:18).

Goldsmith (2005:108) is less conflicted about the situation of Tuvalu when he cautions that if Tuvalu is a 'weak state' it is primarily because it is a very small state and not because the government has major political problems in exerting control over its constituent parts.

The Government of Tuvalu has been the most significant employer in Tuvalu since independence. In 1980 Tisdell and Fairbairn (1983:344) calculated that the Government employed $71 \%$ of waged employees. The 2002 census data does not give us the figures of those specifically employed by government, rather it concentrates on type of employment. It showed that $37 \%$ of employees were in the public administration and 
public services sector, $22 \%$ in the gas, water, electricity and construction sectors (many of these are owned and operated by government), $10 \%$ in the restaurant, hotel and wholesale and retail sectors (the Government owns the only hotel), and $9 \%$ in storage, communications and transport (of which the government has interests). It is only the $20 \%$ who identified as working in real estate and business services who are likely to be completely outside the government sector.

With the government involved in many aspects of Tuvalu life and business it is not surprising that by 2008 the percentage employed by government had not changed much from the 1980 figure above, with the Government still providing employment for an estimated 68\% of the population (Bryant and Wrighton 2008:31).

Tuvalu Government is still highly centralised so the majority of public sector employment is on Funafuti. Island based local government consists of a Falekaupule (Island Council) with its executive arm the Kaupule. The Falekaupule has responsibility for making decisions for the whole island. All those over 18 are able to vote for who is represented on the Falekaupule although Panapa and Frankel (2008) claim the Falekaupule tend to be dominated by elders, chiefs and sometimes by church pastors.

Although a large percentage of working age people in Tuvalu work for the government, the actual size of departments and ministries is very small. The Ministry of Finance, which has the most dealings with development agencies, has only an establishment of 19 staff in relevant departments. At any time, approximately $20 \%$ of these positions are 
unfilled, either due to incumbents being away studying or because vacancies are not being able to be filled.

\subsubsection{Tuvalu's Economy}

Tuvalu has two parallel economies - the semi-subsistence economy operating in the outer islands and a cash economy, largely centred on Funafuti.

In the mid eighties Bertram and Watters conducted research on five Pacific island countries (Cook Islands, Niue, Tokelau, Kiribati and Tuvalu) all with a shared history of 'colonial welfareism'. They identified four key features that were influential in shaping the economic development of each of these countries. These were; the access nationals of each country had to Migration, the rate of Remittance money returning to each country, the size and importance of Aid inflows to the economy and the size and importance of the Bureaucracy and the MIRAB model was born (Bertram and Watters, 1985).

Tuvalu's relative economic stability is evidence of the importance of the MIRAB features as key aspects of the survival of Tuvalu (Goldsmith 2005). To some extent MIRAB flies in the face of the literature around the vulnerability of smallness explored in Chapter Two because MIRAB can be seen as a sensible adjustment by smaller nations to a 'revealed comparative advantage' (Bertram 1999:106). 
Connell and Brown (2005:5) identify the 'complex and important social and economic dimensions' remittances have, and this is certainly the case in Tuvalu which received USD \$4.9million in remittance income in 2001, which equates to approximately USD $\$ 523$ per head of population. The 2002 census showed $18.1 \%$ of Tuvalu households listed remittances as their main source of income. On the Outer Islands remittances are very important with $47 \%$ of households receiving remittances more or less regularly whereas on Funafuti only $7 \%$ of households claim remittances as their main form of income. This is largely due to the size of the civil service and the level of wage employment on Funafuti where $76.5 \%$ stated wages were the most significant earner for them. Much of the remittance inflow comes into Tuvalu from seafarers employed on international merchant and fishing ships. Borovnik (2006:151) refers to this type of employment as 'transversal temporary contract circulation'. Features of this type of employment include regular returns home and institutionalised remittance as part of standard employment structures. Remittances are still an important part of the economy of Tuvalu making up over 10\% of GDP in 2008 (Nuiatui pers com 2010).

Tuvalu's aid inflow will be covered in more detail later in this chapter but sits consistently above $30 \%$ of GDP and at times has been above $60 \%$ of GDP.

The size of government against the rest of the economy is a key feature in MIRAB economies. Pavlov and Sugden (2006) argue funding a large public sector wage and salary bills at the expense of support for basic service provision is evidence of the capture of aid by rural and urban elites. Feeny and Rogers' (2008:527) are far more 
understanding of the realities of small countries and outline four reasons why, in their view, small states tend to have larger governments relative to other developing countries. These are because:

- they are open to trade;

- a larger government cushions the impact of external shocks;

- they are the recipients of large amounts of foreign aid: and

- there is little domestic competition for labour.

Tuvalu certainly proves the final two reasons and it is these that largely explain Hughes and Gosarevski's (2004:17) 'swollen political establishments'. The disproportionate size of political establishment in Tuvalu does not preclude it, and other small states from enjoying what Baldacchino (2006:49) refers to as their special ability to manage to 'extract some special advantages from their metropole'. Baldacchino is referring here specifically to non independent states but the argument holds in Tuvalu if we consider Wellington and Canberra to be Tuvalu's resident metropoles.

\subsubsection{Tuvalu Trust Fund}

One such example of Tuvalu being able to extract some special advantage is the existence of the Tuvalu Trust Fund (TTF). The TTF was established on 16 June 1987 in an international agreement between Tuvalu, New Zealand, the United Kingdom and Australia. The intention of the agreement was to create a sovereign wealth fund where income from investment of the fund monies was channelled automatically into the recurrent budget of the Government of Tuvalu. One of the reasons for Tuvalu being 
ranked highly in terms of economic performance by Hughes and Gosarevski among others is the existence of the Tuvalu Trust Fund (TTF).

Between 1987 and 2005 the Fund earned an average annual 'inflation adjusted' rate of return of about 6 per cent, net of investment management costs. Annual returns to the Government budget have fluctuated from a high of $\$ 11.5$ million in 2005 to a low of a zero distributions in 2001 to 2004 and 2009. (Paeniu 2010, personal communication).

Mellor, et al. (2005) undertook a review of the TTF in 2005 and found that the existence of the Fund had some important economic impacts as it had:

- created a financial asset for the current and future generations of Tuvalu which is currently valued at (in 2005) around $\$ 99$ million (i.e. approaching four times the size of Tuvalu's annual GDP);

- funded around $17 \%$ of total recurrent budget revenue and around $18 \%$ of total recurrent budget expenditure over the period 1988-2004 as a whole;

- strengthened positive external perceptions of Tuvalu's finances through the broadly successful operation of the Fund and its governance structure (including the provision of independent policy advice by the TTFAC);

- directly contributed (in recent years) around 7\% of Tuvalu's Gross National Income and a significantly higher proportion of its ongoing income from overseas.

The Tuvalu Trust Fund (TTF) remains an important source of funding for the Government of Tuvalu's recurrent budget (approximately 15\% in 2008) and the funding 
of government priorities in the medium to longer term. Hughes and Gosarevski (2008) argue that Tuvalu is one of the best-governed nations in the Pacific because it uses its revenue (from the Tuvalu Trust Fund, fishing licenses and from the international marketing of the internet domain suffix .tv) to invest in infrastructure rather than trying to sell passports or run off shore banking.

The independent advice and management Tuvalu receives for the Tuvalu Trust Fund has ensured it does not fall into the situation where very small countries, lacking the opportunity to invest their own resources domestically, invest overseas, beyond domestic supervision and make wrong or corrupt decisions (Larmour and Barcham 2006).

\subsection{Tuvalu as an Aid Recipient}

Tuvalu is classified as a Least Developed Country (LDC) and is highly aid dependent. Soon after its 1979 independence, Tuvalu was listed as a Pacific country likely to be permanently dependant on foreign aid to sustain its standard of living (Fisk 1982, cited in Tisdell and Fairbairn, 1983). Aid has continued to be a significant part of the total GDP of Tuvalu ever since then.

Some AUD\$99.3million (adjusted to the Tuvalu Consumer Price Index) came into Tuvalu between 2002 and 2008 in the form of grant aid. 


\section{Figure 2}

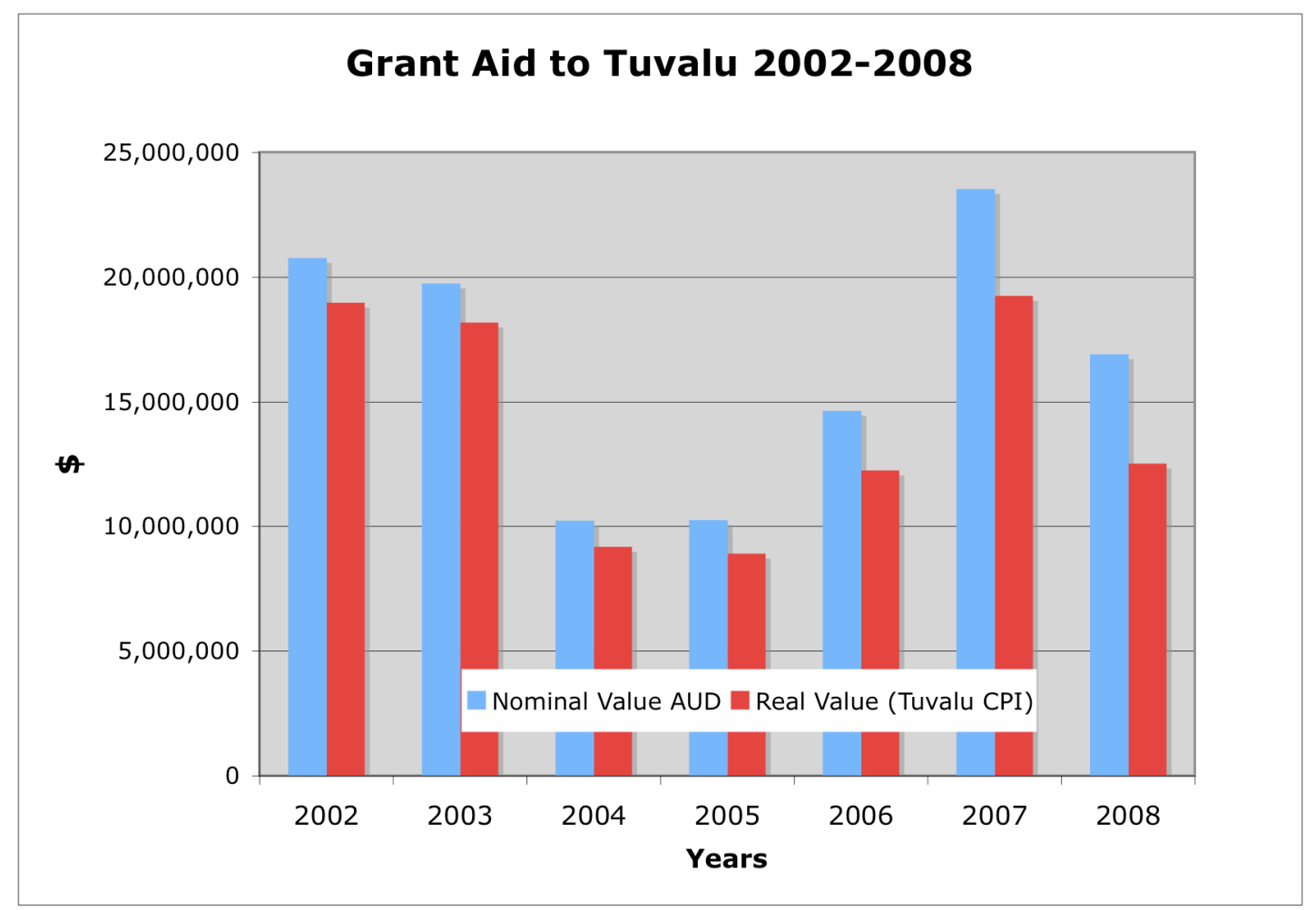

Note: amount shown in Australian \$

Source: (Government of Tuvalu (GOT), 2009)

Figure 2 shows the total grant aid flow annually in both nominal and real (adjusted to the Tuvalu CPI) terms. Grant aid inflow has averaged \$12.4 million per year over this period (ibid:2009). Using the 2002 census data as a starting point and applying the standard SPC population growth projections through to 2008 gives an average annual population of 9724. This equates to an average of $\$ 1,275$ of grant aid per capita per year over this same period.

Figure 3 below annualises the grant aid flow into Tuvalu from 2002 - 2008 (real using Tuvalu CPI) as a percentage of GDP figures. 


\section{Figure 3}

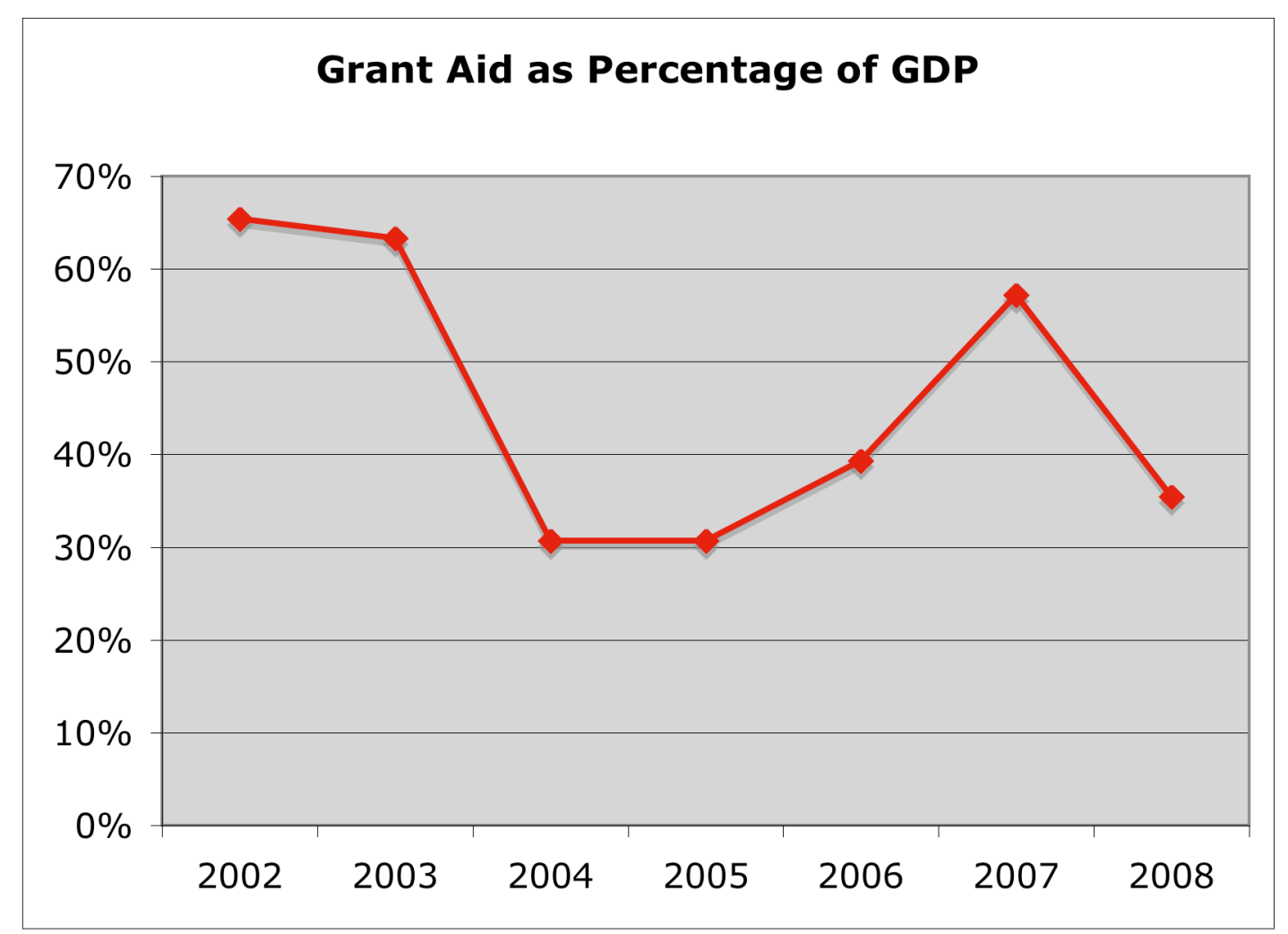

Source: (TTFAC 2009)

Recent comparative data on ODA levels across the Pacific (AusAID 2009), using 2007 data, showed that Tuvalu received the fourth highest percentage of ODA against GDP of the Pacific Island countries in 2007. The three countries that received a higher percentage of aid against GDP in 2007 were: the Solomon Islands, Niue and Nauru. For each of these countries it is possible to identify a specific reason why aid against GDP would be so high. In the Solomon Islands it is because of the costs associated with the RAMSI mission, Niue's dependence on NZ means a large inflow of aid from NZ on an annual basis and in Nauru the Australian funding for the Asylum Seekers processing centres was counted as ODA. However for Tuvalu there is no similar reason for high ODA against 
GDP. The following table shows the percentage of ODA against GDP for the other Pacific LDCs using the same 2007 figures. These figures make the influence of the RAMSI very clear for Solomon Islands and show Tuvalu as the Pacific LDC receiving the highest percentage of ODA against GDP.

Table 5 ODA as \% of GDP for Pacific Least Developed Countries 2007

\begin{tabular}{|c|c|}
\hline Least Developed Country & ODA as \% GDP \\
\hline Samoa & 7 \\
\hline Vanuatu & 13 \\
\hline Kiribati & 35 \\
\hline Tuvalu & 44 \\
\hline Solomon Islands & 65 \\
\hline
\end{tabular}

(Source: AusAID 2009)

The high amount of ODA against GDP for Tuvalu needs to be considered in light of the international commitment to increase aid flows. Feeny and Clarke (2008) are clear that there are limits to the amounts of foreign aid inflows an economy can absorb and these limits have important implications for scaling up of foreign aid. McGillivray and Feeny's (2008:10) research takes this further as they focus on growth efficient levels of aid against GDP and caution against donors providing aid in excess of $13.8 \%$ of GDP for countries that are fragile and $38.38 \%$ of aid against GDP for countries that are not. Even without discussing whether or not Tuvalu can be described as 'fragile' it is already clear that Tuvalu receives significantly more aid than what McGillivray and Feeny would call growth efficient.

Tuvalu, like other small states, depends heavily on bilateral aid donors and international agencies to fund some core government functions. This adds to the vulnerability for 
small countries because, in spite of their judicial sovereignty, their size may make them particularly vulnerable to international pressure (Warrington 1998:101).

Tuvalu is particularly vulnerable in this regard because of what Shroff (2002:42) refers to as the the vertiable 'alphabet soup' of agencies now involved in development in the Pacific in general and Tuvalu in particular. Shroff describes how most Pacific Island countries have broadened their bilateral relationships beyond their former colonial links and now actively engage with other bilateral partners (such as Japan, China, Korea, Taiwan, Canada, Indonesia, and more recently, Cuba). Many also have an expanded relationship with EU. The same Paicifc Island countries have substantial dealings with a large number of regional, and multilateral agencies. The United Nations connection alone has spilled into FAO, WHO, UNDP, UNESCO, UNIFEM, UNICEF and a myriad of other agencies (Shroff, 2002). In the multilateral environment alone, Hughes and Gosarevski (2008) identify some $30 \mathrm{UN}$ and international agencies and multilateral banks Tuvalu belongs to.

This level of dependence creates a tension between Tuvalu's constitutional independence and their becoming what Jackson 1990 (in Larmour and Barcham, 2006:181) refers to as a 'quasi state'. Crocombe (2001) also highlights the tension for countries that are highly dependent on aid because they operate in an environment where it is politically important to stress independence and sovereignty but in reality the practice of politicians is one of maximum dependence. 
Table 6 (below) shows the breakdown of grant aid in the period 2002-2008 by aid donor (GOT, 2009). The Republic of China (Taiwan), and Japan between them provide $50 \%$ of all the grant inflows. Australia and New Zealand are next with a combined inflow of 34\%. Development partners in the 'other' category include the Canada Fund, Turkey, Greece, Germany, India, France and others.

Table 6 Grant Aid Inflow $\mathbf{2 0 0 2}-\mathbf{2 0 0 8}$ by Donor
$\begin{aligned} & \text { \% of Total } \\
& \text { Inflow }\end{aligned}$
\begin{tabular}{|l|rr|}
\hline Donor & Grant Aid & $22 \%$ \\
\hline Japan & $25,420,753$ & $29 \%$ \\
\hline ROC & $22,615,673$ & $19 \%$ \\
\hline AusAID & $15,544,549$ & $14 \%$ \\
\hline NZAID & $8,464,601$ & $7 \%$ \\
\hline EU & $4,071,000$ & $4 \%$ \\
\hline ADB & $3,074,553$ & $3 \%$ \\
\hline Multilateral & $1,875,094$ & $2 \%$ \\
\hline Regional & 794,892 & $1 \%$ \\
\hline Others & $114,928,484$ \\
\hline Total
\end{tabular}

Note: Nominal values

Note: above amount shown in Australian dollars

Source: Government of Tuvalu (2009)

The International Aid for Tuvalu Statistical Summary 2001-2008 (GOT, 2009) classifies grant aid into three types. Table 7 below shows the split between the three types, of aid. 


\section{Table 7}

\begin{tabular}{c|rr}
\multicolumn{2}{c}{ Grant Aid 2002-2008 by Type of Aid } \\
& \multicolumn{1}{|c}{ Amount } & $\begin{array}{c}\text { \%o of } \\
\text { Total }\end{array}$ \\
\hline Capital & $56,883,520$ & $46 \%$ \\
\hline Financial & $55,269,621$ & $45 \%$ \\
\hline Technical & & \\
Assistance & $10,234,531$ & $8 \%$ \\
\hline & $\mathbf{1 2 2 , 3 8 7 , 6 7 2}$ & $100 \%$ \\
\hline
\end{tabular}

Note: Real adjusted by Tuvalu CPI

(Source Government of Tuvalu 2009)

Technical assistance is listed as only $8 \%$ of the total grant aid inflow in these figures. A detailed line-by-line analysis of aid inflow data casts doubt on the $8 \%$ figure. Much of what is classified as 'Financial' in the report prepared by Government of Tuvalu officials, including the myriad of in-country based training programmes will largely be led by technical assistance from outside Tuvalu. This would make the technical assistance percentage of the total aid inflow a lot more substantial.

This is important because, as we will see in Chapter Five, discussions with Tuvalu government officials indicate that the arrival of missions from outside Tuvalu to assist in development work is the component of the aid relationship that takes the largest proportion of their time and input.

AusAID and NZAID between them provided $73 \%$ of the Technical Assistance during the period (AusAID 53\% NZAID 20\%), so issues relating to the impacts of TA on Tuvalu officials explored in Chapters Five and Six will be of particular interest to these donors. 


\subsection{Tuvalu's Development Planning}

Te Kakeega II National Strategies for Sustainable Development 2005-2115 (GOT 2005) is the latest in a series of national planning documents developed by the Government of Tuvalu. Te Kakeega II arose from a nationwide series of development planning workshops and consultations in 2004. The following eight key strategic areas are identified in the Te Kakeega II:

- Good governance;

- Macroeconomic growth and stability;

- Social development: health, welfare, youth, gender, housing, and poverty alleviation;

- Outer island and falekaupule development;

- Employment and private sector development;

- Human resource development;

- Natural resources: agriculture, fisheries, tourism and environmental management; and

- Infrastructure and support services.

Te Kakeega II provides policy objectives and strategies for the achievement of each of the eight areas. There is a general section on performance monitoring for each strategic area, but no specific indicators are given. Tuvalu intends Kakeega II to be the lead document underpinning the funding decisions of donors. For several years the Government has used two documents to support this process: the aid management donor matrix (eg GOT, 2010a), and Kakeega Revisited, in which progress against the strategies 
of the annual plan is reported against annually (eg GOT, 2010b).

Tuvalu hosts an annual Donor Round Table meeting (DRTM). This is a chance for all donors to get together at one time and to discuss development issues and respond to funding requests from Tuvalu. These round table meetings occur in Suva or in Funafuti on a turn about basis. This is a response on the part of Tuvalu to take some control of coordinating development delivery but represents, at best, a partial response to the issue of donor fragmentation.

Tuvalu is a small and remote nation in the Pacific Ocean. It is characterised by significant dependence on development assistance, which is, in turn, characterised by significant asymmetries of power. As a case study Tuvalu provides a graphic and vivid story of the complex challenges facing multi donor development delivery in a specific place. On the one hand this specificity focuses the issues for the purposes of research and analysis yet simultaneously provides a platform for the broader more abstract theoretical debate challenge surrounds it.

Pacific countries have been calling for coordinated donor activity for nearly 50 years. While Tuvalu has established various forums such as the DRTMs in order to grapple with diverse and persistent demands for participation in the development delivery process. These measures are symptomatic of a difficult ongoing juggling act balancing the needs of donors against the realities that face Tuvalu officials. It is this issue which is at the core of this study. 
The following chapter outlines the methodological challenges faced undertaking this research in Tuvalu, the decisions made and the methodological approaches taken during this research. 


\section{Chapter Four - Tuvaluan Reality and the Temporary Insider}

\subsection{Introduction}

It is important to culturally embed debate in particular places and to identify in detail the issues that emerge out of that embedding. Chapter one outlined the nature of the development problem in Tuvalu focusing on a particular set of questions that guide this

study. Against this, chapter two presented a backdrop of theoretical debate regarding the emergence of the participatory paradigm and its institutionalisation. While the subsequent pressures emerging from this process are only recently beginning to be realised the broader issue of coordination clearly has a longer lineage. It is at the confluence of these processes that recipient nations such as Tuvalu, contextualised in Chapter Three, attempt to manage the ongoing relationships, and it is here we must look in order to understand the specific nature of the challenges they face.

This chapter will discuss the objectives for the research and how these informed the methodological approach taken in this study. The chapter will also discuss the theoretical issues that surround the approach taken. The chapter commences with a description of how the background of the researcher informed the method chosen and then looks at research took place in Tuvalu.

\subsection{Positionality of the Researcher}

The challenge I faced as a development professional with over ten years practical experience in the Pacific was how to structure my research so that it did not turn into a self serving exercise that was of more benefit to me than to the respondents who gave me 
so much of their time. This is a particular issue in Tuvalu where the population is so small and those that I wanted to interview are also part of the regular meeting schedule for all other development agency staff and officials. I did not want to be adding to the problem of over-consultation I was writing about.

However my years of working in Tuvalu in a variety of guises (NZAID official, AusAID and NZAID contractor, Canada Fund Coordinator and most recently Tuvalu Government Representative on the Tuvalu Trust Fund Advisory Committee) alongside these same officials I now wanted to interview means I am known to them. I have achieved what Mullings (1999) refers to as temporary insider status so that we have some shared positional space in our discussions.

Initially I was concerned that my multiple roles in Tuvalu might make me less credible as a researcher. After all, as Tuhiwai Smith (1999:136) asserts, 'consent is not so much given for a project or specific set of questions but for a person for their credibility'. However given that my most recent relationship with the Government of Tuvalu has been as their appointment on an international committee, I was confident my credibility could handle the splitting of roles during my visits across one or more tasks.

My ongoing work in Tuvalu has afforded me the luxury of having conversations about donor practice and policy in development work that have been revisited over the years. In some ways I have been able to 'fill in some gaps' before I started the official research 
in a way that is not often able to be achieved by development researchers limited to completing field work in discrete chunks of time (Murray and Overton 2003).

The issue that forms the central core of this research - the views of Tuvalu officials to the practices of donor consultation - has been developed in conjunction with colleagues in Tuvalu, I have had time to revisit the issues and to ensure that the outputs of this research are more than a personal academic thesis but in fact provide some tangible benefits to the Tuvalu officials who have shared their realities with me. I have tried to ensure that the design of the research takes into account the relational aspects of the participants and the researcher (see Tuhiwai Smith, 1999; Mullings, 1999).

As noted by Scheyvens (2003) local voices are seldom heard commenting on development policy or contributing to mainstream development planning, It was important to me that this research allowed the voices of Tuvalu officials to be heard so that I could contribute the development of a Pacific philosophy or ethic - a set of applicable concepts and values to guide interaction within countries, within the region and with the rest of the world (see Huffer and Qalo, 2004; Huffer, 2005).

I wanted, through this work, to present a slice of reality into the practice of development partners operating in Tuvalu.

\subsection{Development Reality in Tuvalu}

Because of the existing and ever changing relationship between the nature of reality (ontology) and the nature of knowledge (epistemology) it is clear that reality is 'socially 
constructed' (subjective). There can be no single reality - it changes as the relationships change and will always only be partially known. The underlying philosophical assumption of this study, therefore, is one of interpretation (interpretive paradigm). The study is interpretive because it relies on gathering in-depth information. Geertz (1973) calls this gathering 'thick-descriptions', from a small number of participants. The interest of this study lies in understanding the lived experiences of Tuvalu government officials as they interact with development partners. This research allowed the individuals being interviewed to identify their reality and what is meaningful for them and then reflects their reality against an assessment of the number of development agency visits and missions occurring over set periods of time.

It is my view that the decision I made to provide quantitative support for the qualitative realities of Tuvalu government officials legitimises their shared reality, provides greater policy relevance and makes it harder for development agencies to discount the experiences of these officials.

It is hoped that this collection of findings will make it possible to construct a shared reality and for this reality to have resonance for other small countries experiencing the same levels of donor traffic.

\subsection{Tuvalu as a Case Study}

As observed in Chapter Three, Tuvalu is a unique developing nation due to its size and location and is therefore appropriate for an individual case study. One of the purposes of 
this research from my own perspective and that of the Tuvalu officials I interviewed is to influence policy. Using a case study methodology is therefore appropriate as the aim of qualitative case study research is to develop analytic, as opposed to scientific, generalisations. Yin (1989) refers to the importance of working on case study research to make level one inferences: those relating to policy and theory. This was an important consideration when setting up a case study approach as it was important to me that the research be useful in a policy sense for both Tuvalu and those development agencies working in Tuvalu.

Yin provides three rationales for the use of single case study as opposed to taking a multiple case study approach. These are:

- When it is analogous to a single experiment (with many of same conditions that justify a single experiment).

- Where the case represents an extreme or unique example or

- Where it is a revelatory case - a chance to observe that which has not been able to be observed before. (ibid: 46-48)

These are all relevant to the use of Tuvalu as a single case given it is 'an object of interest in its own right' and one in which 'the researcher aims to provide an in-depth elucidation of' (Bryman 2004:50).

One of standard criticisms of case study research is that you cannot make generalisations from individual cases. On the other hand research that is inductive in nature adds value to the process of in-depth investigation of a single case. Such inductive reasoning takes the 
researcher on a journey from the particular to the general, that is, from a set of specific observations to the discovery of a pattern that represents some degree of order (Babbie, 2004). Bryman (2004:52-53) supports the value of a single case study as he argues that because case study researchers engage in 'theoretical analysis in relation to their intensive examination of a single case', case study research clearly has a place in the inductive tradition of research because of relationship between theory and research.

\subsection{Research, the Researcher and the Researched}

Research helps to build a sound base of relevant knowledge. The objectives of the research help make decisions about methodology/ies applicable to that research.

Under any research sits the philosophical or theoretical framework (paradigm) of the researcher. Babbie (2002) argues that paradigms are often difficult to recognise as such because they are so implicit and taken for granted. Articulating your research paradigm is based on the answering the following questions: how do you perceive the world (ontology)? What is it possible to know about the world and how might we know it (epistemology)? How might the world be interpreted (methodology) Murray and Overton (2003)? Jennings (2001) goes on to identify 6 forms of paradigm. These are positivism, interpretive, critical theory, feminist perspectives, postmodernism and chaos theory.

This research is an amalgam of a range of theoretical perspectives. My key take on the nature of the development process and how this impacts on Tuvalu is driven by a critique of the modernist paradigm. So in one sense it is postmodern as it utilises the researcher as 
a research tool. More importantly it is postmodern because it is not driven by an expectation that Tuvalu will undertake a development transformation which mirrors that of first world developed states. It is also interpretive in that my in-depth understanding of Tuvalu and the access that Tuvalu officials have given me affords me permission to interpret their realities in relation to the issues that form the core of this research.

As a researcher, understanding my own underlying philosophy has allowed me to make informed decisions relating to the methods I chose to use as I progressed with the research. I took into account Walsh's (2005:89) assertion that decisions about how to approach gathering of data arise directly from the 'philosophy, ontological and epistemological assumptions, disciplinary orientation, and paradigm of the researcher'. For this reason we need to discuss several methodological issues and how my philosophy underpinned the decisions I made when putting this research together,

\subsection{Taking a Qualitative Approach}

In research the distinction between quantitative and qualitative is often associated with the way the researcher collects data. In a quantitative study, data are collected in numbers or are very soon converted into them, and are subsequently analysed and reported in the same form. Quantitative research entails a deductive approach in which the focus is on testing theories. Such an approach also incorporates the practices and norms of a positivist scientific model where reality is viewed as an external objective thing. 
Quantitative methods of data collecting allow for very limited contact with people and are often used to enumerate and compare (eg: dollar amounts, birth rates, number of migrants etc). Such empirical methods ensure objectivity as they do not allow for any personal disclosure and/or emotional involvement.

Qualitative research, on the other hand, collects data as language (the technical language of the researcher or the everyday language of the respondents), emphasises an inductive approach to the relationship between theory and research, rejects the practices and norms of a positivist scientific model and embodies a view of reality as a constantly shifting property created by individuals. Language is used to describe behaviour, social relationships, social processes, social situations, and in particular, the meanings people give to their activities, the activities of others, and to objects and social contexts (Blaikie, 2000; Bryman, 2004).

Qualitative data collection methods often entail immersion into the world of the participants and allow the researcher to become, to some extent, an insider and to discover the culture and world view of the social actors' taking part. As noted earlier the long term relationship I have had with Tuvalu has enabled me to easily slip into the role of a 'temporary insider' for this research (Mullings, 1999).

Qualitative research 'seeks to understand the world through interacting with, empathising with and interpreting actions and perceptions of its actors' (Sullivan and Brockington 2004:5). The tendency of qualitative research to generate theory rather than test it was an 
important consideration in the selection of qualitative interview based methodology for this research.

Regardless of the data collection methods, the data collected needs to be interpreted within the particular ontological and epistemological assumptions of the researcher. In addition, Walle (1997:535) asserts "the choice of emics/art (qualitative) or etics/science (quantitative) must be determined by the situation in which research takes place, not by some misguided search for rigor simply for its own sake".

Travers M (2001), identifies 5 main qualitative methods observation, interviewing, ethnographic fieldwork, discourse analysis and textual analysis. This research is largely qualitative and the use of semi structured in-depth interviews as the main form of data collection responds to Walle's (1997) insistence on appropriacy to the field situation being a significant driver of the research method chosen. Semi structured interviews balance the need for a certain degree of rigour so that participants take a similar journey throughout the interview, while allowing responsiveness to the field setting which enables participants to better reflect their own realities.

\subsection{Talanoa Research}

Some work has been done around the use of Pacific specific methodologies in research (see Tuhiwai Smith, 1999; Crocombe, 2001; Nabobo Baba, 2004; Tuhiwai Smith, 2004; Robinson and Robinson, 2005; Vaioleti, 2006; Otsuka, 2006). 'Talanoa research' has received some focus as a Pacific relevant research methodology. Talanoa means 'talk' or 
'discussion' in Fijian, Samoan and Tongan (Robinson and Robinson 2005). Broadly the term refers to formal or informal conversations, talks or exchanging of ideas. The freedom of a Talanoa approach literally 'talking about nothing in particular and interacting without a rigid framework' (Vaioleti 2006:23) does not imply that information gathered from such processes is without importance, in fact the opposite is the case, as Talanoa offers the potential for the emergence of critical discussion and/or knowledge creation out of the multi layered discussions and free conversations that take place.

Given that the Pacific way is oral rather than written, the use of interviewing as one of the main data collection methods is a good fit in this setting. Relationships are important in Talanoa conversations. Otsuka (2006) refers to the good interpersonal relationship and rapport needed between researcher and researched, but also acknowledges the expectation that researchers and participants share not only time and interests but also emotions.

The Talanoa approach is relevant especially to the culture of Fiji, but has resonance in Polynesia where oratory and verbal negotiation are also important. My approach to the use of a semi structured interview leads to a greater degree of control over the subject and direction of the interview than other Talanoa approaches. This increased control is set balanced by the use of myself, as a known insider, which fits well within the Talanoa tradition as the distance between researcher and researched is removed and participants work alongside a human face they can relate to. 


\subsection{Researching in the Developing World}

Nabobo-Baba's claim that the knowledge derived from researchers has had a hand in how indigenous peoples have been projected and represented to the world reminds us of the representational power researchers have (Nabobo-Baba U 2004:21). Tuhiwai Smith (1999:176) articulates the power researchers have more strongly when she says:

"It is critical the researchers recognize the power dynamic which is embedded in the relationship with their subjects. Researchers are in receipt of privileged information. They may interpret it within an overt theoretical framework, but also in terms of a covert ideological framework, they have the power to distort, to make invisible, to overlook, to exaggerate and to draw conclusions based not on factual data, but on assumptions, hidden value judgements.... they have the power to extend knowledge or to perpetuate ignorance”.

Development research differs from research in other disciplines in three ways: firstly it is often carried out in an environment that is different from, and distant to, the one in which the researcher normally lives and operates, secondly it is often carried out in a language that is not the primary one of the researcher and finally it usually takes place in discrete time periods (Murray and Overton 2003). All of these features challenge the philosophical underpinnings of qualitative work because it is the relationship between the interviewer and the respondent that will determine the quality of the material gathered during the interviews. All of these features also challenged me to analyse closely what I was hoping to achieve, so the research methods I used, the time I spent in country, and 
the outputs of the research all sought to legitimise Pacific knowledge and experience rather than undermining it.

Escobar's (1995) assertion that development discourse, over time, has been constructed to legitimise the voice of western experts and undermine those of local people. should raise concern for any development researcher and certainly caused me to pause for thought. While it may be the duty of development researchers to 'inform development practise' ... and 'to provide alternatives to existing patterns of development' (Corbridge 1998:42 cited in Scheyvens, et al. 2003:139) it is also important to recognise that research, as well as being a moral search for knowledge is also a set of human activities that reproduces particular social relations of power (Tuhiwai Smith L, 1999).

Being aware that the research I was undertaking was in an environment and a reality that is not my own, and working alongside participants who operated from paradigms that are not necessarily shared with me meant I had to be careful that I answered for myself how the voices of 'others' could be incorporated into the research without "colonizing them in a manner that reinforces patterns of domination?" (England 1994:85).

The issue of domination has particular resonance in the Pacific. Nabobo-Baba (2004:17) identifies aspects of Pacific culture 'our abilities to connect, relate to one another and benefit from our relationships' as having been effectively 'silenced' in research. This is because researchers cannot recognise value in ways of operating that are outside the paradigm underpinning the work of the researcher. 
Huffer and Qalo (2004:98) refer to the challenge for Non Pacific researchers working in Pacific environments as being the need to highlight and mainstream Pacific ideas and values so that they are understood, integrated and 'recycled' into a body of thought from which a strong negotiating stance can be developed.

Taking this issue further, they argue that 'economists have been looking for ways to successfully integrate Pacific societies into the world of western economic rationalism that they have come to see Pacific attitudes as a constraint or barrier to their mission rather than as an area to be taken seriously' (ibid:89) has resonance for researchers as well, who spend their time trying to make sense of what they are seeing from the viewpoint of their own experience.

\subsection{Research Design}

Initially my research had one major focus to identify the realities of Tuvalu officials face when dealing with development agencies.

However, as part of the work I do as the Government of Tuvalu adviser on the Tuvalu Trust Fund Advisory Committee (TTFAC) I am charged (along with the other two advisers) to undertake particular pieces of analysis in response to requests from donors and from the Tuvalu Government. While in country during the October 2009 TTFAC mission, TTFAC had been asked to look into donor consultation and aid management issues. This was, in part, in response to interest in my thesis from both Government of 
Tuvalu officials and donor partners but also as a result of AusAID's interest in these matters as a response to the recently signed Cairns Compact. I proposed, and it was agreed by all parties, that I would undertake a rapid appraisal of visitor arrivals into Tuvalu. I would do this by meeting each plane as it arrived into the Tuvalu International airport and identifying each development related visitor. Using networks I had in Tuvalu I would attempt to identify each person who arrived into Tuvalu.

It was hoped that this rapid appraisal would enable the government to get a sense of the level of development agency traffic in and out of Tuvalu over the three week period. There was such a lot of interest generated by the results of the October appraisal, which I reported to the Development Coordination Committee at the end of the TTFAC mission, that I repeated this rapid appraisal on my two week April 2010 visit. The results of both appraisals show a startling number of development related activity.

The expansion of my research into the provision of quantitative data on number of missions has had the bonus of providing some legitimacy to the shared reality expressed by officials in their interviews and added significant value to the overall research.

\subsection{Interviews with Government Officials}

Qualitative in-depth, semi structured interviews of six current and two past Tuvalu Government officials was the main method of data collection for the first part of the research. 
An in-depth semi structured interview schedule was used to collect data from Tuvalu government officials. The interview schedule (Appendix One) was constructed around a core of standard predetermined questions. The interview questions were open-ended and the respondents were asked for facts as well as opinions. Open-ended questions were devised to allow for a closer link to the 'Talanoa Approach' discussed in Chapter Three. In this approach the questions are used as a guide, rather than a prescription, the time spent together is more conversational in tone and the length of the interview is not fixed, rather it responds to the realities faced by the participants. Such interviews are highly appropriate in a Pacific oral culture as they give participants a place to start but are not prescriptive in where the participant might go in their response. Jennings (2001) identifies among the many advantages in the use of semi-structured interviews the responsiveness that such an approach allows the interviewer who is able to follow paths the interviewee is interested in pursuing while collecting material on complex issue (Jennings 2001:166).

In-depth interviews were conducted with six current senior Government of Tuvalu officials and two previous senior officials who worked in the aid coordination area, both of whom now no longer work within government. I had informally chatted with potential participants on a work visit to Tuvalu in April 2009. I confirmed that I was undertaking the Masters research and that the research field visit would take place in October 2009. I canvassed interest in taking part in the research. I communicated with potential interviewees by email and telephone over the period April - September 2009 and was able to confirm a list of respondents by the middle of September 2009. 
The field visit took place in October 2009. Whereas one week was specifically set aside for the research component of this thesis, I added the week onto two other pieces of work I was contracted to do in Tuvalu - thus giving me a three week period in country.

Interview questions had been sent to each respondent prior to my departure from New Zealand and well prior to the actual interview being conducted. This helped in three ways. Firstly, it allowed respondents to seek clarity on questions they found ambiguous. Secondly, they had time to prepare themselves to provide most accurate and updated information during the actual interview. Thirdly, it helped the interviewee to get familiar with the questions, thus allowing the interview session to proceed in a smooth and natural fashion. Each interview was intended to last between 45 minutes to an hour.

The six serving government officials interviewed are all busy people and they form the elite in the Tuvalu government cadre of high ranking officials. They are busy balancing the needs of their government for domestic related policy and implementation work with the expanding global agenda for development. This agenda seeks to consult on most things and seeks the participation of as many as possible in the interests of ownership and transparency. Appointments I had made in advance were often changed at the last minute due to the arrival of a development mission or team of consultants, or the departure at short notice of the official concerned to travel to represent Tuvalu at an international meeting. It was therefore important to be flexible. One interview took place over more than two days as our first scheduled meeting was interrupted due to the arrival of a donor 
mission and throughout the second meeting another donor mission was kept waiting to allow the interview to be completed.

The work related visit to Tuvalu I undertook in April 2010, during the thesis writing period allowed me to complete the second rapid appraisal and helped to ensure that the requirements for any follow up interview time were able to be met within the constraints of the officials' schedules. It also provided an opportunity for respondents to read and check the chapters where their comments appear. I was also invited to give a presentation to the Planning and Budget Division of the Ministry of Finance on the thesis findings during my April 2010 visit.

I have had conversations relating to development with Tuvalu government and with donor officials over a long period of time. I felt able, therefore, to refer to these discussions in the analysis chapter by way of comparing them with findings arising from the formal interviews and in order to demonstrate a historical perspective to the analysis.

\subsection{Attribution}

In the initial stages of this research I had intended to attribute comments, thus making the comments non-anonymous. All those interviewed were aware that their comments were attributable. ${ }^{2}$ However as I wrote up the findings I became aware that assigning comments to particular individuals could be counter productive and might lead to a lessening in significance of the comments. As I want this research to be useful for the

\footnotetext{
${ }^{2}$ See Appendices 2 and 3 for Information Form and Consent Sheet
} 
Government of Tuvalu and to influence donor practice I do not want those using the research to qualify any statements made based on personal knowledge by the reader of the individual who had made them. Discussion with my supervisor and with the Tuvalu officials interviewed agreed to a change to anonymous contribution.

I accept, as do those interviewed, that given the small size of the civil service in Tuvalu it may still be possible to identify respondents in some cases. For clarity of reading I have referenced responses A $-\mathrm{H}$. I have not differentiated the responses of the current and the past government officials. This is for two reasons. Firstly there are significant overlaps in the responses of both groups. But more importantly the fact that there are only two ex aid officials interviewed makes them too easy to identify if they are referenced differently from the current officials.

On my second visit to Tuvalu in April 2010 only two of the initial six currently serving senior officials were still in the country. A combination of overseas postings, leaving on scholarship and maternity leave had moved four senior officials within a six month period. This degree of shift of personnel is normal in Tuvalu where at any one time the Personnel and Training Division of the Office of the Prime Minister estimate that $20 \%$ of civil servants might be away from the office (Apinelu, 2010 pers com). Both the exgovernment officials were in the country when I returned in April 2010 and employed on the same basis as they were during the October 2009 visit. 
Tracking down the officials who were out of the country proved to be difficult. With the exception of two respondents I did manage to get hold of all those interviewed to confirm their acceptance of the chapters where their anonymous comments appear.

\subsection{Conclusion}

This chapter has outlined the key issues underpinning the methodology for this research.

We have discussed the selection of Tuvalu as a single case study, the choice of qualitative 'talanoa based' methodologies backed up with quantitative rapid appraisals. We have examined the issues facing me as a researcher doing interpretive postmodern research in an environment where I am only a temporary insider with multiple roles.

Keeping the methodology consistent with the Tuvalu cultural context was discussed as were some of the practical considerations of undertaking work in Tuvalu. As such the chapter seeks to embed the research findings of the next chapter within the cultural and institutional context of Tuvalu's development relations. 


\section{Chapter Five - Participation Practice and Pressure}

\subsection{Introduction}

This chapter will present the findings of the semi-structured interviews with Tuvalu government officials and the rapid appraisal of development related arrivals into Tuvalu, both of which took place during the field work period in October 2009. I will also briefly cover the second rapid appraisal of development arrivals I was able to complete on my visit to Tuvalu in April 2010 for my ongoing work on the Tuvalu Trust Fund. The first part of the chapter will concentrate on the statistics around development visitor arrivals, the scope of their missions, the time they take in country and raise the potential impacts of this for analysis in the next chapter. The second part of this chapter presents the findings from the interviews with Tuvalu government officials.

\subsection{Rapid Appraisal Findings}

Air Pacific, through their subsidiary Pacific Sun uses 42 seat ATR 42 propeller planes to fly two services a week return between Suva and Funafuti. Wherever you work in Funafuti you can hear the siren that warns of the plane's impending arrival and you can hear the plane itself land and take off. Most people 'down tools' to wander to the airport and watch the arrival and departure of the plane. Planes fly in and out on Tuesdays and Thursdays. The period between the two flights is the busiest for donors and government officials alike as many donor officials fly in on Tuesday and out on Thursday. They arrive on Tuesday about $1 \mathrm{pm}$ and have to check in for departure about 11.30 on Thursday. This gives visiting officials less than 2 working days in country. 
In the interests of establishing a quantitative backdrop to the research a rapid appraisal of visitor arrivals was undertaken over the three week period in October 2009. Several tourists, and a dozen or so unidentified visitors arrived during this period. However, at least 34 people entered the country as part of approx 25 development related missions or visits over this period. These arrivals are included in Table 8 below. What is surprising and raises questions relating to efficiency, capacity and impact of programming for both the development agency and Tuvalu itself is the number of missions that appear to overlap each other. In this period overlap was evident in the environment, meteorology and taxation sectors. It was also possible that there was some degree of overlap in the employment, trade, public sector reform area. In the absence of time to analyse the objectives of each these missions, one can only assume that, in a best-case scenario, they have some area of overlap, but in a worst case scenario they are completely duplicative.

Approximately $80 \%$ of the development arrivals listed above in Table 8 were spoken to and the rest were spoken about with members of my wider Tuvalu network. Each of the ones I spoke to had ticked either the 'Business/Conference' or the 'Other Purposes' boxes on their arrival card. As very few meetings or conferences are held in Tuvalu that are not related to development, and given the $100 \%$ selection of these arrivals categories by the consultants spoken to, it is therefore reasonable to assume that the significant majority of those ticking the 'Business/Conference' and the 'Other Business' boxes are related in some way to development. 
Table 8 Number of Development Related Visitors - October 2009

\begin{tabular}{|c|l|}
\hline No of People & Purpose of Mission \\
\hline 1 & $\begin{array}{l}\text { Researcher for Masters thesis and member of Tuvalu Trust fund } \\
\text { Advisory Committee (myself) }\end{array}$ \\
\hline 1 & Filmmaker (climate change and environment related) \\
\hline 1 & Environmental researcher \\
\hline 3 & Consultants from single ADB mission on public sector reform \\
\hline 2 & Consultants from different agencies on meterology \\
\hline 2 & Consultants from different agencies on taxation \\
\hline 4 & Consultants from single mission relating to labour and employment \\
\hline 6 & $\begin{array}{l}\text { People from at least four different missions relating to the } \\
\text { environment }\end{array}$ \\
\hline 2 & Consultant members of the Tuvalu Trust Fund Advisory Committee \\
\hline 1 & $\begin{array}{l}\text { AusAID placement under the Pacific Technical Assistance Mission } \\
\text { (PACTAM) }\end{array}$ \\
\hline 1 & PACTAM programme Manager \\
\hline 1 & Consultant for the Pacific Regional Infrastructure Facility (PRIF) \\
\hline 1 & Consultant for ADB on Integrated Framework for Trade \\
\hline 1 & Consultant working on Tuvalu Government Accounts system \\
\hline 1 & AusAID official \\
\hline 3 & Staff from the Australia Pacific Technical College \\
\hline 1 & Consultant working with Tuvalu Public Works \\
\hline & Consultant working with Tuvalu Customs \\
\hline & \\
\hline 1 &
\end{tabular}

As far as is known, apart from the PRIF mission which is (jointly funded by AusAID, NZAID, ADB and World Bank) none of the other missions represented more than one donor or agency. 


\section{$\underline{\text { 5.1.1 Tuvalu Visitor Statistics }}$}

The majority of all visitors to Tuvalu are not tourists, rather they enter the country in order to undertake visits or consultancies, or other such work. In Tuvalu statistics relating to visitor arrivals are kept by two departments, the Department of Immigration and the Statistics Department. Given the research took place in October 2009, Figure 4 below shows visitor arrivals for 2008 by arrival category.

\section{Figure 4}

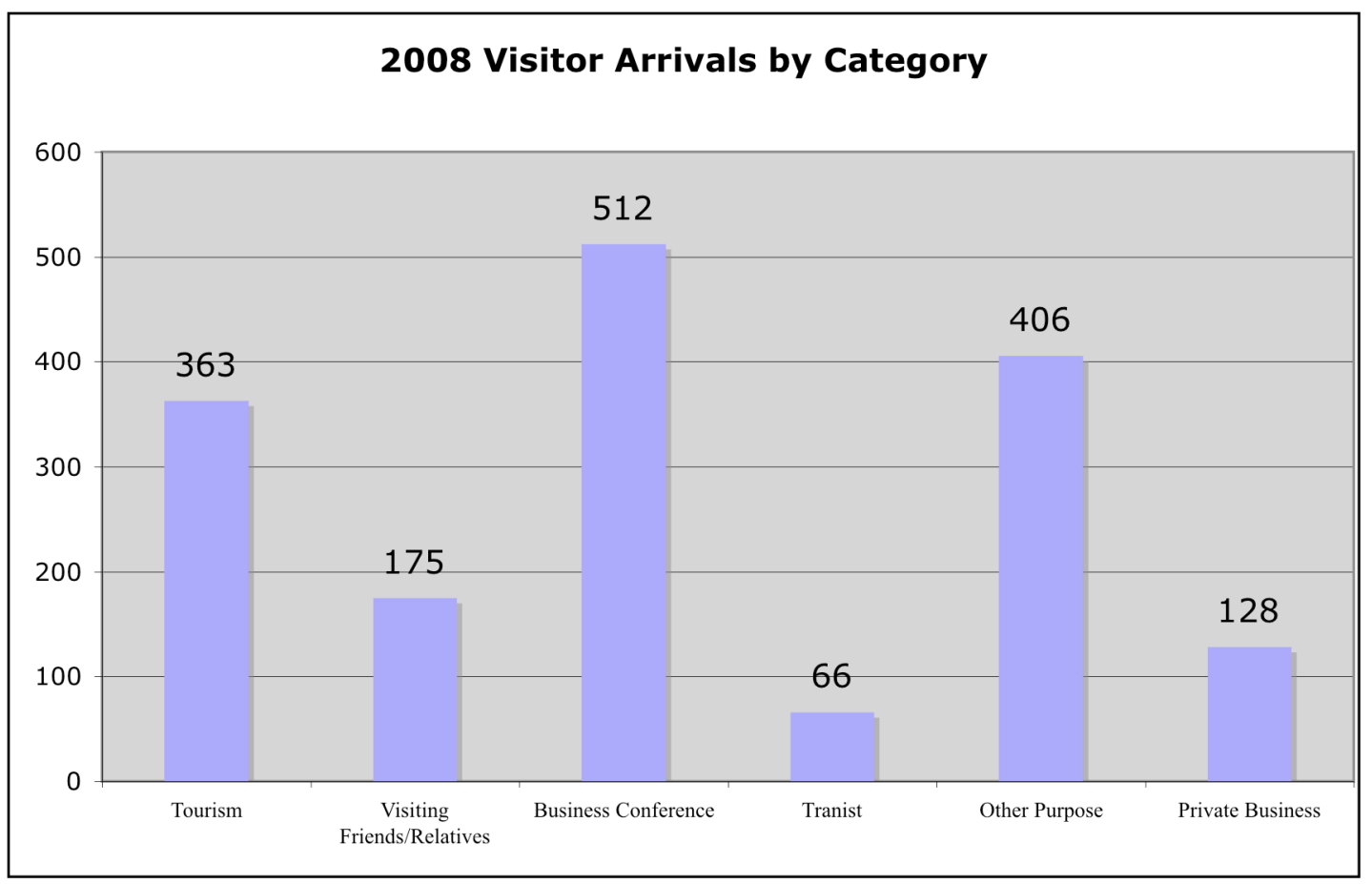

Figure 4 above shows 928 visitors arrived into Tuvalu under the 'Business/Conference' or the 'Other Purposes' categories during 2008. Assuming the significant majority of these relate in some way to development, it is fair to estimate that annual development related visitors comprise approximately 900 or $10 \%$ of the total population of Tuvalu. 
This is a huge percentage and extrapolated to a NZ setting would be roughly equivalent to 400,000 development related visitors coming into Wellington or, in an Australia setting, 2 million development related visitors arriving into Canberra annually on development related business.

\subsubsection{Development Mathematics}

The impact on a small civil service of this level of development traffic is huge. To try to get a sense of this impact consider the following 'back of the envelope' calculation:

If each of the approximately 900 development related visitors entering Tuvalu during 2008 had meetings totalling an average of 6 hours, over the period they were in country, and if there were two Tuvalu government officials present at each meeting, both of which are fairly typical for such meetings in Tuvalu. this would equate to 10,880 hours per annum which over a period of 48 weeks. This equals approx 227 hours of GOT official time per week. This shows that five fulltime staff $(5 \%$ of the government civil service) would be needed just to attend the meetings with development visitors. While this is a significant impact itself it is important to remember that this time commitment does not take into account the time also needed for meeting preparation and meeting follow up. Officials indicated that it is these activities before and after the actual meetings which often take up significantly more time than attendance at meetings themselves.

Tuvalu's ministries and departments are small. In 2008, the Ministry of Finance had an establishment of four staff at the Permanent/Assistant Secretary level (GOT, 2009a). 
These are the senior officials who receive the majority of all bilateral and multilateral visits. The Planning and Budget Department, which houses the single Senior Aid Advisor had an establishment staff of nine in 2008 (ibid 2009). This is the division charged with all aid coordination and effectiveness work. The Tuvalu Meteorological Division of the Office of the Prime Minister, which had two missions visit it during the October field visit, had an establishment staff of 17 in 2008 of which only six are at policy level (GOT 2009a). The impact of two separate missions in this area, for a small staff, in a short period of time is significant.

In April 2010 I spent another 14 days in Tuvalu this time for consultancy work largely related to my role on the Tuvalu Trust Fund Advisory Committee. The proximity of the airport to the TTFAC office combined with the high degree of interest in the October 2009 findings persuaded me, with the agreement of my colleagues, to undertake a second appraisal of development arrivals into the country.

Table 9 below shows the number of development arrivals during the two week period of the April visit. Noting that I was able to meet two fewer planes given the shorter period in country on this visit I was still able to identify 31 development related visitors during this two week period. 
Table 9 Number of Development Related Visitors - April 2010

\begin{tabular}{|c|l|}
\hline No of People & Purpose of Mission \\
\hline 2 & $\begin{array}{l}\text { Consultants for different agencies (WHO and SPC) on Health } \\
\text { policy }\end{array}$ \\
\hline 2 & $\begin{array}{l}\text { Police personnel (1 x Australia and 2 NZ) on different missions } \\
\text { working with Tuvalu police }\end{array}$ \\
\hline 3 & Tuvalu Trust Fund Advisers \\
\hline 1 & UN Volunteer placement as Aid Management Coordinator \\
\hline 1 & UNDP Official from the Suva office \\
\hline 1 & South Pacific Bureau of Educational Assessment official \\
\hline 1 & Consultant working on airport equipment calibration \\
\hline 1 & ADB official from the Suva office \\
\hline 7 & Consultant from UNESCO on education \\
\hline 3 & $\begin{array}{l}\text { Consultants working on various environment projects/programmes } \\
\text { (including SPREP, NZ Dept of Conservation, NBSAP work) }\end{array}$ \\
\hline 2 & Journalists all covering environment stories \\
\hline 5 & Consultants doing airport terminal safety training \\
\hline 1 & Taiwanese medical volunteers \\
\hline
\end{tabular}

If anything this is an increase in the number of visitors over the analysis period in October 2009. As the interview findings covered later in this chapter show, the majority of those interviewed believe they are taking part in an increasing number of missions. Given the probable squeezing of a large proportion of these meetings into the short time period between the arrival of the Tuesday plane and the departure of the Thursday plane it is not difficult to imagine that this level of engagement, all ostensibly for the 'good of Tuvalu', has a significant and negative impact on the amount of time GOT officials have 
to do their own jobs. The following section outlines the nature of these relationships thereby providing a context for the interview findings.

\subsection{Semi Structured Interview Findings}

Interviews were held with six senior Tuvalu government officials and two ex senior aid officers now outside government. This section presents the findings to reflect the way the interview questions were structured.

\subsubsection{Types of Consultation}

A large number of parts of Tuvalu government are involved in development. Specific departments respond to and meet with consultants and missions working in areas specifically related to their work for example, the Ministry of Health works directly with the World Health Organisation on health matters. The Ministry of Foreign Affairs has the overall responsibility for international relationships so meets with bilateral country partners. However the specific functions of aid management are split across two parts of the Ministry of Finance, Treasury is responsible for the flow of money, while the Planning and Budget Department coordinates donors, and has oversight of donor requests and priorities across government. With this split development visitors often need to see at least two people in Ministry of Finance as well as their partner Ministry/Department.

The number of people who arrive into Tuvalu to consult with officials and the agencies they represent is diverse but can broadly be split into four groups:

- those who represent bilateral donors/governments, 
- those who represent regional agencies;

- those from multilateral agencies; and

- others who include researchers, journalists and students.

\subsubsection{Bilateral}

Tuvalu over ten bilateral donor partners, (GOT, 2009) several of whom provide regular annual aid inflow in excess of AUD\$1m. Bilaterally, meetings and consultation occur at two levels. At the macro government level, meetings usually take the form of government delegations, officials' visits and are led by relevant government officials. At the micro level consultation is specific to a particular project or programme and is usually led by a consultant or a consultancy team contracted to a donor to manage or implement a specific project.

Several donors fund in-country liaison personnel to assist in the management of their programmes. The intention of these positions is to smooth the way in the management and running of the specific aid programme, track monies and facilitate reporting and acquittals. Table 10 shows who is employed in Tuvalu in this capacity and where they are housed inside or outside of Government. 
Table 10 Donor Representation in Tuvalu

\begin{tabular}{|l|l|}
\hline ROC Taiwan & $\begin{array}{l}\text { Manage their programme through their Embassy } \\
\text { in Funafuti }\end{array}$ \\
\hline Japan & $\begin{array}{l}\text { Development Policy Coordinator - placed in } \\
\text { Office of the Prime Minister to oversee JICA } \\
\text { programme }\end{array}$ \\
\hline EU & $\begin{array}{l}\text { Assistant to National Authorising Officer (NAO) } \\
\text { placed in Ministry of Finance to oversee } \\
\text { management of EU programme } \\
\text { UN }\end{array}$ \\
$\begin{array}{l}\text { Local Staff member in One UN Office (outside } \\
\text { government) to oversee programmes of UN } \\
\text { agencies }\end{array}$ \\
\hline NZAID & $\begin{array}{l}\text { Local staff member (outside government) to } \\
\text { oversee NZAID programmes }\end{array}$ \\
\hline AusAID & Solely managed from Suva agency office \\
\hline ADB & Solely managed from Suva agency office \\
\hline
\end{tabular}

Source: (GOT 2009)

ROC Taiwan has the only diplomatic mission in Tuvalu. It is headed by an Ambassador and has several other staff who are Taiwanese diplomatic staff. Both Japan and the EU employ an expatriate national who is responsible for the ongoing management of their programme in Tuvalu but who is housed within the Government offices.

JICA has a Japanese national working in the Office of the Prime Minister and the EU has an American national based in the Ministry of Finance. The New Zealand and the United Nations representatives are both Tuvaluan nationals working for their respective agencies in adjoining offices but outside Tuvalu Government. 
The way the bilateral programmes are managed will be discussed in relation to the traffic and time needed for meetings and input on behalf of Tuvalu government officials but the funding levels, the sectors they cover, the modalities of the aid delivered is outside the gamut of this research.

Some bilateral partner governments are working towards formalising bilateral agreements with the Tuvalu government. The Partnership for Development Agreement between the Government of Australia and the Government of Tuvalu was signed in Cairns in September 2009, and is intended to provide structure to the relationship by clearly identifying priority outcomes in the relationship and identifying the types of activities Australia and Tuvalu agree that Australia should be assisting with in country. A New Zealand delegation received in Tuvalu in September 2009 indicates that according to Respondent C they are 'moving towards a formal agreement with us well'.

Respondent A explained that working with ROC is 'more convenient to us' than working with some of the other donors 'because the relationship they have with us is different and because it is direct support into the budget is easy to administer'. Respondent A went on to say that having donor people in country is not always helpful as

'we want to fully utilise our allocations and the lack of authority often given to those on the ground means that we can't benefit from having them here. What is the use of having them here if we can't utilise them? The only way we benefit from people on the ground is if they help us fully utilise what is available'. 
Several respondents specifically mentioned the EU as having 'good programme' (Respondent D) with Tuvalu because of the in-house EU Technical Assistant who, according to Respondent $\mathrm{C}$ 'gets things done ... works to expedite programme activities ... (and is) more proactive about making things happen'. D went on to say that Tuvalu officials meetings with visiting EU delegations can therefore focus on relevant issue and wide ranging discussions rather than specific programme or project updates that is the way 'other donors tend to focus'.

The work of the Aid Coordinator is, by its nature, fully donor focussed. The aid coordinator has responsibility for donor coordination and is responsible for keeping track of aid programmes/projects that operate in Tuvalu. All aid coordinator officials noted that they tended to see mainly bilateral donors.

Respondent B saw that their key role with bilateral partners was 'having a specific project or programme focus ... link Tuvalu Government processes into donor processes'. To this end B is involved in many Tuvalu Government committees to give advice to other departments where their projects overlap with concerns of their department.

\subsubsection{Regional}

Tuvalu regularly receives visits from CROP agency officials or consultants. These visits are often project or programme specific. Meetings take place with officials from the line ministry that is hosting the project or programme. According to relevant GOT officials, 
officials and consultants from regional agencies rarely make calls on the aid unit, planning department or foreign affairs staff.

However this differs in the case of the Pacific Islands Forum Secretariat (PIFS) who have a wide brief and require member country officials to spend a lot of their time gathering information, writing reports and providing feedback for regional initiatives. One finance official commented that most of their work under the regional agenda was in response to requests from PIFS.

Some bilateral donors are making efforts to strengthen the linkages themselves between their programmes and regional ones in similar sectors. Respondent $\mathrm{C}$ referred to a recent EU meeting they attended in Nadi attended by the CROP agencies as well as all bilateral partners of the EU. C was impressed with this and made the point that as 'big money is going through regional programmes we need to work with them' in order to maximise the efficiency and effectiveness of the work they do'.

Officials identified several areas where regional programmes significantly overlapped with each other and with bilateral programmes. These areas were: water, environment and health.

\subsubsection{Multilateral}

Multilateral agencies especially from the UN family are also regular visitors to Tuvalu. Under the One UN policy an appointment has recently been made of a Tuvalu national to 
be the UN focal point in country. (This person left a job in the civil service to take up this position). There are regular missions from members of the UN family of agencies. UNDP (based in Suva) has regular project related engagement in-country and has projects housed in the Ministries of Finance and Home Affairs and Rural Development, in many of these cases officials leave the civil service to take up these project positions based back in the civil service. Several respondents were not very complimentary about multilateral agencies. Respondent D commented: 'UN agencies take a lot of our time, they expect us to make logistical arrangements etc for their missions and spend a lot of their time with the Aid and Planning staff.' This was seen by way of contrast to the ADB whose missions, according to Respondent $\mathrm{H}$ go straight 'to the bosses'. Respondent G, when discussing the UN said 'UN funding is too demanding, there is a lot of paperwork and frequent reporting yet requests for this arrive in an adhoc way and we are not given time to do much'. Respondent A commented similarly on the ADB who are 'quite demanding because we have to meet their deadlines'.

\subsection{Meetings, Meetings and More Meetings}

All the Tuvalu officials interviewed in the formal part of the research had taken part in development related meetings in the country. All, but one (who had only been in the job for two months) had taken part in meetings outside the country and several headed departments and were responsible for staff who had attended such meetings.

The two previous aid officials were able to provide comparative information as to scale and number of development visitors in recent years. 
Respondent $\mathrm{C}$ noted that they had been involved in 'approximately 50 development related meetings in the last six months' and went on to say that although there has been no real difference to the number of meetings over their two years in the job, the 'organisation of such meetings has improved due to improved communications'. Respondent A commented that they had experienced an increased number of consultations since they first started in the department due, in their view, to the increased number of projects and increased number of donors and development agencies operating in recent years in Tuvalu. Respondent A went on to note that visits from researchers and journalists have also increased recently.

The schedule in the Environment Department which had an establishment staff of five in 2009, (GOT, 2009a) showed regular visits of donors, journalists and university students as well as many consultants and agencies with an environmental mandate. Given the centrality of climate change and Tuvalu's prominence on the international stage in this dialogue it is not surprising that the Environment Department is the main contact point for journalists, film crews and students doing research on environmental issues.

Respondent E, with a whole of government mandate, mentioned that they receive at least one development related visitor every second day. E went on to highlight that in recent years they have been aware of an increasing number of meetings and phone calls and emails from journalists seeking comment on Tuvalu. In E's experience meetings are 'rarely just a briefing' and most get into detailed discussion of development issues. Respondent E maintains a relationship with most donors at a macro level leaving most of 
the micro level detail to be handled by other parts of government. Respondent $\mathrm{E}$ is thankful to partners who do take the time to come and brief as they feels that this gives Tuvalu flexibility and the ability to input into an issue, 'a chance to direct what we want done'.

As is common in all governments Tuvalu officials are charged with covering specific parts of the portfolio of their Department or Ministry. This tends to mean that interaction with missions and/or donors is on a context/subject specific basis. Respondent $\mathrm{F}$ commented specifically about this when they noted that the number of meetings they are involved in depends entirely on the nature of the consultancy/ies who are in Tuvalu at any one time. During my October visit in Tuvalu the ADB had a large team working on public sector reform related issues, and this mission was taking up a lot of time for Respondent F. F said 'In a normal month I might have two meetings. but I have many more when a mission that overlaps with my areas is in town. I have been really busy in the most recent two months because there have been lots of visits especially from a recent $A D B$ mission related to trade'. Respondent $\mathrm{F}$ went on to comment that 'Missions often want a lot of meetings because of pressing issues for them and they want to move things along'.

The role of Aid Coordinator in the Planning and Budget department of the Ministry of Finance is a crucial one for donors and development partners, Interviews with current and previous Aid Coordinators show a regular inflow of visitors, Respondent $\mathrm{G}$ mentioned having ' 12 meetings per month during my time, about 3-4 a week' and is sure there are 
many more now 'People are more interested in Tuvalu than they were - especially because of climate change'.

\subsubsection{Overseas Meetings}

While there is no research into the frequency of Tuvalu officials travelling overseas to attend development related meetings, anecdotal evidence is that such attendance is frequent. Respondent B commented that they had attended at least one international meeting a month over the recent 4-5 months and that 'this was normal'.

The difficulty with overseas travel for Tuvalu officials is the distance they have to travel and the limit in the number of flights in and out of Tuvalu. Respondent $\mathrm{C}$, who attends frequent meetings, explained how a recent four day workshop in Nadi meant nine days out of the country. Respondent A referred to a staff member being away for more than two weeks to attend a short meeting in Geneva. Respondent A commented that although it causes pressure on the department having their staff member away for so long it was good exposure for them to go. A recent two day meeting in Japan took Respondent B away from the office for more than two weeks and they commented 'I feel am becoming ineffective - I attend too many meetings taking too much time away'

It is fortunate for Tuvalu officials that many of the meetings they attend are hosted in Fiji, as all international flights in and out of Tuvalu are routed through Suva and this minimises the time needed to be away from Tuvalu. However analysis of recent Fiji based meetings, shows that, depending on the days of the week the meeting takes place, 
in most cases attendance still means being out of the country for one week but in several cases time out of the country was up to 12 days.

It is not just attendance at meetings in and out of the country that takes up the time off officials. With the ease of communications respondents noted that they are now the recipients of many more project and programme based information requests and briefings and regular email exchanges.

\subsection{Issues with Level of Engagement}

Most people interviewed expressed issues with the level of engagement. These issues are summarised below and form the basis of the analysis of issues in the next chapter.

\subsubsection{Time}

Many respondents complained that missions take up too much of their time. Respondent D acknowledged that the level of donor consultation is demanding is terms 'of the amount of time some donors need from officials'. D gave the example of the ADB, whose TA missions stay for some time in country and require a lot of support in terms of meetings. 'Our own work is sometimes delayed as we have to prioritise donors work above our own work'. Respondent A noted that it was not just the presence of TAs that takes time. The requirement for electronic comment, requests to furnish information and requests for responses to things requires more time and leads to problems in completing their own work. All Respondents acknowledged that meetings take up a lot of time 'especially when other staff are away on duty travel or study leave' added Respondent B. 
'Sometimes it is hard to manage to do my own work stuff in house and the donor stuff' Respondent $\mathrm{H}$ commented. Respondent $\mathrm{B}$ commented that they seemed to be 'permanently juggling my priorities so that I can fit in the number of meetings I have to attend, alongside other work I have to do'.

By way of contrast Respondent G (an ex official) now working outside government commented that the "level of engagement I experienced, sharpened my management skills and got me used to thinking about what donors might need'.

Respondent E summed the issue up when they said 'with many visitors seeking my view I am often left with little time to do management tasks. I am not always able to be as involved as I would like to be with either my own work or with the donors because I am too busy'.

\subsubsection{Overlap}

Present and past aid coordinators noted that due to the overlap of bilateral, regional and multilateral project work and the sheer number of consultancies it was hard to know about everything that was going on. Some sectors were especially prone to overlap, several respondents mentioned work in climate change as one such area. Respondent B stated 'climate change can be used as a way to get funding, the threat here is that without good collaboration among donors, we are going to duplicate effort and resources'

Respondent $\mathrm{H}$ claimed UNDP and AusAID are often doing things that overlap. 'They all claim to be assisting towards Kakeega but many things they do are overlapping, that they 
do not communicate with each other is making more work for us'. Respondent A summarised this issue in saying 'they all come on their own and do their own stuff yet they say they are trying to work together'.

\subsubsection{Reporting}

None of the officials interviewed were in any way opposed to the need to report to donors but many commented on the onerous nature of that donor reporting. Respondent $G$ summed it up as follows: 'Obligations on reporting are very time-consuming - we are faced with different types of reporting, different timeframes, projects, programme and international instruments reporting, and as well as that the templates of some donors not similar with our terms and structure'.

Past and present officials involved in Aid Coordination commented that with the sheer number of projects and programmes supported bilaterally, regionally and multilaterally they don't know about everything that is going on which also makes reporting difficult.

\subsubsection{Preparedness}

Many respondents felt they did not get enough time to be able to feel fully prepared to engage with officials and consultants on development issues. Respondent D expanded this in their claim that there is not enough knowledge about development in general across Tuvalu government officials and that this impacts on their ability to be responsive and understand processes. 
Several respondents commented on the lack of notice given of the arrival of missions into the country. Respondent F said 'on some occasions we are informed only one or two days in advance of the arrival of a mission', F gave the example of a recent UNDP joint strategic meeting mid term review, where very little advance notice was given and gave them 'no real time to go through documents' yet they had to facilitate the one day meeting. Respondent $\mathrm{H}$ commented on the recent discussions about the Australian Tuvalu Development Partners Agreement and said 'we only go the draft document about two days before the arrival of the mission that was coming to sign it, this didn't give us any time to really look at it before they arrived'.

Anecdotally in previous personal conversations many Tuvalu officials have commented that the regional and multilateral agencies are 'far worse' than the bilaterals in terms of preparedness and notice given about missions. Someone commented to me that the bilaterals 'seek our permission' for a visit, the multilaterals 'tell us' when they are coming.

Respondent $\mathrm{G}$ said that on several occasions they were 'taken by surprise' by visits of donor/development partners. There was also comment about the lack of preparedness on the part of consultants. Respondent E referred to several studies that in their opinion were too general and broad and where partner results were not helpful. Respondent E put this down to a lack of focus on behalf of the funding agency 
'who have not done their own research to find out the Tuvalu specific situation, instead they want to take our time to find out stuff they could have found out by themselves or by talking to other development agencies.'

Respondent $\mathrm{C}$ went on to add 'Many consultants are not prepared' and gave several recent examples of consultants who just asked open ended general questions. 'It felt like they didn't know basic information and just wanted me to provide it'. Respondent B was more specific when they commented 'I would love to see more consultants who are scientifically prepared and don't waste my time'.

\subsubsection{Projects That Take Place Inside Government}

A final area of concern mentioned by several respondents is the stress placed on departments who have donor projects placed within them. Respondent A mentioned several UNDP projects are based in their office, one with accompanying Technical Assistance and one using local staff. Respondent A commented that the 'workload of these projects sometimes gets in the way of our staff doing other work they should be doing'.

The Environment Department is especially affected with several projects placed within their small department. For the Global Environment Facility Sustainable Land Management Project, a consultant was sent out to work with the office for three weeks

just to write up the proposal. So it is not just the time taken when projects are being implemented that is at issue, a large amount of people's time is spent on application 
procedures (which often fail) and in this case are so tortuous that a specialist consultant is required just to complete the form.

Discussion with officials identified several issues with donor programmes that fund people placed in government departments. UNDP pays eight project management staff across few departments. In nearly every case the project officer was a civil servant before taking up the project role. UNDP has a further two young professional or UNV placements planned. AusAID has funded three PACTAM personnel and the October visit of the PACTAM Coordinator identified a possible eight positions for consideration. This is all a huge impact on government, much of the impact positive: projects have time allocated to their implementation, and inline positions are filled or advisory personnel provided. But there are significant risks to this level of TA/project based support.

The Government of Tuvalu may be unable to support the level of output at the end of placements and often finds it difficult to recruit staff to replace those on a project contract. Departments (especially environment) are often depleted of staff able to undertake their own GOT work. These issues will be revisted in the next chapter.

\subsection{Opportunities that exist for Tuvalu}

None of the interviewees had any problem identifying opportunities to meet the challenges they identified. They were able to identify opportunities for changes in donor practise as well as changes in internal government practises. 


\subsubsection{External Relationships}

All respondents agreed that the annual donor round table meeting (DRTM) was, in principle, a positive thing. Many suggested making more use of these events, with Respondent H noting that 'at the moment it is boring update matrix gap filling exercise'. Interview comments centred around using the DRTM as a chance to have strategic discussions about the best direction for aid assistance. Respondent D suggested that 'it was a chance for Tuvalu to set the agenda more effectively than we do now by leading discussions that are more wide ranging than simply identifying areas where funds were needed'. Respondent $\mathrm{C}$ suggested that progress on project funding discussions issues would be enhanced with the establishment of a group in Suva comprising donors, agencies who met regularly at the Tuvalu High Commission. It could be this group who would discuss projects and programmes - leaving the higher level DRTM to debate issues such as overlap, consultation levels, programmatic focus.

\subsubsection{Internal Structure}

Several opportunities for strengthening the internal structure of Tuvalu government processes were made. Respondent A noted that due to the 'fragmented structure of aid on the part of the donors and agencies, Tuvalu needs to develop a more holistic system allow a more coordinated approach'. This was backed up by Respondent H official who suggested that what was needed was a 'stand alone department' staffed with all officials who have anything to do with aid 'so that staff can focus on this and not have to do other stuff'. Taking this idea further was Respondent C, who suggested that in order to deal with the multiple in country representatives working in different ways and with different 
degrees of autonomy, all representatives of external agencies (eg NZAID, UN) should work in one unit - for example within the Ministry of Finance. The argument for this was couched in terms of 'donor representatives facing outwards not inwards' in relation to understanding of Government issues and processes.

Strengthening planning within Tuvalu was identified as a major opportunity. Respondent $\mathrm{C}$ suggested 'If we work to develop more sector (and across government) policies we can sell these to the donors for them to pitch in when they can', $\mathrm{C}$ went on to note that 'we need to sell it like a package - eg tax AND trade not as separate components'. As regards strengthening Tuvalu Government planning Respondent D suggested 'an increased number of people within Tuvalu government need to rotate in and out of the Planning department so more people know what is going on and how it works', this would also assist to alleviate the concern noted above of there being too little understanding in the civil service generally about development issues.

Several people noted that the number of staff in government departments is not adequate to actually do all the work they are required to do. Respondent $\mathrm{B}$ proposed a 'comprehensive review of government, that asks what is happening now and what can be done better?' This review could lead to a tighter structure that ensures departments enough people and they have sufficient capacity to cope and to be responsive to realistic needs of donors. Respondent $\mathrm{H}$ was clear that any strengthened systems should also ensure 'line ministries report back to planning and aid coordination'. 
Other opportunities identified to strengthen internal structure included: running a 'profile writing week across government tied to donor coordination timetable', (Respondent C), 'a chance to learn from other Pacific countries', (Respondent D) and 'tidying up record management.' (Respondent D).

\subsubsection{Donor Changes}

Respondents saw several opportunities for donors to strengthen their processes and minimise the stresses placed on Tuvalu officials. All ideas related to the ways donors work on the ground in Tuvalu. Respondent A raised the desirability of delegating more authority to donor representatives based in Tuvalu, enabling them to make decisions in a timely manner rather than having to revert to their capital city at every decision point. Respondent $\mathrm{E}$ went further and suggested that there be 'more donor representatives on the ground in Tuvalu provided they operate like the JICA representative' who works in the Office of the Prime Minister, converses regularly with government and is able to make decisions. Respondent E considered this an ideal set up from Tuvalu's perspective.

Many respondents proposed increased harmonisation of donor visits, which, in turn would lead to fewer visits. 'All donors should come on one mission and harmonise everything' (Respondent H), or 'Organise donor visits on a set annual basis'. (Respondent G). Respondent B suggested that if projects were orientated to spend more of their funds 'on the ground rather than on consultants visits and report writing' the impact on Tuvalu officials would be extremely positive as well as leading to 'increased 
amount of money actually benefiting Tuvalu rather than the consultants' pockets'. Respondent A was clear donors need to ask themselves the question

'who are you working for? The good of Tuvalu or to meet your own systems?'

\subsection{Conclusion}

What can we learn from the Tuvalu case study in terms of the wider context of development delivery? We must start with Respondent A who has identified the crux of the issue, when they ask development agencies to ask themselves 'who are you working for? The good of Tuvalu or to meet your own systems?' Respondent A is asking here who drives the agenda in donor and partner country relationships? We will explore this in the next chapter.

We have seen in this chapter the startling number of development related visitors to Tuvalu and have an understanding of the impact on officials that this level of traffic has. We have also seen that in the two periods of the rapid appraisals there were several overt examples of overlap and many others where some degree of overlap was likely. In an environment where donors have committed to increased harmonisation this is unacceptable and we analyse this issue further in the next chapter.

The voices of Tuvalu officials interviewed during this research are loud and clear as they articulate their views on such issues as: partner country representation in Tuvalu, the 
cluttered meeting agenda, ways that they and their development partners could improve processes to minimise the impact of development work on Tuvalu officials.

We recall that the value of case studies is their ability to inform the theoretical domain. In order to explore the potential the Tuvalu experience has to contribute to theory it is first necessary to integrate the above findings with the body of literature covered in chapter two. The following chapter seeks to analyse the experiences of officials in Tuvalu by embedding the experience with the theory. 


\section{Chapter Six - The Case In Context}

\subsection{Key Questions}

The findings covered in the previous chapter arising from the rapid appraisals of development related visitors in October 2009 and April 2010 alongside the semi-formal interviews with Tuvalu officials raise three important questions that reflect the objectives of this research:

- How can Tuvalu, a SID with a small and stretched civil service, respond professionally to the myriad of ways it is asked to participate in the development of its own citizenry?

- How can Tuvalu, a small country with a relatively high percentage of GDP comprising aid assistance, manage the conflicting values that exist in the power relationship between its partners who disburse the money and itself, as recipient of these funds?

- What improvements can be made to both donor and recipient practice to enhance the efficiency and effectiveness of the development partnership?

This chapter will look at the core issue in each of the above questions, Participation, Power and Practice, in turn using the findings as a starting point. I will place the findings against both the literature on development effectiveness covered in Chapter two and the informal discussions I have had with government officials in Tuvalu over recent years.

\subsection{Participation: a Blessing or a Burden?}

Figure 5 symbolises the issues facing Tuvalu officals identifed in the previous chapter. 


\section{Figure 5 Participation Pressures}

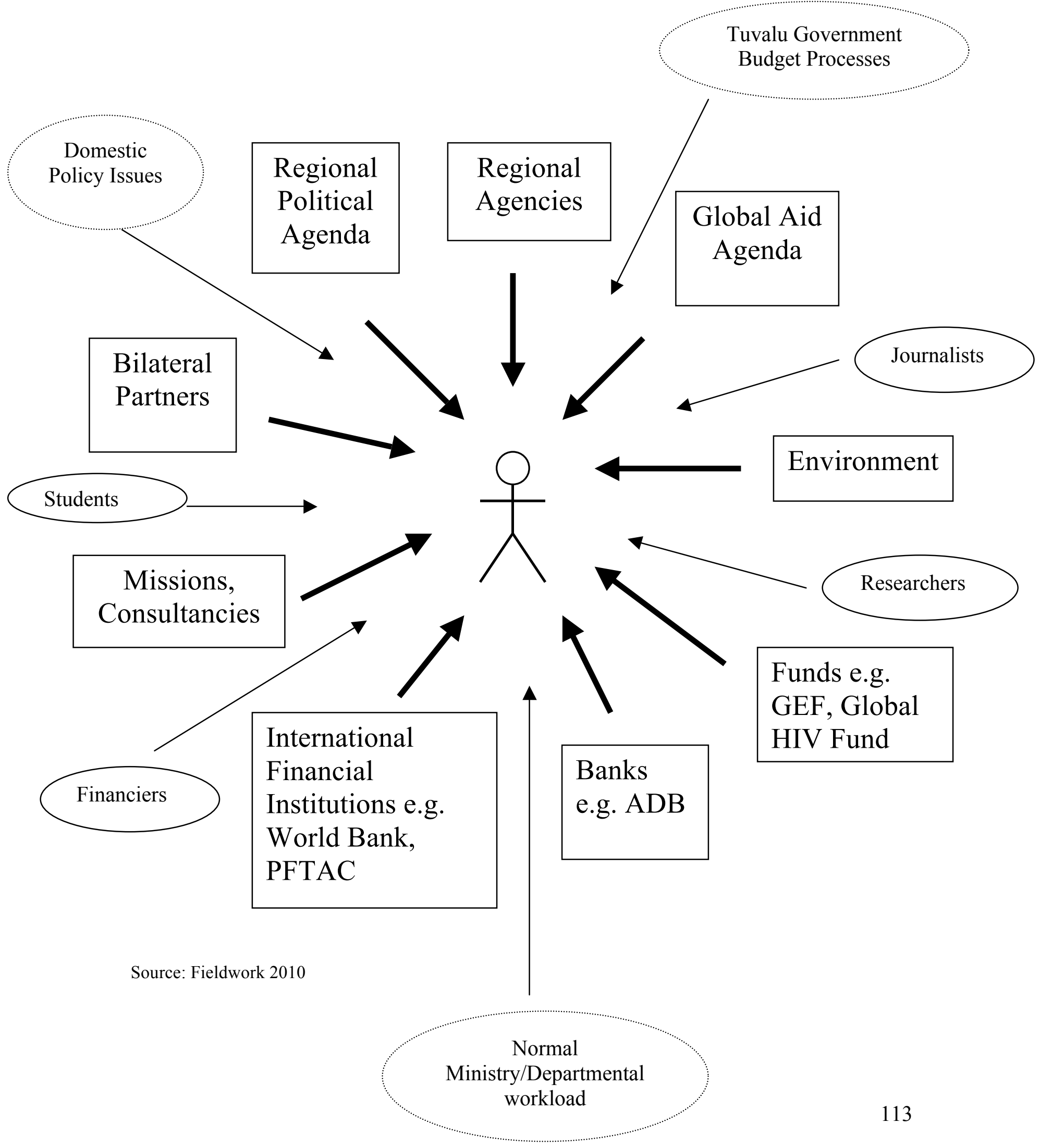


Gordon Shroff (2002) in his paper presented to the New Zealand Institute of International Affairs graphically illustrated the large number of players now involved in development and diplomacy in the Pacific. He described how most PICS have broadened their bilateral relationships beyond their former colonial links (of New Zealand, Britain, Australia, France and Germany) and now have substantial dealings with Japan, China, Korea, Taiwan plus smaller players like Canada, Indonesia etc. Alongside this broadening of bilateral ties, PICS have sought to engage more actively with multilateral agencies like the UN, ADB, and the Commonwealth, as well as an expanded relationship with the EU. The UN connection alone spills into separate relationships with a 'veritable alphabet soup' of agencies, many of which now have offices throughout the Pacific. (ibid:41-42). Tuvalu itself belongs to 'some $30 \mathrm{UN}$ and international agencies and multilateral banks' (Hughes and Gosarevski, 2004:17).

Table 6 in Chapter Three shows the relative amounts of money coming into Tuvalu annually from each donor/agency. A far greater annual amount of money is received from bilateral donors than from the multilateral agencies. However from my discussions with officials it is clear that the relationship between quantum of money received, and the amount of time officials need to spend dealing with agencies and consultants relating to that money, is inversely proportional.

The agencies who provide small amounts of assistance (such as UNDP) are regularly mentioned as being those who take the most time on the part of officials. These same agencies, while providing less are also those who give the least notice of impending 
visits. This must be an issue for such agencies. It cannot be in their interest to be seen as more trouble than they are worth in terms of time spent for fiscal returns gained.

In my own experience many missions have a broad-brush approach to planning meetings. They seek to visit and talk to everyone so that they can say all relevant officials have been consulted. I have been part of missions with this approach myself. In truth however, much information is widely available in reports and on the websites of donors and other development agencies. A more judicious use of this sort of analytic information could lead to missions placing far less stress on partner officials

Respondent C commented that 'Many consultants are not prepared' and mentioned examples of consultants who just asked open ended general questions. 'It felt like they didn't know basic information and just wanted me to provide it'. This indicates a level of frustration with this broad brush approach to meetings.

Tuvalu officials are remarkably open and available. The literature on size in Chapter Two made a strong link between smallness and openness, (Hau'ofa, 1995; Thaman, 1995; Baldacchino, 2006) maybe this is because visiting officials form part of what Baldacchino (2006:46) refers to as the 'hinterland' of such a small country. The ease of access to officials is one reason why they are so busy seeing people who call in. It is possible to knock on the door of the Secretary to Government, ask if he is free for a few moments and then take up his time on matters of note to you. I doubt that any senior official in any of the donor countries is able to be accessed quite so simply. This access 
is also granted to journalists, students and scientists who come in to visit Tuvalu. When asked, in informal discussions, why officials were so open and available to all people who visited, Respondent A summarised the issue when they said 'we have to be available, because any chance is a good one to let people know about Tuvalu and our needs'.

Respondent E's summary of the issues for them ('with many visitors seeking my view I am often left with little time to do management tasks. I am not always able to be as involved as I would like to be with either my own work or with the donors because I am too busy') highlights for me an interesting tension. I have heard donor colleagues complain about how impossible it is to get Tuvalu officials to actually do any follow up to anything once the donor colleague leaves. This is an interesting comment given these same colleagues, departing Tuvalu after a full schedule of meetings squashed into the $1 \frac{1}{2}$ day window between flights, fail to see the impact of the next plane arriving, then the next plane arriving, then the next plane arriving and the resulting weekly cramped meeting schedules unfolding for the same officials who they complain 'don't do anything'.

Tuvalu officials feel that the chance to participate is something donors give to Tuvalu, and comes with the implicit assumption that if you do not participate in this event/process/mission/meeting you will lose your chance to have your say. However, this surely is unethical and does not acknowledge the fact that people do already participate in the most real sense possible by dint of living in Tuvalu and being part of everything that 
happens there. As Scott-Villiers (2004) asserts control of the participation process is not possible, what is possible is to engage with it the process.

The added difficulty of turning 'participation' from an esoteric theory (theory for an initiated few) into exoteric theory (theory for the masses) or turning the rhetoric of participation into practice is an area that will be revisited later in this Chapter.

I have been part of conversations over my career in Tuvalu where consultants and donor officials have been dismissive of the material they do get when they visit officials, comments are along the lines that 'the message they receive in Tuvalu is always the same, the officials say the same thing, ask for the same thing and are not strategic in their thinking'. As people tend to value more what they have to work harder to get, I wonder if the officials in Tuvalu were far less accommodating and available for all who arrived, sought clarity on who was coming when and why, the information gathered would be treated in a far more serious manner.

When we refer to the extensive list of development related visitors entering Tuvalu over each of the field visit periods in October 2009 and April 2010 we can see them as perfect examples of what Respondent A called the "fragmented structure of aid on the part of the donors and agencies'. We can reflect this against Bowman and Chand (2008:161) as they refer to as the 'excessive representation plague' faced by small nations. But we can also reflect this against the risk Little and Clifford (2006) predicted in the 1960s when they 
foresaw all donors wanting individual relationships with developing countries and input into their planning and policies.

For example, there were two separate missions related to meteorology in October 2009. One of these missions was funded by a bilateral donor and the other by an international meteorology organisation. There were two separate missions related to health policy in April 2010, one mission funded by a multilateral agency, and the other by a regional agency. One can only assume that in both these cases these missions had agendas that overlapped to some degree. Given the small number of relevant policy staff in both Tuvalu government departments it is likely the same people were consulted and required to commit to spend time with each mission. It is not difficult to see the profound impact on small departments of development agencies not working together.

With the exception of two missions from regional programmes (PRIF and PSIP) no other missions represented more than one donor. This is surprising as donors and the other development agencies have committed to the harmonisation principle of the Paris Declaration. Little and Clifford (2006) identified the risk, back in the 1960s, that the desire by donors for separate representation would cause problems for recipient countries. All respondents in this research would agree that greater harmonisation is necessary. That this is not happening even in such an obvious place as Tuvalu calls into question the donor commitment to a harmonisation agenda and could be because donors want to hold on to their separate engagement as Little and Clifford predicted. Even in the absence of similar Tuvalu data for other time periods, by way of comparison, it is more than likely 
that this dominance of single donor/agency mission is the norm as it has been for decades.

The high degree of subject overlap and duplication alongside the prominence of single donor/agency representation found in missions entering Tuvalu is more than likely replicated across the Pacific and, indeed, in all SIDS. Tuvalu officials were clear that they needed to be more proactive in their aid discussions. Respondent $\mathrm{C}$ suggested 'If we work to develop more sector (and across government) policies we can sell these to the donors for them to pitch in when they can, "we need to sell it like a package-eg tax AND trade not as separate components'. This would be helpful, no doubt, but in an environment of power inequality it is doubtful that such processes from within Tuvalu would influence donors at all.

It seems some Tuvalu officials, especially in Ministries of Environment, Finance and Foreign Affairs, spend a large amount of time overseas attending regional or international meetings. It would not be surprising if this was the case, given the membership of Tuvalu in the 'alphabet soup' of agencies mentioned eaerlier in this chapter. Opinions expressed by officials in the chapter 5 identified both positive and negative impacts from this level of overseas representation and travel. On the plus side, respondents recognise attendance at such meeting is a chance to get exposure for their staff and an opportunity to get their message on the international stage, and on the minus side, attendance at international meetings also leads to increased time away from their office, and a huge 
increase in the workload generated and the stress on trying to complete other work on their return.

Tuvalu has been particularly successful at 'reaching the apex of their jurisdictional powers' (Baldacchino 2006:50) or getting their message onto the international stage in recent years. Respondent G's recognition that 'People are more interested in Tuvalu then they were - especially because of climate change' is proven in the disproportionate amount of coverage Tuvalu's position receives compared to the coverage achieved by other nations who are significantly bigger at the Cimate Change meeting in Copenhagen in December 2009 and on other environmental matters receives (BBC 2009, RNZ 2009, Oneworld 2009, Democratic Underground 2009, Sydney Morning Herald 2009). Baldacchino (2006: 50) refers to this as a 'shrewd survival strategy' and acknowledges that it constitutes a 'skill reportoire that the small and powerless deploy, and being small often get away with'.

Back in 2002, Shroff gave an example of the impact of the attendance by Tuvalu's two person Attorney General's office at one international fisheries negotiation meeting who were required to spend two weeks or more, depending on plane schedules out of Tuvalu.

'Quite apart from the difficulties of covering concurrent formal and informal discussions across the range of technical issues at the meeting with the help of one fisheries colleague, you know that at home your in-tray is accumulating pressing demands for legal advice on UN Security Council binding resolutions on 
combating terrorism, trade access agreements, regulations to prevent money laundering, various bilateral agreements on civil aviation and a slew of domestic legislation' (Shroff 2002:47).

My story at the start of this thesis, also supports the likelihood of this degree of tension being replicated throughout the civil service for every overseas meeting attended by an official.

Development agency colleagues on the one hand decry the fact that people are overseas all the time yet on the other push officials to attend such meetings so they can participate in the presentation of their views and have their voices heard. Respondent B's cry that they seemed to be 'permanently juggling my priorities so that I can fit in the number of meetings I have to attend, alongside other work I have to do' is one that donors and development agencies need to take account of so their level of engagement with small island nations like Tuvalu is more of a blessing than a burden.

\subsection{Who Holds the Power in the Development Relationsip?}

Partnership in a development sense usually refers to the relationship between the funder and the receiver. It is implicit in the literature from development agencies that they see this relationship as one of equality, and of 'mutual dependence' Shutt (2006:154). Respondent F's comment that 'Missions often want a lot of meetings because of pressing issues for them and they want to move things along' is indicative of a range of comments that indicate officials believe the agenda is firmly led by the donors, especially in so far 
as it is their missions, their funded consultancies, their structure for design, planning and implementation that drive the implementation of the development partnership in Tuvalu.

It is when we look at the relationship between funder and receiver in terms of power that the discussion achieves further significance. Larmour (2002), for example, identifies three dimensions of power in relationships. The first dimension of power is the ability of one side to get the other side to do something it might not otherwise do. A second dimension of power is the ability to control the agenda: to decide what is important and should be talked about and what is unimportant and should not be talked about. Finally the third dimension of power is the use of power as ideology or the ability to control thoughts and desires. Those subject to the third dimension do not necessarily know they are being subjected to it, whereas victims of the second dimension know their item is not on the agenda but are not able to do much about it (Larmour 2002:251, see also Lukes 1974).

Development agencies must ask themselves whether the way they behave in country is demonstrating one of the above dimensions of power. I would argue, in the examples cited in Chapter Five where respondents talked of the impact for them on the lack of notice given by both UNDP and AusAID on separate bits of work, that both agencies were demonstrating the second dimension of power. In both cases development partners provided material in nearly final form with a tight timing deadline, thereby not allowing Tuvalu the chance for reasonable analysis and input before the workshop occurred, (in the case of UNDP) or the document had to be signed, (in the case of AusAID). 
The party with the money controls, to a greater or lesser degree, the decisions made about how that money will be spent this is also the case in the development relationship. Funders and receivers must ask how can the partnership be equal when both partners do not share mutual accountability for the results of the interventions funded by one of them? A donors' primary responsibility is not to the poor people in the country they are funding for the development outcomes of the funding rather it is to the tax payer in their country for the use of taxpayer funds. This makes it inherently difficult for donors to meet the Paris Principle of Mutual Accountability.

Easterley (2006) ties the near invisibility of results by aid agencies to the lack of feedback and accountability of their efforts he goes on to say that you only know if something has worked if people at the bottom can give feedback. There is a challenge here for donors to deal with this issue of accountability and power as part of their commitment to the Mutual Accountability principle in the Paris Declaration. Respondent A got to the core of the issues of power when they asked donors to ask themselves the question 'who are you working for? The good of Tuvalu or to meet your own systems?

Lewis and Sobhan (2000:202) titled their chapter about the funding modalities for northern and southern NGOs 'Routes of funding, roots of trust?' While their focus is on the different degrees of trust felt by NGOS with their development partners, and how this is dependant to some degree on the way their funds are received. The link between funds and trust has relevance for development agencies in their relationship with partner 
governments as well. Donors need to consider the power inequalities that exist between funder and receiver as this is hugely influential in the development of the roots of trust between them and their recipient country government 'partner'.

Tuvalu's national planning document Te Kakeega II is referred to as the base document in all of the strategic agreements signed by donors in Tuvalu (see for example Government of Australia, 2009; NZAID, 2010a; ADB 2010). On the surface this shows that development partners are being led by the priorities identified by Tuvalu, and are committed to the alignment principle of the Paris Declaration. However as Respondent C commented, the underpinning truth really on the part of these donors is that 'you (Tuvalu) can decide but we will only fund what fits in with our agenda'. This truth is not explicit, rather it is a hidden reality of the aid partnership and serves to illustrate that the power relationship is not an equal one. Donors want recipients to want what donors want. Development is characterised by these relationships of 'tutelage and trusteeship', (Larmour, 2002:258). Cooke and Kothari's (2001:4) argument that participatory development itself is tyrannical in that it facilitates the 'illegitimate and/or unjust use of power' is one that rings true in Tuvalu. While Cooke and Kothari (2001) identify three tyrannies, the one that is most relevant in the Tuvalu setting is how current aid structures promote the tyranny of decision making and control and this links in tightly to Larmour's second dimension of power talked about earlier in this chapter.

On this subject Eyben and Ladbury (1995) talk of the tension that exists in so called equal partnerships when one partner is working to build up the other. At the root of this tension 
is a difference in Power between the two partners. Thaman (1995):44-45) claims that relationships with donors are not at all equal but rather are relationships of 'dominance and subordination' (ibid:44) which force the Pacific further into dependency and confine Pacific Islanders themselves to 'mental reservations' (ibid:45) as they are driven from a state of optimism to a state of despair. The messages of frustration from the Tuvalu officials as they try to manage their own business in a professional manner in the midst of the relentless onslaught of donor demands to participate might lead them to head towards that state of despair.

The findings outlined in the previous chapter remind us of Easterley's (2006) observations (described in Chapter Two) that there are two sorts of people in the development business - the planner who announces good intentions but is not motivated to carry them out, who works at the top levels focussing on making plans, and raises expectations but takes no responsibility for meeting them and - the searcher who finds out what those at the bottom need then find ways of delivering them. Alternatively Porter and Onyach-Olaa (2000:119) describe 'the fox (darting around, seizing opportunities and looping back) and the tortoise (plodding along a straight path)'. The approach of the tortoise and the planner are more akin to the classic linear project cycle mode of development delivery. The project cycle approach is predicated on there being a straight path through a range of necessary planning stages (pre feasibility, feasibility, scoping, design) before anything can actually happen on the ground (see FAO, 2001; Europe Aid, 2004). 
Much aid activity seen by Tuvalu (and demonstrated in the long lists of development visitors in October 2009 and April 2010) consists of consultancies/missions that are more attuned to a planner/tortoise mentality as opposed to a searcher/fox mentality. The majority of the missions that came in during the research period collected information and planned or designed interventions, conducted training, or developed policy. The predominance of such work is an indication of the importance of the planning agenda for development agencies. This, in turn, supports Larmour's (2002:152) assertion that 'power in the development business is often linked to professional knowledge and expertise, and is expressed in sets of data, reports and publications'.

Planning activities are not value neutral and serve to reinforce the power of the planner rather than the power of the doer. Respondent B encapsulated the current focus on the planner rather than the doer when they suggested that if projects were orientated to spend more of their funds 'on the ground rather than on consultants visits and report writing', the impact on Tuvalu officials would be 'extremely positive'. More importantly such a change would lead to an increased amount of money actually benefiting Tuvalu rather than the 'consultants' pockets' and a shift away from the power of the planner. The emergence of a tone of response that indicates what could and should happen to improve practice provides a normative dimension and introduction for the next point of discussion.

\subsection{Improving Practice}

The Paris Principles and the Pacific Principles of Aid Effectiveness arose from the 
identification of weaknesses in development agency and partner country practice. Both sets of principles aspire to change practice for the better. Notwithstanding the international commitments donors have made to improve aid delivery practices on their part, the reality of Tuvalu respondents argues donors have made little progress towards meeting these commitments. At the heart of this failure, there lies a lack of accountability on the part of the donor for either the amount of aid they commit or the quality of aid. The International Aid for Tuvalu Statistical Summary (GOT, 2009:10) claims donors continue to

- make excessive demands on Tuvalu for 'upward' accountability,

- seek the application of financial benchmarks

- restrict the ability of the country to design its programmes to its own path.

The reality of donor engagement for the Tuvalu respondents takes the form of more work to support an increased number of meetings, missions, and projects.

Respondents had no trouble identifying aspects of internal structure and practise they could change and strengthen to improve the aid management within their country. But such administrative improvement will mean little if donors do not improve their practise as well (Little and Clifford, 2006). Respondents had even less trouble identifying changes in donor practise that could be made to make it easier for Tuvalu to work with them. We will look at each of these in turn. 


\subsection{Internal Practice}

A common theme emerging from discussion with respondents in this section of the interview was the need for Tuvalu to take more control in the aid relationship by changing its own practices relating to donors. As Reinhardt recognised, being a party in a funding relationship can 'force the recipient' to improve internal operations in order to improve the perceptions donors have of the efficiency and effectiveness of the recipient. Reinhardt argued, and Tuvalu officials are well astute enough to accept, those recipients who produce the best signals are considered the better implementers and therefore attract more funding (Reinhardt, 2006:301).

In order to produce better signals, and deal with what one respondent has called the 'fragmented structure of donor aid', Respondent A argued: 'Tuvalu needs to develop a more holistic system to allow a more coordinated approach'. As part of this coordinated system, many respondents talked at some length about the ways donors are represented inside Tuvalu. Models of representation that were considered to be more advantageous to Tuvalu were those where the in-country representative:

- had authority to make a greater range of decisions without having to refer to their capital or head office; and

- was placed within government rather than outside in order to have a greater degree of engagement with relevant staff

These features are part of the model of representation employed by the EU and JICA and were considered superior to those employed by New Zealand, Australia or the United Nations. 
The situation foreseen by Little and Clifford in the mid 1960s is now reality in Tuvalu, with all donors wanting their own representation in country thereby enhancing the pressure on recipient governments. Little and Clifford's suggestion that a single multilateral but donor-controlled office in each country might be the best way to manage aid in a multi donor setting is echoed in the stated desire of Tuvalu officials for a single 'aid office' within government. This office would house the Tuvalu Government Aid Coordination staff as well as all donor in-country representatives. There were various suggestions as to where it could be housed, whether within the Ministry of Finance either alongside Planning and Budget Division or alongside Treasury or in Ministry of Foreign Affairs, but most agreed on the need for a more coordinated approach for in-country representatives was evident.

Tuvalu government officials prepared and presented Tuvalu Aid Management and Coordination Case Study, for the Pacific Regional Workshop on Aid Effectiveness (GOT, 2008) in April 2008. This case study identified many options for strengthening internal practise relating to aid management within Tuvalu. Most of these were raised again in one form or another in the interviews and are included in Table 11.

These suggestions indicate a comprehensive understanding of the limitations of Tuvalu's current aid management architecture and clarity of thought as to what is needed in order to achieve a positive change. The question is begged however whether officials have the 
time needed with the required government willingness to undertake such whole of government change.

Table 11 Strengthening Tuvalu Government Aid Management

\begin{tabular}{|c|c|}
\hline $\begin{array}{l}\text { Where } \\
\text { suggestion came } \\
\text { from }\end{array}$ & Suggestion for Improvement \\
\hline Tuv 2008 & $\begin{array}{l}\text { Instigate a regular meeting process for aid agency representatives } \\
\text { based in-country, in order to get an update on expenditure } \\
\text { patterns, raise issues re implementation and to coordinate other } \\
\text { planning. }\end{array}$ \\
\hline Tuv 2008 & Develop a strengthened aid management database \\
\hline $\begin{array}{l}\text { Tuv 2008, } \\
\text { Respondent C }\end{array}$ & $\begin{array}{l}\text { Develop more sector policies linked to Te Kakeega and promote } \\
\text { these to the donors for them to 'pitch in when they can' }\end{array}$ \\
\hline Respondent $\mathrm{C}$ & $\begin{array}{l}\text { Take more control on selling our need for assistance 'like a } \\
\text { package - eg tax AND trade not separate' }\end{array}$ \\
\hline Responder & $\begin{array}{l}\text { Use the mid term review process of Kakeega to identify changes } \\
\text { and or improvements }\end{array}$ \\
\hline $\begin{array}{l}\text { Tuv 2008, } \\
\text { Respondents H, } \\
\text { D, A }\end{array}$ & Make more use of donor round table \\
\hline Respondent B & $\begin{array}{l}\text { Undertake a comprehensive review of govt to ask 'what is } \\
\text { happening now, what can be done better' }\end{array}$ \\
\hline Respondent D & $\begin{array}{l}\text { Enhance internal reporting structure so all line ministries report } \\
\text { back to the Planning and budget division to improve internal } \\
\text { coordination. }\end{array}$ \\
\hline Respondent G & Organise all donor visits on an annual basis set in advance \\
\hline
\end{tabular}




\subsection{Donor Practice}

An example of conflict between in-country and donor practices is illustrated by the following situation. Rather than leaving the Government of Tuvalu to progress on making the improvements they had already identified in planning documents (GOT, 2008), the UNDP (funded by AusAID) have placed a UN Volunteer as Aid Management and Coordination Specialist within the Planning and Budget Division on a 12 month assignment. It is cited in the documents supporting this placement that it was agreed by Tuvalu, (UNDP 2009) however Tuvalu proposed two things relating to the attachment, neither of which had any bearing on the final placement, they proposed the assignment be six months long and that it commence at such a time that best fitted with the government budget cycle (Anonymous Pers com 2009). The Aid Management and Coordination Specialist, recently deployed, will have four primary functions: 'Review of the Aid Management \& Coordination Architecture within the Government of Tuvalu Framework' $(25 \%)$ before they start the body of their work which is to 'Identify, develop and implement an appropriate aid management database' (35\%) and move onto to 'Capacity development in Aid Management' (30\%), they will spend the final $10 \%$ of their time to Strengthen UN Joint Presence and build capacity of the Country Development Manager' (UNDP 2009:1).

Placing a long term technical assistant in country can be seen by recipient countries as a way for donors to enhance effective partner government so that things get done to the timetable of the donor rather than taking into account the reality of the recipient. Such a focus on results draws on an economically deterministic approach to politics and the aid 
relationship. Such an approach supports the idea of donor power over recipient and flies in the face of donors' stated desire for equal partnerships in which recipients participate equally in decisions relating to their own development.

In Tuvalu technical assistance (TA) is defined as 'technical services that donors provide to Tuvalu as opposed to any donation in the form of money' (GOT 2009:12). The sheer number of TAs at any one time in the Pacific is astounding. With the definition of TA used by the government of Tuvalu, the majority of the list of development related visitors coming into Tuvalu during the two rapid appraisals were TA, in one form or another.

Tuvalu officials have noticed an increased number of Advisers being placed on a long term basis to provide support to government departments. In recent years AusAID has funded three Advisors under its PACTAM programme: Budget Management Advisor, an Advisor to the Attorney General, and an Advisor to the Auditor General. The visit of the PACTAM Coordinator in October 2009 identified a further eight positions for consideration.

Such an inflow of technical assistance is in an environment where donors have signed the Pacific Principals of Aid Effectiveness, one of which relates specifically to minimising the impact for recipient countries of the large number of TAs reminds us of the discussion in Chapter Two on the asymmetrical power relationship between donors and recipients (Crush, 1995; Cooke and Kothari, 2001; Chambers and Pethit, 2004; Robb, 2004; Sobhan, 2004). A relationship recognised by the Pacific themselves when, at the 
Development Partners meeting in Funafuti in 2005, convened by the PIFS, mention was made of the need for Forum Island Countries and donors 'to determine whether there are other, lower cost and more appropriate alternatives to the use of technical advisers in their aid programs' and called for 'policies that encourage donors to reduce the reliance on technical advisers and offer more appropriate alternatives' to be developed (PIFS 2005:4).

Jayaraman and Ward (2006) relate a cautionary tale about technical assistance in a Vanuatu setting. They recount how, in 1997, the ADB approved a loan of US\$20 million for comprehensive governance reforms, relating to improving budgetary procedures and methods and involved the preparation of supporting manuals. The ADB was joined by Australia, which contributed technical assistance in terms of expatriate skills. At one time there were about 42 international consultants in Port Vila preparing manuals for various ministries and agencies. Yet once they left, there were "few lasting results" (Gay, 2004:30 referred to in Jayaraman and Ward 2006:5). This is unfortunate as the Vanuatu government is still paying off the loan, the major part of which was used for payment of expatriate salaries during their stay in the country (Jayaraman and Ward 2006:9). The legacy of poor planning is one that recipient countries often have to bear to a far greater extent than does the instigator of that poor planning.

Australia provides $54 \%$ of the TA into Tuvalu, NZ 21\% and the ADB 15\%. Therefore it is these agencies who need to work the hardest to ensure that they do all they can to maximise the positive effects and minimise the negative effects of any TA they fund. 
The onus is on donors as the more powerful player in the aid partnership to make real efforts to improve their practice in terms of coordination and harmonisation. Once again, Tuvalu officials are not witnessing any evidence of improvement in this area,

\subsection{Conclusion}

This chapter has sought to integrate the observations of the Tuvalu case with the theoretical discussions of Chapter Two. On the one hand theory must be embedded in a geographical and cultural context in order to achieve real significance. But on the other hand, and equally important, the case study findings, achieve added significance when set against a theoretical backdrop.

This chapter has examined the impact of developing agency commitment to participation on the officials in Tuvalu.

It is in this examination of impact that the Tuvalu case study adds to contemporary understanding and further challenges the ideas that lie behind policy and practice of development agencies. Rather than confining the discussion to the relationship between theory and reality this chapter has included the perspectives of those involved on how the relationships could be improved.

This analysis chapter has focused its discussion on three areas: that of participation, power and practice. The examination of participation identified the extensive number of 
development related visitors who arrive into Tuvalu and the impact of this level of traffic on Tuvalu officials. These officials are clear that there is an inverse relationship between the amount of support given by donors and the amount of time servicing the relationship takes. The smallness of Tuvalu seems to work against them as the openness and availability they have to donors and development visitors undermine their ability to service those visitors and to complete their own work. The ability, of development agencies to move from the rhetoric to the reality of participation is made more complex given the asymmetrical power relationships that exist between them and their recipient government partners.

It is obvious from the examples in this chapter, that these inequitable power relationships are manifested in Tuvalu. There are many examples of donors, consultants and other development visitors seeking agreement and involvement without giving enough time for input, or having done enough preparation themselves. Many of these tensions stem from the situation of one partner trying to build up the other when they are not equal. The emphasis on planning at the expense of action is further evidence that the development agenda is driven by the needs of the donor at the expense of the recipient.

Finally by giving voice to the myriad of suggestions Tuvalu officials, through publications or interviews, have made for improvement of both their own practice and that of donors, the chapter has highlighted ways that development practise on the part of both donor and recipient can be improved to enhance development effectiveness. 
There is a certain irony in the fact that a study that focuses on the needs and pressures facing Tuvalu ultimately gravitates towards adjusting the relevance of donor agencies and processes. This is, of itself, a reflection of the inherent structural misalignment not only of the development relationship in question, but the idea of development itself.

The next chapter concludes the thesis by drawing on the integration of theory and reality presented here. 


\section{Chapter Seven - Who Are You Working For?}

The story in the opening to Chapter One in this thesis illustrated the pressures government officials in small island nations are under to participate in fora that others feel are important for them. Such pressures arise from agencies adopting a participate or perish approach to development. This thesis has provided some background to this situation and illustrated the issues facing not just this official, but officials across all of the Tuvalu Government.

Throughout this thesis we looked at the processes of institutionalised participation and argued that the process of institutionalising participation may indeed be counter productive to the overall objectives of development. This thesis has sought to shed some light on the reality for such recipient government officials and to contribute to the emerging critique of the participation paradigm.

The emergence of the paradigm of the people (Chambers, 1995; Chamber, 1997) sought to invert the power relations of the modernist development approach by implementing a people centred agenda where development was a bottom up process rather than a top down imposition (Chambers, 1983; Friere, 1970). The relevance of the participation paradigm can be seen in its wholesale adoption by bilateral, regional and multilateral development institutions as together they ensured participation has become the catch cry of modern development practice. However even with three decades of entrenchment of participatory approaches, the reality for recipients in small island nations such as Tuvalu is little different to what it was prior to the emergence of the new approach. The power 
relations remain asymmetrical, the development agenda is driven from the outside, either at global, regional, national or institutional level, and ultimately development practice is rendered impotent as a result. Development that began as a process of reinvention has in fact become a simulacrum of the same shortcomings it sought to address but it wears a different mask.

Tuvalu, a small island nation of less than 26 square kilometres of land set in 757,000 square kilometres of ocean can be called the ultimate recipient. Tuvalu is a MIRAB economy with access to remittance income as well as aid. Grant aid is an important part of the Tuvalu economy and aid inflow sits consistently above $30 \%$ of GDP. This reliance on outside factors, especially aid, for its survival adds to its vulnerability for, as Warrington (1998) argues in spite of their judicial sovereignty, small sized states are particularly vulnerable to international pressure. Tuvalu is not just physically remote but it also culturally distant from those who offer assistance.

It is for these reasons that Tuvalu is such a valuable case study. As Yin reminds us the value of case studies lies in their ability to inform the development of the theoretical context. Yin (1989:39-40) also refers to the importance of using case study research to make policy related inferences. This was an important methodological consideration when setting up a case study approach as it was important that the research be useful in a policy sense for both Tuvalu and development agencies working in Tuvalu. 
In undertaking research in the Pacific it is important to take account of Smith's (1999:136) assertion that 'consent is not so much given for a project or specific set of questions but for a person for their credibility'. My multiple roles in Tuvalu over nearly a decade have afforded me access and given me that local credibility. I have continually returned to Tuvalu over a long period. This has given me a relational advantage which fits well with the talanoa tradition as the distance between researcher and researched is removed and participants work alongside a human face they can relate to. The value of the interpersonal relationship that is the crux of the development delivery process is precisely the same place in which my methodology is situated.

The findings chapter raises a range of issues, the following ones stand out to be at the heart of the matter.

Tuvalu is the recipient of a large number of development related visitors huge in proportion to its population. Approximately 900 people, nearly $10 \%$ of the population of Tuvalu, arrive annually into Funafuti in order to allow Tuvalu to participate in its own development. it is worth repeating the point made in Chapter five that placing this number of visitors in a setting we are more familiar with, this would equate to over 400,000 development visitors descending on Wellington each year or 2 million such visitors arriving into Canberra. How long would these developed country administrations be willing to sustain that sort of pressure? Each development visitor to Tuvalu has virtually unlimited access to Ministers, Permanent Secretaries and the upper echelons of government, often without the respect of advance notice or appointments. It is unlikely 
that any of these officials or consultants has the same amount of access in their own home administrations.

We saw in the long list of arrivals in October 2009 and April 2010 only two missions representative of more than one donor. Several missions directly overlapped and many more that indirectly overlapped. Yet many of the donors and agencies funding these missions have committed to the Paris and Pacific Principles of Aid Effectiveness with their focus on coordination and harmonisation. The Tuvaluan officials who so readily and openly articulated their own reality in this research have seen little evidence of any improvement in practise as a result of these international commitments. This is completely unacceptable. More controversially, is the fact that this activity continues unquestioned by international donor agencies as being in Tuvalu's own best interest and consistent with the doctrines of 'good development practice'.

Much aid activity seen by Tuvalu consists of consultancies and missions that are more attuned to what Easterley (2006) refers to as a planner mentality as opposed to a searcher mentality. This, focus on 'planning' rather than 'doing', supports Larmour's (2002:152) assertion that 'power in the development business is often linked to professional knowledge and expertise, and is expressed in sets of data, reports and publications'. Planning activities reinforce the power of the planner rather than the power of the doer and are not value neutral. Respondent B encapsulated the current focus on the planner when they suggested that if projects were orientated to spend more of their funds 'on the 
ground rather than on consultants visits and report writing' this would be beneficial to Tuvalu but also lead to a shift away from the power of the planner.

Key findings from the interviews with Tuvaluan officials challenged current donor practice in a range of ways. Respondents claimed that many missions were 'unprepared', and took a broad brush approach to the meetings, seeking answers to questions they 'could have found out for themselves' in order to tick people off as having been consulted. Respondents gave examples of the 'lack of time they are given' to feel fully prepared, the sense of being 'taken by surprise' they felt with the arrival of some missions. Respondents expressed frustration at in-country aid management structures that did not facilitate decision making due to the lack of autonomy of the in country staff member. Comments from several respondents suggest that the relationship between monetary inflow and time taken to service the relationship is an inverse one, with the development partners who provide the least taking the most time.

Throughout the responses the stress of meetings was apparent. Officials had to deal with meetings, the requirements to prepare for and follow up from each one in the face of a full inbox of domestic work and the arrival of yet another plane full of development visitors needing attention. Yet these officials are complained about by donors who say it is impossible to get Tuvalu officials to actually do any follow up to anything once the donor colleague leaves. 
The interviews with officials all seem to culminate in the question asked by Respondent A to development agencies 'who are you working for? The good of Tuvalu or to meet your own systems?' Respondent A is asking here who drives the agenda in donor and partner country relationships? Throughout the whole thesis it has become clear that it is the agencies who are setting the agenda to meet their own needs.

Given the above the frustration evident in the responses of some of the Tuvalu officials is not at all surprising.

The issues raised in this thesis are not new. Little and Clifford identified many of the situations Tuvaluan officials face today over 45 years ago. The Pacific as a region was highlighting the same issues of lack of coordination from the inception communique of the PIFS in 1974. The fact that such a core platform of aid theory and practice, that was adopted in order to generate a more empathetic and responsive partnership approach to aid generates the very same set of issues and problems it was set up to address is a tragedy.

Donors need to identify clearly and openly their primary responsibility for the delivery of their aid assistance. Is it to the people in the country they are funding for the development outcomes of the funding? Or is it to the taxpayer in their own country for the use of taxpayer funds? If it is the former, then development agencies have some work to do to improve their performance. Development is about relationships and at present in the Tuvalu setting there is some stress in the levels of trust arising from these 
relationships. If it is the latter then donors need to be explicit about this and not disguise their behaviour behind the rhetoric of participation.

Clearly the interests of donor agencies cover both of the responsibilities covered above. Aid agencies have their own agendas relating to expenditure levels and appropriations, policy platforms and sectoral focus. Agencies are competitive and often want attribution of their own effort while also wanting positive development outcomes. In reality it is this contradiction that is at the centre of the problems raised in this thesis.

Development agencies need to recognise the effect that this contradiction is having on their practise. They need to address the ethics of this contradiction, in order to deliver aid effectively against the intentions of the commitments they have signed and taking into account the realities they face.

These last points expose the pressing urgency to push this research agenda further. There are several areas of research that would be particularly useful. Firstly, research using the same or similar methodological approaches in other small developing nations to confirm that Tuvalu is not an isolated case and to strengthen the body of data and supporting literature on the tyranny of participation in these environments. Secondly research across other nations in the Pacific to develop a regional understanding which is able to accommodate diversities of scale, culture, and political and economic contexts. Finally research is needed into the systems, processes and cultures of development bureaucracies 
and the extent to which the inherent inertia of such organisations will nullify any attempts to make significant changes in practice.

The situation outlined in this thesis graphically illustrates the very real tyranny of participation in Tuvalu. The failure of development agencies to cooperate and harmonise their activities and to adhere to the commitments they have made to the Paris Principles of Aid Effectiveness is a clear contradiction of their policy objectives. Not only are these agencies ignoring their international obligations but they are systematically undermining the ability of Tuvalu to effectively govern itself.

As Naidu (1995) reminds us, it is in the interests of development agencies to fashion Pacific Island dependency. Given the inadequacies in power, participation and practice in development covered in this thesis, what remains to be seen, is whether or not such agencies, who are on the winning end of the power relationship, truly wish to instigate change. 


\section{Appendix One}

\section{Power, Participation and Development: A Case Study of The Effect of Theoretical Doctrines and International Development Agency Practice on Tuvalu Government Activity- Interview Schedule}

1) What is your role? How long have you been in the position? What are the key relationships you have within the Tuvalu Government?

2) Who are the key development partners you work with and what are the key relationships you have with them and other development agencies?

3) If we think about the following can you give me the most recent example of the type of consultation, what was required from you in terms of time and input, and the desired results from both your and the agency's perspective?

- Government to Government bilateral missions

- Visits from bilateral partner officials

- Consultancy technical assistance missions

- Regional agency missions

- Multilateral agency missions

- International NGO missions/consultancies

- Meeting attended by you outside the country related to development

- Meetings attended by you within Tuvalu but facilitated by a development agency/partner

- Meetings with researchers or journalists about Tuvalu and development

4) Approximately how many people have come though your office in the last 6 months from development agencies? To what extent is this a typical level of engagement? Has the level of engagement from development agencies changed over time?

5) Does the level of engagement raise any issues at a professional or government management level for you?

6) Give me some examples of the issues you are referring to.

7) What opportunities exist for streamlining development agency interactions with the Tuvalu Government at a personal, departmental, structural or whole of government level? 


\section{Appendix Two}

\section{Participant Information Sheet for research into the effects of development agencies' focus on participation and consultation on Tuvalu Government practise.}

Researcher: Nicki Wrighton: School of Geography, Environment and Earth Sciences, Victoria University of Wellington

I am a Masters student in Development Studies at Victoria University of Wellington. As part of this degree I am undertaking a research project leading to a thesis. The project I am undertaking is examining how the activities of the Tuvalu Government are shaped by relations with the development community's demands for local participation and consultation.

The University requires that ethics approval be obtained for research involving human participants.

I am inviting Tuvalu government officials to participate in this study. Participants will be asked to take part in a semi structured interview. It is envisaged that the interview will take about an hour to complete and will be undertaken at a time that suits you.

Should any participants feel the need to withdraw from the project, they may do so without question at any time before the data are analysed.

Interviews will be taped and transcribed for use as both attributable and non-attributable comments and quotes in the research. No person other than my supervisor Dr John Overton and myself will see the fully transcribed material.

The thesis will be submitted for marking to the School of Geography, Environment and Earth Sciences and deposited in the University Library. It is intended that one or more articles will be submitted for publication in scholarly journals based on findings.

Tapes and transcripts will be destroyed two years after the end of the project.

If you have any questions or would like to receive further information about the project, please contact me at 12 Te Miti Street, Paekakariki, Kapiti Coast NZ, wrighton.doorne@paradise.net.nz

or my supervisor, Dr John Overton, at the School of Geography, Environment and Earth Sciences, at Victoria University, P O Box 600, Wellington, NZ john.overton@vuw.ac.nz.

Nicki Wrighton 


\section{Appendix Three}

VICTORIA UNIVERSITY OF WELLINGTON (on letterhead)

CONSENT TO PARTICIPATION IN RESEARCH

Title of project: Power, Participation and Development: A Case Study of The Effect of Theoretical Doctrines and International Agency Practice on Tuvalu Government Activity

I have been given and have understood an explanation of this research project. I have had an opportunity to ask questions and have them answered to my satisfaction. I understand that I may withdraw myself (or any information I have provided) from this project (before data collection and analysis is complete) without having to give reasons or without penalty of any sort.

I understand that full interview transcripts will be kept confidential to the researcher, the supervisor and the person who transcribes the tape recordings of our interview.

I consent to information or opinions which I have given being attributed to me in any reports on this research.

I understand that the tape recording of interviews will be electronically wiped at the end of the project unless I indicate that I would like them returned to me.

I understand that I will have an opportunity to check the attributable quotes used before publication.

I understand that the data I provide will not be used for any other purpose or released to others without my written consent.

I would like to receive a summary of the results of this research when it is completed.

I agree to take part in this research

signed:

Name of participant (please print clearly)

Date: 


\section{References}

Anonymous, 2008. Personal Communication, Government of Tuvalu Offices, October, 2008.

Apinelu, S., 2010. Personal Communication, Staff Development Officer, Personnel and Training Division, Office of the Prime Minister, Government of Tuvalu.

Armon, J., 2007. Aid Politics and Development: A Donor Perspective, Development Policy Review, 25 (5): 653-656.

Armstrong, H. and Read, R., 2002. The Phantom of Liberty?: Economic Growth and the Vulnerability of Small States in Journal of International Development, 14: 435-458 http://www3.interscience.wiley.com/

Arora-Jonsson, S. and Cornwall, A., 2006. Making Connections: Learning About Participation in a Large Aid Bureaucracy. In R. Eyben (ed.), Relationships for Aid, Earthscan: London, pp. 80-93.

Asian Development Bank, 2010. Asian Development Bank \& Tuvalu Fact Sheet http://www.adb.org/Documents/Fact_Sheets/TUV.pdf

AusAID, 2009. Tracking Development and Governance in the Pacific August 2009, Canberra.

Baaz, M., 2005. The Paternalism of Partnership: A Postcolonial Reading of Identity in Development Aid. Zed Books: London.

Babbie, E., 2004. The Practice of Social Research (10 ${ }^{\text {th }}$ Ed), Thompson/Wadsworth: Belmont CA. 
Baldacchino, G., 2006. Managing the Hinterland Beyond: two Ideal-type Strategies of Economic Development for Small Island Territories in Asia Pacific Viewpoint, 47(1). Victoria University: Wellington.

Bertram, G., 1999. The MIRAB model twelve years on, in The Contemporary Pacific 11(1): 105-138.

Bertram, G. and Watters, R., 1985. The MIRAB economy in South Pacific microstates. Pacific Viewpoint, 26 (3): 497-519.

Bertram, G. and Watters, R., 1986. The MIRAB process: Earlier analysis in context, Pacific Viewpoint, 27(1): 47-59.

BBC 2009 http://news.bbc.co.uk/2/hi/asia-pacific/8158604.stm

Blaikie, N., 2000. Designing Social Research: the Logic of Anticipation Polity Press: Cambridge.

Bowman, C. and Chand, S., 2008.Size Matters: The Impact of Aid on Institutions. Pacific Economic Bulletin, 23(2): 145-165.

Bryant, C. and Wrighton, N., 2008. Fiji and Tuvalu Tracer Study. AusAID: Canberra.

Bryman, A., 2004. Social Research Methods. Oxford University Press: Oxford.

Chambers, R., 1983. Rural Development: Putting the First Last. Longman Press: London

Chambers, R., 1994. Participatory Rural Appraisal (PRA): Analysis of Experience. World Development, 22(9): 1253-1268 
Chambers, R., 1995. Paradigm Shifts and the Practice of Participatory Research and Development in Nelson N and Wright S (eds.) Power and Participatory Development: Theory and Practice. Intermediate Technology Publications London, pp 30 - 42.

Chambers, R., 1997. Whose Reality Counts? Intermediate Technology Publications: London.

Chambers, R., 2002. Participatory Workshops a sourcebook of 21 sets of ideas and activities. Earthscan: London.

Chambers, R. and Petit, J., 2004. Shifting Power to Make a Difference. In R. Groves, and L. Hinton (eds.), Inclusive Aid Changing Power and Relationships in International Development. Earthscan: London, pp. 137-162

Clarke, M., Fry, T. and Mihajilo, S., 2008. The volatility of aid to small island states in Pacific Economic Bulletin, 23(2): 179-195.

Connell, J. and Brown, R., 2005. Remittances in the Pacific: an Overview. ADB: Manilla.

Cooke, B. and Kothari, U., 2001. The Case for Participation as Tyranny. In B. Cooke and U. Kothari (eds.), Participation: the new tyranny. London: Zed Books, pp. 1-15.

Cowan, M. and Shenton, R., 1996. Doctrines of Development. Routledge: London.

Crocombe, R., 2001. The South Pacific. University of the South Pacific: Suva.

Crewe, E. and Harrison, E., 1998. Whose Development? An ethnography of aid. Zed Books: London.

Crush, J. (ed.), 1995. Power of Development. Routledge: London and New York. 
Dale, R., 2004. Development Planning: Concepts and tools for planners, managers, and facilitators. Zed Books: London.

Democratic Underground, 2009.

http://www.democraticunderground.com/discuss/duboard.php?az=view_all\&address $=102$ x4182739

Easterley, W., 2006. The White Man's Burden Why the West's Efforts to Aid the Rest Have Done So Much Ill and So Little Good. Penguin Group: New York.

Easterly, W., (ed.), 2008. Reinventing Foreign Aid. Massachusetts Institute of Technology Press: Massachusetts.

Easterly, W. and Pfutze, T., 2008. Where Does the Money Go? Best and Worst Practices in Foreign Aid. Journal of Economic Perspectives, 22( 2): 1-24.

England, K., 1994. Getting Personal: Reflexivity Positionality and Feminist Research. Professional Geographer, 46 (1): 80-89.

Escobar, A., 1995. Encountering Development: the Making and Unmaking of the Third World. Princeton University Press: Princeton, NJ.

Eyben, R. and Ladbury, S., 1995. Popular participation in aid-assisted projects : why more in theory than practice? In N. Nelson and S. Wright (eds.) Power and Participatory Development Theory and Practice. Intermediate Technology Publications: London, pp. 192-200.

Feeny, S. and Clarke, M., 2008. Achieving the Millenium Developmet Goals in the AsiaPacific Region: the role of international assistance. Asia Pacific Viewpoint, 49(2): 198212. 
Feeny, S. and Rogers, M., 2008. Public Sector Efficiency, Foreign Aid and Small Island Developing States. Journal of International Development, 20: 546-546.

Fraenkel, J., 2006. Beyond MIRAB: Do Aid and Remittances Crowd Out Export growth in Pacific Microeconomies. Asia Pacific Viewpoint, 47(1): 15-30.

Freitag, S., 2006. Vision or Fiction? Prospects of a Regional Integration in the South Pacific. Issue Analysis, 76. Centre For Independent Studies: Sydney.

Friere, P., 1970. Pedagogy of the Oppressed. Seabury Press: New York.

Geertz, C., 1973. The Interpretation of Cultures Selected Essays. Basic Books Inc: New York.

Goldsmith, M., 2005. Theories of governance and Pacific microstates: the cautionary tale of Tuvalu. Asia Pacific Viewpoint, 26(2): 105-114.

Government of Australia, 2009. Partnership for Development between Government of Australia and Government of Tuvalu. Canberra.

Government of Tuvalu, 2005. Te Kakeega II National Strategies for Sustainable Development, 2005-2115. Funafuti.

Government of Tuvalu, 2008. Tuvalu Aid Management and Coordination Case Study. Planning and Budget Section, Ministry of Finance, Govt of Tuvalu: Funafuti.

Government of Tuvalu, 2009. International Aid for Tuvalu Statistical Summary 20012008. Planning and Budget Section, Ministry of Finance, Govt of Tuvalu: Funafuti. 
Government of Tuvalu, 2009a. Tuvalu Government National Budget and Program

Estimates. Ministry of Finance, Government of Tuvalu: Funafuti.

Government of Tuvalu, 2010. http://www.tuvaluislands.com/gov_info.htm

Government of Tuvalu, 2010a. Aid Management Donor Matrix (annual update).

Planning and Budget Division, Ministry of Finance, Government of Tuvalu: Funafuti.

Government of Tuvalu, 2010b. Kakeega Revisted (annual update). Ministry of Finance, Government of Tuvalu: Funafuti.

Groves, L., 2004. Questioning, Learning and 'Cutting Edge' Agendas: Some thoughts from Tanzania. In R. Groves, and L. Hinton (eds.), Inclusive Aid Changing Power and Relationships in International Development. Earthscan: London, pp. 76-86.

Groves, R. and Hinton, L. (eds.), 2004. Inclusive Aid Changing Power and Relationships in International Development. Earthscan: London.

Hickey, S. and Mohan, G., 2004. Participation: From Tyranny to Transformation? Zed Books: London.

Holland, J. and Blackburn, J., 1998. Participatory Research and Policy Change. Intermediate Publications: London.

Horstman, J., 2005. Reflections on Organizational Change. In R. Groves, and L. Hinton, In R. Groves, and L. Hinton (eds.), Inclusive Aid Changing Power and Relationships in International Development. Earthscan: London, pp.42-56.

Huffer, E., 2005, Governance, Corruption and Ethics in the South Pacific. Contemporary Pacific, 17(1): 118-140. 
Huffer, E. and Qalo, R., 2004. Have We Been Thinking Upside-Down? The Contemporary Emergence of Pacific Theoretical Thought. Contemporary Pacific, 16(1): 87-116.

Hughes, H. and Gosarevski, S., 2004. Does Size Matter? Tuvalu and Nauru Compared. Policy, 20(2): 16-20. Centre for Independent Studies: Sydney.

Isala, T., 1983. Sucession and Independence. In H. Laracy (ed.), Tuvalu a History. Institute of Pacific Studies: Suva, pp. 153-177.

Jassey, K., 2004. The Bureaucrat. In R. Groves, and L. Hinton (eds.), Inclusive Aid Changing Power and Relationships in International Development. Earthscan: London, pp. 128-136.

Jayaraman, T. K. and Ward, B., 2006. Aid Effectiveness in the South Pacific Island Countries, a Study of Vanuatu. Discussion Paper 110, Commerce Division, Lincoln University: Christchurch.

Jennings, 2001. Tourism Research. John Wiley: Queensland.

Kakande, M., 2004. The Donor-Government-Citizen Frame as Seen by a Government Participant. In R. Groves, and L. Hinton (eds.), Inclusive Aid Changing Power and Relationships in International Development. Earthscan: London.

Knapman, B., Ponton, M. and Hunt, C., 2002. Tuvalu : 2002 Economic and Public Sector Review. ADB: Manila.

Kotze, D. A. (ed.), 1997. Development Administration and Management: A Holistic Approach. Van Schaik Publishers: Pretoria.

Laracy, H. (ed.), 1983. Tuvalu a History. Institute of Pacific Studies: Suva. 
Larmour, P., 2002. Conditionality, Coercion and Other Forms of 'Power': International Financial Institutions in the Pacific. Public Administration and Development, 22: 249260.

http://www3.interscience.wiley.com/

Larmour, P. and Barcham, M., 2006. National Integrity Systems in Small Pacific States. Pacific Administration and Development, 76: 173-184.

http://www3.interscience.wiley.com/cgi-bin/home

Lewis, D. and Sobhan, B., 2000. Routes of funding: roots of trust? Northern NGOs, Southern NGOs, donors and the rise of direct funding. In T. Wallace (ed.) Development and Management. Oxfam Great Britain, in association with the Open University: Oxford, pp. 202-219.

Little, I. M. D. and Clifford, J. M., 2006. International Aid the Flow of Public Resources from Rich to Poor Countries. Transaction Publishers: New Brunswick.

Mappery 2010 http://www.mappery.com/Tuvalu-Map

Marsden, R., 2004. Exploring Power and Relationships: A Perspective From Nepal. In R. Groves, and L. Hinton (eds.), Inclusive Aid Changing Power and Relationships in International Development. Earthscan: London, pp. 97-107.

McGillivray, M. and Feeny, S., 2008. Aid and Growth in Fragile States. Research Paper 2008/03, World Institute for Development Economics Research: United Nations University.

Mavrotas, G., 2007. Scaling Up of Foreign Aid and the Emerging New Agenda. In S. Lahiri (ed.) Theory and Practice of Foreign Aid. Elsevier: Amsterdampp. 213-232. 
Mellor, J. Wrighton, N. and Conway, J., 2005. Evaluation of the Tuvalu Trust Fund, AusAID: Canberra.

Mosse, D. 2001. People's Knowledge, Participation and Patronage: Operations and Representations in Rural Development In B. Cooke and U. Kothari (eds.), Participation: the new tyranny. London: Zed Books, pp. 16-35.

Mullings, B., 1999. Insider or outsider, both or neither: some dilemmas if interviewing in a cross-cultural setting. Geoforum, 30: 337-350.

Murray, W., Overton, J., 2003. Designing Development Research. In R. Scheyvens, and D. Story (eds.), Development Fieldwork: A Practical Guide. Sage Publications: London, pp 17-35.

Mutu, M., 2004. Researching the Pacific. In T. Baba, O. Mahina, N. Williams and U. Nabobo-Baba (eds.). Researching Pacific and Indigenous Peoples: Issues and Perspectives. Centre for Pacific Studies: University of Auckland, pp 54-62.

Nabobo-Baba, U., 2004. Research and Pacific Indigenous Peoples: Silenced Parts and Challenged Futures. In T. Baba, O. Mahina, N. Williams and U. Nabobo-Baba (eds.). Researching Pacific and Indigenous Peoples: Issues and Perspectives. Centre for Pacific Studies: University of Auckland, pp 17-32.

Naidu, V., 1995. Whose Sea of Islands? In E. Waddell, V. Naidu and E. Hau'ofa, A New Oceania Rediscovering Our Sea of Islands. University of the South Pacific: Suva.

Nations Encyclopedia, 2010. http://www.nationsencyclopedia.com/economies/Asia-andthe-Pacific/Tuvalu.html 
Nelson, N. and Wright, S., 1995. Participation and Power. In N. Nelson and S. Wright (eds.), Power and Participatory Development Theory and Practice. Intermediate Technology Publications: London, pp 1-18.

NZAID, 2010. http://nzaid.govt.nz/programmes/c-pac-countries.html

NZAID, 2010a. http://nzaid.govt.nz/programmes/c-tuvalu.html

Nuiatui, N., 2010. Personal Communication. Economic Adviser, Ministry of Finance, Government of Tuvalu.

OECD, 2008. Paris Declaration on Aid Effectiveness and the Accra Agenda for Action. OECD: Paris.

OneWorld, 2009. http://us.oneworld.net/article/368299-tiny-tuvalu-shocks-climate-talks.

Otsuka, S., 2006. Talanoa Research: Culturally Appropriate Research Design in Fiji. In Proceedings of the Australian Association for Research in Education 2005 International Education Research Conference: Creative Dissent-Constructive Solutions. Melbourne.

Owusu, C., 2004. An International NGO’s Staff Reflections of Power, Procedure and Relationships. In R. Groves, and L. Hinton (eds.), Inclusive Aid Changing Power and Relationships in International Development. Earthscan: London, pp. 108-122.

Panapa, P. and Frankel, J., 2008. The Loneliness of the Pro-Government Backbencher and the Precariousness of Simple Majority Rule in Tuvalu. In State Society and Governance in Melanesia. Research School of Pacific and Asian Studies, ANU: Canberra. 
Pasteur, K., and Scott-Villiers, P., 2004. Minding the Gap Through Organizational Learning. In R. Groves, and L. Hinton (eds.), Inclusive Aid Changing Power and Relationships in International Development. Earthscan: London, pp. 181-198.

Pavlov, V. and Sugden, C., 2006. Aid and Growth in the Pacific Islands. In Asian Pacific Economic Literature, Australian National University and Blackwell Publishing: Canberra, pp. 38-45.

PIFS, 1972a. Leaders' Communiqué 1. PIFS: Suva. http://www.forumsec.org.fj/resources/uploads/attachments/documents/

PIFS, 1972b. Leaders' communiqué 2. PIFS: Suva.

http://www.forumsec.org.fj/resources/uploads/attachments/documents/

PIFS, 1984. Leader's communiqué. PIFS: Suva.

http://www.forumsec.org.fj/resources/uploads/attachments/documents/

PIFS, 2005. Aid Effectiveness In The Pacific. Session 3, Paper 1, Pacific Island Forum Secretariat, Pacific Island Countries/Development Partners Meeting Funafuti, Tuvalu 10 June 2005.

PIFS, 2010. Pacific Aid Effectiveness Principles.

http://www.forumsec.org.fj/resources/uploads/attachments/documents/Pacific_Aid_Effec tiveness_Principles_Final_2007.pdf

PIFS, 2010a. http://www.forumsec.org.fj/pages.cfm/about-us/

Paeniu, L., 2010. Personal Communication. Secretariat of the Tuvalu Trust Fund Advisory Committee.

Pretty, J., 1995. The Many Interpretations of Development. Focus, 16: 4-5. 
Pretty, J. and Scoones, I., 1995. Institutionalizing Adaptive Planning and Local Level Concerns: Looking to the Future. In N. Nelson and S. Wright (eds.) Power and Participatory Development Theory and Practice. Intermediate Technology Publications: London, pp 157-169.

PNG Government, 2008. Kavieng Declaration on Aid Effectiveness: A Joint Commitment of Principles ad Actions Between the Government of Papua New Guinea and Development Partners. http://www.aidharmonization.org/actionplans

Pronk, J., 2004. Aid as a Catalyst. In J. Pronk (ed.), Catalysing Development? - A Debate On Aid. Blackwell Publishing: Maldon, pp. 1-21.

Read, R., 2008. Policy Arena Foreign and Direct Investment in Small Island Developing States. Journal of International Development, 20: 502-525

http://www3.interscience.wiley.com/

Reinhardt, G. Y., 2006. Shortcuts and Signals: an Analysis of the Microlevel Determinants of Aid Allocation, with Case Study Evidence from Brazil. Review of Development Economics, 10 (2) pp. 297-312.

RNZ, 2009. http://www.rnzi.com/pages/news.php?op=read\&id=50833

Rist, G., 2003. The History of Development: From Western Origins to Global Faith. Zed Books: London.

Robb, C., 2004. Changing Power Relations in the History of Aid. In R. Groves, and L. Hinton (eds.), Inclusive Aid Changing Power and Relationships in International Development. Earthscan: London, pp. 21-41. 
Robinson, D. and Robinson, K., 2005. Pacific Ways of Talk - Hui and Talanoa. Social and Civic Policy Institute Wellington and Council on Public Policy Education: Dayton, Ohio. http://www.scpi.org.nz/documents/Pacific_Ways_of_Talk.pdf

Rubin, H. and Rubin, I., 1995. Qualitative Interviewing. The Art of Hearing Data. Sage Publications: London.

Sachs, J. D., 2005. The End of Poverty Economic Possibilities for Our Time. Penguin Press: New York.

Sanga, K., 2004. Making Philosophical Sense of Indigenous Pacific Research. In T. Baba, O. Mahina, N. Williams and U. Nabobo-Baba (eds.) Researching Pacific and Indigenous Peoples: Issues and Perspectives. Centre for Pacific Studies: University of Auckland, pp 41- 52.

Scheyvens, R., Nowak, B., Scheyvens, H., 2003. Ethical Issues. In Scheyvens R and Story D (eds) Development Fieldwork A Practical Guide. Sage Publications: London, pp. 139-167.

Scheyvens, R. and Storey, D., 2003. Introduction. In R. Scheyvens and D. Story (eds.) Development Fieldwork A Practical Guide. Sage Publications: London, pp. 1-13.

Shroff, G. 2002. New Zealand and the Pacific: a Diplomatic Perspective. In G. McGhie and B. Brown, New Zealand and the Pacific: Diplomacy, Defence and Development. New Zealand Institute of International Affairs: Victoria University Wellington.

Scott-Villiers, P., 2004. Personal Change and Responsible Well-Being In R. Groves, and L. Hinton (eds.), Inclusive Aid Changing Power and Relationships in International Development. Earthscan: London, pp. 199-209. 
Shutt, C., 2006. Money Matters In Aid Relationships. In R. Eyben (ed.), Relationships for Aid. Earthscan: London, pp. 154-170.

Slocum, R., Wichhart, L., Rocheleau, D. and Thomas-Slayter, B., (eds.), 1995. Power, Process and Participation - Tools for change. Intermediate Technology Publications: London.

Sobhan, R., 2004. Aid Effectiveness and Policy Ownership. In J. Pronk (ed.) Catalysing Development? - A Debate On Aid. Blackwell Publishing: Maldon, pp. 171-180.

SOPAC, 2010. http://www.sopac.org/CROP+agencies

SPC, 2005a. Tuvalu 2002 Population and Housing Census Volume 1-Analytical Report. SPC: Suva.

SPC, 2005b. Tuvalu 2002 Population and Housing Census Volume 2 -Demographic Profile 1991-2002. SPC: Suva.

SPC, 2005c. Tuvalu 2002 Population and Housing Census - Administration Report and Basic Tables. SPC: Suva.

Storey, D., Bulloch, H. \& Overton, J., 2005. The Poverty Consensus: Some limitations of the 'popular agenda'. Progress in Development Studies 5 (1): 30-44.

Sullivan, S. and Brockington, D., 2004. Qualitative Methods in Globalisation Studies: or, Saying Something About the World Without Counting or Inventing it. CSGR Working Paper No 139/04. University of Warwick: Warwick.

Sydney Morning Herald, 2009. http://www.smh.com.au/environment/climatechange/you-caused-it-you-fix-it-tuvalu-takes-off-the-gloves-20091210-kksq.html 
Thaman, R., 1995. Moana Nui, Vanua and Wontoks. In E. Waddell, V. Naidu and E. Hau'ofa, A New Oceania Rediscovering Our Sea of Islands. University of the South Pacific: Suva, pp. 38-48.

Tisdell, C. and Fairbairn, T. I., 1983. Development Problems and planning in a resourcepoor Pacific country: the case of Tuvalu. Public Administration and Development, 3: 341-359.

Travers, M., 2001. Qualitative Research Through Case Studies. Sage Publications: London.

Tuhiwai Smith, L., 1999. Decolonizing Methodologies Research and Indigenous People. University of Otago Press: Dunedin.

Tuhiwai Smith, L., 2004. Building Research Capability in the Pacific, for the Pacific and by Pacific Peoples. In T. Baba, O. Mahina, N. Williams, U. Nabobo-Baba (eds.) Researching Pacific and Indigenous Peoples: Issues and Perspectives. Centre for Pacific Studies: University of Auckland, pp. 4-16.

TTFAC, 2009. Tuvalu Trust fund Advisory Committee Report October 2009. Tuvalu Trust Fund: Funafuti.

UNCTAD, 2006. Doubling Aid: Making the "Big Push" work. United Nations: New York and Geneva.

UNDP, 2009. Terms Of Reference - Aid Management Specialist. UNDP: Suva.

Vaioleti, T. 2006. Talanoa Research Methodology: A Developing Position on Pacific Research. Waikato Journal of Education, 12: 21-35 
Walle, A., 1997. Quantitative versus qualitative tourism research. Annals of Tourism Research, 24 (3): 524-536.

Walsh, C., 2005. Essential Research Skills. Amokura Publications: Suva.

Warrington, E., 1998. Gulliver and Lilliput in a New World Order: the impact of external relations on the domestic policies and institutions of micro-states. Public Administration and Development, 18:101-105. 